\title{
Teaching internal medicine in general practice: an evaluation
}

Citation for published version (APA):

Murray, E. (2001). Teaching internal medicine in general practice: an evaluation. [Doctoral Thesis, Maastricht University]. Universiteit Maastricht. https://doi.org/10.26481/dis.20010511em

Document status and date:

Published: 01/01/2001

DOI:

10.26481/dis.20010511em

Document Version:

Publisher's PDF, also known as Version of record

\section{Please check the document version of this publication:}

- A submitted manuscript is the version of the article upon submission and before peer-review. There can be important differences between the submitted version and the official published version of record.

People interested in the research are advised to contact the author for the final version of the publication, or visit the DOI to the publisher's website.

- The final author version and the galley proof are versions of the publication after peer review.

- The final published version features the final layout of the paper including the volume, issue and page numbers.

Link to publication

\footnotetext{
General rights rights.

- You may freely distribute the URL identifying the publication in the public portal. please follow below link for the End User Agreement:

www.umlib.nl/taverne-license

Take down policy

If you believe that this document breaches copyright please contact us at:

repository@maastrichtuniversity.nl

providing details and we will investigate your claim.
}

Copyright and moral rights for the publications made accessible in the public portal are retained by the authors and/or other copyright owners and it is a condition of accessing publications that users recognise and abide by the legal requirements associated with these

- Users may download and print one copy of any publication from the public portal for the purpose of private study or research.

- You may not further distribute the material or use it for any profit-making activity or commercial gain

If the publication is distributed under the terms of Article $25 \mathrm{fa}$ of the Dutch Copyright Act, indicated by the "Taverne" license above, 


\title{
Teaching internal medicine in general practice: an evaluation
}

\author{
PROEFSCHRIFT \\ ter verkrijging van de graad van doctor \\ aan de Universiteit Maastricht \\ op gezag van de Rector Magnificus, \\ Prof.dr. A.C. Nieuwenhuijzen Kruseman, \\ volgens het besluit van het College van Decanen, \\ in het openbaar te verdedigen \\ op vrijdag 11 mei 2001 om 14.00 uur \\ door

\section{Elizabeth Murray} \\ geboren te London, \\ United Kingdom, in 1960
}




\section{Promotores:}

Prof.dr. C.P.M. van der Vleuten

Prof.dr. R.P.T.M. Grol

\section{Co-promotor:}

Dr P.A.J. Bouhuijs

\section{Beoordelingscommissie:}

Prof.dr. H.F.P. Hillen (voorzitter)

Prof.dr. J.G. Bligh (University of Liverpool)

Prof.dr. H.F.J.M. Crebolder

Prof.dr. A.J.J.A. Scherpbier

Prof.dr. J.O. Woolliscroft (University of Michigan) 
For Robert

Love and Courage always 
(C) Elizabeth Murray, London 2001

ISBN 90-5398-058-X

Department of Educational Development \& Research, Maastricht, The Netherlands 


\section{Contents}

Preface / Acknowledgements

Chapter 1

Introduction. The background and rationale for development of undergraduate medical education in general practice.

Chapter 2

Can general internal medicine be taught in general practice? A feasibility study.

First appeared as: Can General Internal Medicine be taught in General Practice? Murray E, Todd C, Modell M. Medical Education 1997;31:369 - 374

Chapter 3

Can students learn clinical method in general practice? A randomised crossover trial comparing student acquisition of clinical skills in general practice and in hospital.

First appeared as: Can students learn clinical method in general practice? A randomised crossover trial based on objectives structured clinical examinations. Murray E, Jolly B, Modell M. British Medical Journal 1997;315:920 - 923.

\section{Chapter 4}

A comparison of the educational opportunities on junior medical attachments in general practice and in a teaching hospital: a questionnaire survey.

First appeared as: A comparison of the educational opportunities on junior medical attachments in general practice and in a teaching hospital: $a$ questionnaire survey. Murray E, Jolly B, Modell M. Medical Education 1999;33:170 - 176 .

\section{Chapter 5}

Students' perceptions of the relative advantages and disadvantages of general practice-based and hospital-based teaching: a qualitative study.

First appeared as: Students' perceptions of the relative advantages and disadvantages of community-based and hospital-based teaching: a qualitative study. O'Sullivan M, Martin J, Murray E. Medical Education 2000;34: 648 - 655. 
A comparison of teaching and learning activities on junior medical attachments in hospital and in general practice: a log diary study.

Accepted for publication in Medical Education. What do students actually do on an internal medicine clerkship: a log diary study. Murray E, Alderman P, Coppola W, Grol R, Bouhuijs P, van der Vleuten $C$.

Chapter 7

Costs of teaching internal medicine in general practice.

First appeared as: Community-based medical education: feasibility and cost. Murray E, Jinks V, Modell M. Medical Education 1995;29:66 - 71.

Chapter 8

Influence on general practitioners of teaching undergraduates: qualitative study of London general practitioner teachers.

First appeared as: Influence on general practitioners of teaching undergraduates: qualitative study of London general practitioner teachers. Hartley S, Macfarlane F, Gantley M, Murray E. British Medical Journal 1999;319:1168 - 1171

Chapter 9

A qualitative study of patients' views and feelings on teaching undergraduate medical students in general practice.

Submitted for publication in Family Practice. A qualitative study of patients' views and feelings on the community based teaching of undergraduate medical students. Coleman K, Murray E.

Chapter 10

Discussion and Conclusions.

Part of this chapter first appeared as: Community-based teaching: the challenges. Murray E, Modell M. British Journal of General Practice 1999;49:395-398.

Summary

Samenvatting 


\section{Preface / Acknowledgements}

None of the work in this thesis would have been possible without the constant support and encouragement from Professor Michael Modell, starting with the day in 1991 when he offered me a job to work on developing a course in general practice to teach internal medicine to undergraduate medical students. He over-rode my protestations that I knew no medicine, and nothing about teaching, and duly set out to show me that I could learn about both. He has my deepest gratitude, both for this, and for all the subsequent help through some fairly turbulent times.

I am very grateful to many colleagues both within the Department of Primary Care and Population Sciences and further afield. There are too many to name them all, but particular thanks to the following. Professor Andy Haines insisted I evaluate the new Medicine in the Community firm and through his outstanding supervision in other parts of my work, taught me almost everything I know about research. Many people have helped me with carrying out the studies reported here: Chas Todd arrived in my office when I was "not waving but drowning" in the early days of the project and rescued me; Brian Jolly opened my eyes to new vistas in the use of OSCE and questionnaire data; Madeleine Gantley introduced me to the intellectual rigor possible in qualitative research; Jon Martin, Mary O'Sullivan, Sarah Hartley, Fraser MacFarlane, Katie Coleman and Peter Alderman helped with data collection, conducting interviews and data analysis. Sharon See Tai and Will Coppola have patiently attempted to lessen my profound statistical ignorance. Jo Burns made it possible for me to work on this thesis by doing most of my job for me under the guise of administering the Medicine in the Community firm, and being a brilliant PA. Thanks too to Terri Charrier for making the department such an efficient place to work.

I am grateful too to all the partners in my practice who have allowed me time away from patients to write up, and provided a supportive working environment.

Many thanks to my promoters, Cees van der Vleuten and Richard Grol, and my co-promoter, Peter Bouhuijs. They may have had their doubts, but they never gave up on me, despite somewhat fitful progress at times. They have been very accommodating to "an odd duck in the pond", and for this, and their help and encouragement I am grateful.

On a more personal note I would like to thank my family and friends for their love, humour, companionship and practical help.

The British Medical Journal hold the copyright for chapters 3 and 8 and have granted permission for their reproduction here. Part of chapter 10 has been published in the British Journal of General Practice and is reproduced with permission. The copyright for the papers making up chapters 2 and $4-7$ is held by Medical Education and are reproduced with permission. I am grateful to all three journals for allowing me to reproduce the work here. 


\section{Curriculum Vitae}

Elizabeth Murray was born in London in 1960. She read Physiological Sciences at St Hilda's College, Oxford. She transferred to Wolfson College, Oxford to complete an M.Sc by thesis in reproductive endocrinology. Subsequently she completed her undergraduate medical training at the London Hospital School of Medicine, graduating in 1985. She constructed her own vocational training scheme, receiving her certificate of satisfactory completion of training in General Practice, and passing the Membership of the Royal College of General Practitioners in 1991. She started as a job-share principal in General Practice, a lecturer in primary care at University College London Medical School (UCLMS) and won a Research Training Fellowship from the Royal College of General Practice in September 1991. She became a Senior Lecturer in Primary Care at UCLMS in 1996. She is currently Director of Undergraduate Medical Education (Bloomsbury and Archway Sites) at the Department of Primary Care and Population Sciences, Royal Free and University College Medical School at University College London, and a job share principal in general practice at Lonsdale Medical Centre, an inner city practice, nominated as a "beacon practice for clinical excellence" by the Secretary of State for Health in 1999. 


\section{Introduction}

This thesis explores the theme of undergraduate medical education in general practice, using the experience of designing, setting-up and evaluating a junior internal medicine clerkship taught in General Practice. This opening chapter provides a conceptual framework to the thesis, including the rationale for focusing on this area; an overview of the research contained in the body of the thesis; and an introduction to some of the methodological issues which arise in this type of educational research.

\section{Rationale for studying general practice based medical education}

\section{Background to the development of general practice based medical education}

Traditionally, undergraduate clinical education took place largely in teaching hospitals, with some experience in district general hospitals. Recently, however, there has been a move toward siting an increasing proportion of clinical teaching in general practice. This section outlines the reasons underlying this change.

\section{a) International trends in Primary Health Care}

Internationally, primary health care is seen as increasingly central to health care provision. This is happening both in the developed world, where primary health care is seen as an effective method of cost containment, and in the developing world, where primary care is an essential part of strategies to reduce infant and maternal mortality, and increase life expectancy ${ }^{\prime}$.

There are a number of trends in health care common to the whole of the Western world: an increase in the proportion of elderly and very elderly in the population; a decrease in the impact of acute infection on the mortality and morbidity, with concomitant increase in the prevalence of chronic and degenerative diseases, such as ischaemic heart disease and cancer; and a reduction in the total number of hospital beds. These have contributed to the move toward health care systems based on primary care ${ }^{1}$. Thus the situation in the UK, which made the commitment both to primary health care, and medical education in general practice, relatively early in international terms, has relevance to most of the developed world.

\section{b) The role of general practice within the British National Health Service}

The National Health Service (NHS) was established in 1948 to provide health care that was free at the point of delivery to all British residents who needed it. The fundamental principle underlying the NHS was one of equity - health care should be available to all, on basis of need not on basis of ability to pay. Right from the beginning, it was recognised that primary 
care had to take a central role, and general practitioners were given the role of "gate-keeper", controlling patients' access to specialist services. Patients have to register with a general practitioner, and can only be registered with one GP at a time. GPs have a contractual responsibility to provide general medical services to all patients registered with them, including providing care for urgent health problems twenty-four hours a day, 365 days a year $^{2}$. At any point in time, over $90 \%$ of the UK population are registered with a GP, and approximately $90 \%$ of health care episodes are dealt with entirely in primary care.

The last ten years has been a time of great upheaval within the NHS, with successive governments attempting major re-organisation of the service. Both Conservative and Labour governments have placed general practice at the forefront of the changes, extending GPs influence over secondary care services. This started with the Conservative government and the introduction of "fundholding" in April 1991 - through which general practitioners have a fund for purchasing specialist secondary care. Although "fundholding" has been phased out under the Labour government, the emphasis is still strongly on a "Primary Care Led NHS"3. Primary care has an increasing influence on secondary care through commissioning services and stipulating quality standards. Patient care is increasingly being devolved back to primary care; for example, much of the management of chronic disease that used to occur in outpatient departments now takes place solely in general practice. GPs have increasing "open access" to investigations such as echocardiograms and gastroscopy that used to require specialist agreement. The number of hospital beds has been greatly reduced ${ }^{4}$. Procedures that previously required admission are increasingly undertaken in out-patients, and day surgery is on the increase $e^{5}$.

Taken together, these changes mean that in-patients in teaching hospitals are more severely ill than they were 20 years ago. As a result, they may be less able, and less willing, to help medical students learn clinical medicine. There is evidence that students' clinical experience in hospital is declining ${ }^{6}$. Moreover, if students are to gain experience of a wide range of common morbidities, understand the natural history of disease, and learn about management of chronic disease, they may need to go outside the teaching hospital environment and learn in general practice ${ }^{7: 8}$.

\section{c) Academic General Practice in the UK}

General Practice has in the past, and still is in some countries, been seen as a low prestige specialty, suitable for doctors who could not make the grade as hospital specialists. In the UK this perception started to change relatively early. In 1952 the Royal College of General Practitioners was founded with the aim of "establishing an academic headquarters for general practice in order to raise the standards and status of general practice, to persuade other doctors to enter the profession and to encourage medical students to regard general practice as a specialism which could offer them an interesting and rewarding career"9. Early achievements of the College included the development of academic departments of general practice in universities. Post-graduate training for general practice became mandatory in 1981, confirming the principle that general practice is a discipline which requires specific professional development beyond that provided in medical school and the pre-registration house officer year ${ }^{10}$. Over the last $20-30$ years there has been increasing recognition of the need for, and importance of, research in general practice, with a concurrent increase in the amount and quality of research undertaken by general practitioners. In financial terms, 
research in primary care is currently a growth area, with specific provision of funding for developing the necessary infrastructure and research culture ${ }^{11}$.

\section{d) The growth of undergraduate medical education in general practice}

Between 1960 and 1990 all medical schools introduced a specific general practice attachment for medical students. This attachment aimed to teach students about the discipline of general practice, and provide some experience of the work and lifestyle of general practitioners. Typically, the attachment lasted about four weeks, and was based on the apprenticeship style of learning, with one student attached to one GP. The student would "sit-in" with the GP while s/he consulted, undertake supervised consultations, accompany him or her on home visits, and would often live with the GP for at least part of the attachment ${ }^{12}$.

By the early 1990's there were numerous calls for increasing the amount of general practice based teaching to reflect health service delivery ${ }^{13 ; 14}$. In 1993 the General Medical Council published "Tomorrow's Doctors", calling for an overhaul of undergraduate medical education. One of the changes recommended was an increase in community based teaching ${ }^{15}$. Together with the service changes detailed above ${ }^{5}$ this proved a powerful impetus for change.

In the 1990's, almost all UK medical schools have increased the amount of community based teaching, mostly through increasing the amount of teaching in general practice ${ }^{16}$. Unlike previous general practice based teaching, this new teaching has involved knowledge and skills previously seen as the sole domain of hospital specialists, and as such, has resulted in teaching in general practice replacing hospital based teaching.

The most radical version of this was the parallel track curriculum which ran at the University of Cambridge Medical School from 1993 - 1998 for four students per annum. At Cambridge, students enter a 27 month clinical curriculum after a traditional two year basic science course and a one year Bachelor of Arts degree course. After a short introductory course for all students, those on the parallel track spent the next 15 months in one general practice. During these fifteen months students acquired skills in clinical method; experience and understanding of common and important problems in general internal medicine, surgery, obstetrics and gynaecology, paediatrics, psychiatry, and the minor specialties; understanding of the role of the GP, the Primary Health Care Team and community services; understanding of the principles of prescribing in General Practice; and understanding of the importance of preventive health care $^{17: 18}$.

Less radical, but possibly more generalisable were the initiatives by King's College Medical School $^{19}$, University College London Medical School ${ }^{20}$, and Birmingham Medical school ${ }^{21}$ to introduce teaching of general internal medicine to first year clinical students by GPs. The London initiatives started in 1991, the Birmingham one a few years later. All three set out to replace a traditional hospital based junior medical clerkship with one taught in General Practice. The learning objectives of these clerkships concentrated on acquisition of clinical method.

Subsequently, a collaborative venture of all the North London medical schools received funding from the Department of Health in 1995. Known as Ce-MENT (Community based Medical Education in North Thames), this venture aimed to increase community based teaching across all participating medical schools (The Royal London and St Bartholomew's 
School of Medicine, University College London Medical School, Royal Free Hospital School of Medicine, Imperial College School of Medicine at St Mary's and Charing Cross and Westminster Medical School). Under the Ce-MENT umbrella, GPs have started teaching Ear Nose and Throat medicine, dermatology, paediatrics, obstetrics and gynaecology, general internal medicine, general surgery and introduction to clinical skills courses ${ }^{22}$. By 1998 , nearly 4,000 students had been taught by GPs through the Ce-MENT programme.

\section{e) International comparisons.}

Many Western countries have a well developed system of primary care, which, as in the UK, is based on general practice or family medicine. Innovative curricula in schools such as Maastricht (the Netherlands) and Linkoping (Sweden) include a very substantial amount of general practice based education.

In Maastricht the Department of General Practice is responsible for $11 \%$ of the delivery of the curriculum, as calculated by full time equivalents ${ }^{23}$. Many of the clinical problems used in encounters with the simulated patients are generated by GPs, and students have a 10 week clerkship at the end of their clinical course which allows them to integrate and practice previously acquired knowledge and skills. The specific aims of the attachment are for students to become familiar with the characteristic morbidity of the population and how this presents in General Practice; gain experience in recognising the interactions between physical, psychological and social factors in ill health, including the impact of ill health on the family; and acquire skills in the general practice approach to health problems.

In Linkoping General Practitioners take part in all eleven semesters of the curriculum; in the first five semesters GP input is concentrated into the communication skills training while in semesters $6-10$ there are recurrent three week clerkships in general practice. These clerkships aim to develop basic skills in: interviewing, physical examination, record-keeping, management of common problems, team-work with other health professionals, whole person medicine and health promotion ${ }^{24}$.

Flinders University in South Australia has set up a parallel track curriculum based in rural general practice. During the fifth year of the course, students on the traditional track undertake clinical attachments in Medicine, Surgery, Psychiatry, Obstetrics \& Gynaecology, and Paediatrics. Selected volunteer students undertake an alternative attachment to a division of rural general practice for the entire year. At the end of the year, all students take a common exam ${ }^{25}$.

Family practice plays a much less central role in the American health care system. In the US, community based teaching has concentrated more on ambulatory care teaching, or what would be called "out-patient" teaching in the UK. In some instances ambulatory care teaching is undertaken by family physicians, but in the majority of published reports, it has been done by specialists, such as general internists, gynaecologists or paediatricians, in their consulting rooms ${ }^{26: 27}$. This crucial difference makes it difficult to know how transferable the results of evaluations of ambulatory care teaching are to general practice based teaching. 


\section{f) Pre-existing evidence base}

At the time the work described here started, there was little published work evaluating general practice based teaching of undergraduate students. The bulk of the available literature concentrated on ambulatory care teaching in America, and for the reasons stated above, it was uncertain to what extent data from that environment would transfer to the UK situation.

\section{g) Research questions.}

\section{(i) Was it feasible to develop an internal medicine clerkship taught in general practice?}

Initially, there was widespread scepticism in the UK as to whether it was possible to teach general internal medicine in general practice. The most common reactions to the proposal to pilot this were scorn and disbelief. Thus the initial research questions focused on feasibility: was it possible to set up a junior medical clerkship in general practice? What were the practical problems? and what solutions were available? We needed to know what the students thought about it, what the tutors involved in the early development phase thought, and whether students appeared to be learning what we intended to teach them. These issues are addressed in Chapter 2.

(ii) Did students acquire clinical skills as well on the general practice based clerkship as on a hospital based clerkship?

The pilot study reported in chapter 2 highlighted a number of important research questions. Did students acquire the basic clinical skills of history taking and physical examination that are so fundamental to medicine and were the main aims of the clerkship? There was very little evidence on this question in the international literature. In America Satran et $\mathrm{al}^{28}$ used an OSCE (Objective Structured Clinical Examination) to compare the acquisition of clinical skills by students learning from hospital-based or community-based paediatricians. Three studies used a pen and paper test to compare student learning of internal medicine in ambulatory care and in-patient settings. Gruppen et $\mathrm{al}^{29}$ used an MCQ with 21 students and found twice the knowledge gain in the 1 month ambulatory care experience as in the 2 months in-patient experience. This finding has not been replicated since: Butterfield and Libertin ${ }^{30}$ found no difference in knowledge gain as assessed by an MCQ in 75 students who had either an ambulatory + in-patient clerkship or in-patient only clerkship in internal medicine. In 1994 Steinmet $\mathrm{z}^{31}$ found that students taught internal medicine in an ambulatory care setting scored significantly better on a diagnostic pattern recognition test, but not on an MCQ than students taught only in an in-patient setting. None of the 3 studies involved teaching by general practitioners.

An OSCE (Objective Structured Clinical Examination) was used as the main outcome measure as:

- the skills under study were clinical skills (history taking and physical examination) rather than knowledge, critical reasoning or other skill domains

- OSCEs are the favoured method for testing clinical skills, as they have adequate validity, reliability and feasibility ${ }^{32}$ 
- traditional clinical tests such as long or short cases or even the OSLER (Objective Structured Long Examination Record) have low reliability ${ }^{33: 34}$

- paper and pencil tests including multiple choice questions, modified essay questions, patient management problems, and the triple jump have low validity for testing clinical skills ${ }^{33}$

- Although there are problems with the reliability of small (less than 23 station) OSCEs, they can and have been used for comparing groups ${ }^{35}$.

As with much educational research our research design was limited by practical considerations. There would have been considerable resistance within the medical school to randomising students for experimental reasons, so we were fortunate that the structure of the year allowed for a randomised cross-over trial. Financial considerations limited the size of the OSCE. Our sample size had to be determined by the number of students in the year, not by formal power calculations.

Within these limitations this piece of work is one of the few that formally examines outcomes of community based teaching compared to hospital based teaching.

(iii) What were the relative strengths and weaknesses of teaching internal medicine in hospital and in general practice?

There was a pressing need to determine the relative strengths of hospital based and community based teaching to plan a rational curriculum which built on the strengths of the two environments. Although the OSCE provided broad brush assessment of students' acquisition of clinical skills, it was not able to dissect out specific components of clinical method. This question was addressed in two complementary studies, one using quantitative methods (reported in chapter 4), and the other qualitative. The quantitative study used a questionnaire to determine students perceptions of the extent to which each of the learning objectives for the whole of the first clinical year (which applied to both hospital based and general practice based teaching) were acquired in each environment. This study was undertaken at the same time as that reported in chapter 3, and used the same randomised crossover design to control for individual student attributes such as enthusiasm.

A qualitative study was necessary to explore students perceptions of the wider benefits of learning in each environment (chapter 5). The semi-structured interview and focus group approach allowed the students to raise topics they perceived as important, without guidance or prompting from the researchers.

(iv) What were students actually doing on the general practice and hospital based clerkships? Did this explain some of the previous findings?

Having determined some answers to this question we were interested in finding out what the explanation for these differences might be. We postulated that this might be due to differing leaning opportunities in the two environments, and sought to determine what students were actually doing (as opposed to what they were meant to be doing) on their hospital and general practice based medical clerkships (chapter 6). 
In an ideal world, we would have chosen to undertake direct observation of student activities in hospital and in general practice. Direct observation studies provide the hardest evidence of student and teacher activity, and also allow for judgements on the learning opportunities available and the teaching methods in use $\mathrm{s}^{36: 37}$. The cost of such studies is considerable, and it can be difficult to obtain consent from both teachers and students ${ }^{37}$. The knowledge that they are observed may also alter the behaviour of both teachers and students. We did not have the resources to undertake a direct observation study, and decided to use a proxy method of determining student activity.

One possibility was a further questionnaire study, but there are limitations to these. We already had process data on numbers of patients clerked and examined per week (chapter 4), and deemed it unlikely that retrospective recall of learning and teaching activities would be accurate. Another option was asking the GP and hospital tutors, but in our experience tutors do not always have an accurate perception of their students' activities. Log diary studies have been extensively used to determine activity - perhaps the best known example is the General Medical Council workload survey of general practitioners, which is a recurrent exercise aimed at measuring the workload of GPs.

Log diaries have been used in studies of undergraduate education ${ }^{38: 39}$, both to document the clinical experiences of students and to document their use of time. As diaries are filled in contemporaneously there is less opportunity for recall bias. Moreover, our continued use of a cross-over design, with students completing diaries for both their hospital and GP attachments was intended to control for student factors, such as enthusiasm.

\section{(v) What were the costs of the general practice based clerkship?}

As long-term sustainability of such innovations will be partially determined by economic considerations, we needed to know the cost of this model of community based teaching (chapter 7). It would have been preferable to have comparable costings of hospital based teaching. Unfortunately this was not possible, as there is a dearth of data on this, and at that time, all attempts to disentangle teaching and service costs in hospitals had been unsuccessful $^{40}$.

\section{(vi) What was the impact of teaching internal medicine on the GP tutors?}

Sustainability of teaching programmes depends on the active and willing participation of all those involved, not just the students. GP tutors were taking on a new role, requiring skills and knowledge over and above those needed for clinical work or traditional, apprenticeship-style teaching about general practice. At the same time, they were facing massive change in working practices ${ }^{41: 42}$. Stress levels were reported to be high in the profession ${ }^{43}$. Many GPs were taking early retirement, and recruitment was difficult, with fewer doctors choosing to go into general practice ${ }^{44}$. The effect of teaching on GP morale was therefore crucial to the sustainability of the programme. By 1997, when this work was undertaken, there was a panLondon programme for increasing the amount of general practice based teaching. It was therefore possible to undertake the interview study of GPs involved in teaching clinical skills for any of the participating medical schools reported in chapter 8 .

(vii) What were the reactions of patients to this type of teaching? 
Patients are also a vital part of any general practice teaching programme. This sort of clinical skills teaching requires patients to give up 2 - 3 hours of their time to assist medical students learning. Some patients do this regularly, 6 - 10 times a year, which is a substantial time commitment. Patients do not receive routine medical care while attending for teaching purposes. It was therefore important to determine patients' views of this sort of teaching, and whether they felt pressurised to participate, what their motivation for participating was, and whether the programme should be altered in any way to accommodate patients needs. An independent researcher was employed to interview patients participating in the programme. The intention was to interview patients who had declined to assist with teaching, or who had done it for a bit and then stopped, but no patients in these categories were prepared to be interviewed. The results are therefore only representative of patients who had on-going participation in the teaching programme. This study is reported in chapter 9 .

To summarise, the research questions addressed in this thesis are: is this model of community based teaching of internal medicine feasible? Do students acquire the key clinical skills of history taking, physical examination and communication with patients as well in general practice as on the traditional hospital based clerkship this replaced? What are the relative strengths of community based and general practice based clerkships? What is it about students experience in the two environments that contributes to these findings? Is it economically viable? What is the impact of this model of the GP tutors and patients? Inevitably in an evolving field, as each research question is answered, a myriad more arise. Some of these are discussed in chapter 10 .

As each chapter is based on a paper published in a peer reviewed journal there is inevitably some repetition, particularly in the description of the educational experience under evaluation. 


\section{References}

1. Tarimo E, Webster EG. Primary Health Care: Concepts and Challenges in a Changing World. Alma-Ata Revisited. 1-118. Geneva: WHO; 1997.

2. Department of Health. Statement of Fees and Allowances payable to General Medical Practitioners in England and Wales from 1 April 1990. London: HMSO; 1990.

3. National Health Service Executive. Developing a primary care led NHS. London: HMSO: 1996.

4. Hensher M, Edwards N, Stokes R. International trends in the provision and utilisation of hospital care. BMJ 1999;319:845-8.

5. Hensher M, Edwards N. Hospital provision, activity, and productivity in England since the 1980s. BMJ 1999;319:911-4.

6. Ahmed SF, Hughes IA. Clinical experience during the paediatric undergraduate course. J R Soc Med 1999;92:293-8.

7. O'Connor DW, Clarke DM, Presnell I. How is psychiatry taught to Australian and New Zealand medical students? Aust N Z J Psychiatry 1999;33:47-52.

8. Parle JV, Greenfield SM, Skelton J, Lester H, Hobbs FD. Acquisition of basic clinical skills in the general practice setting. Med Educ 1997;31:99-104.

9. Royal College of General Practitioners. History of the College. www.rcgp.org.uk. accessed 28 Sept 2000.

10. Royal College of General Practitioners. History of the Joint Committee on Postgraduate Training in General Practice. www.rcgp.org.uk. accessed 28 September 2000.

11. Rook R. Strategic Framework for the Use of the NHS R \& D Levy. 1-7. Wetherby: Department of Health; 1997.

12. Undergraduate medical education in general practice. Association of University Teachers in General Practice, United Kingdom and Republic of Ireland. $J$ R Coll Gen Pract Occas Pap 1984;1-25.

13. Oswald N. Where should we train doctors in the future? Less in hospitals, more in general practices. BMJ 1991;303:71-.

14. Towle A. Critical Thinking: The Future of Undergraduate Medical Education. London: King's Fund Centre; 1991.

15. General Medical Council. Tomorrow's Doctors: Recommendations on Undergraduate Medical Education. London: General Medical Council; 1993.

16. McCrorie P, Lefford F, Perrin F. Medical Undergraduate Community-based Teaching: A Survey for ASME on Current and Proposed Teaching in the Community and in General Practice in U.K. Universities. Dundee: Association for the Study of Medical Education; 1993. 
17. Oswald NT, Alderson TS. A core curriculum in general practice. Med Educ 1997;31:352-3.

18. Oswald N, Jones S, Date J, Hinds D. Long-term community-based attachments: the Cambridge course. Med Educ 1995;29:72-6.

19. Booton P. Teaching General Medicine in General Practice. In Towle A, ed. Community Based Teaching - Sharing Ideas 1, London: King's Fund Centre, 1992.

20. Murray E, Todd C, Modell M. Can general internal medicine be taught in general practice? An evaluation of the University College London model. Med Educ 1997;36974.

21. Parle J, Greenfield S, Thomas C, Ross N, Lester H, Skelton J et al. Community-based clinical education at the University of Birmingham Medical School. Acad Med 1999;74:248-53.

22. Macfarlane F, McLennan E, Murray E, Wallace P. CeMENT (Community Based Medical Education in North Thames) Project Report. London: CeMENT; 1998.

23. Crebolder HFJM, Metsemakers JFM. General Practice, Medical Education and Community-Based Teaching: the Maastricht Experience. Annals of CommunityOriented Education 1994;7:121-9.

24. Foldevi M, Trell E. Learning the Basics of Medicine in General Practice in the Faculty of health Sciences, Linkoping, Sweden. Annals of Community-Oriented Education 1993;6:97-113.

25. Worley P, Silagy C, Prideaux D, Newble D, Jones A. The parallel rural community curriculum: an integrated clinical curriculum based in rural general practice. Med Educ 2000;34:558-65.

26. Yonke AM,.Foley RP. Overview of Recent Literature on Undergraduate Ambulatory Care Education and a Framework for Future Planning. Acad Med 1991;66:750-5.

27. Irby DM. Teaching and Learning in Ambulatory Care Settings: A Thematic Review of the Literature. Acad Med 1995;70:898-931.

28. Satran L, Harris IB, Allen S, Anderson DC, Poland GA, Miller WL. Hospital-based versus community-based clinical education: comparing performances and course evaluations by students in their second-year pediatrics rotation. Acad Med 1993;68:3802 .

29. Gruppen LD, Wisdom K, Anderson DS, Woolliscroft JO. Assessing the Consistency and Educational Benefits of Students' Clinical Experiences during an Ambulatory Care Internal Medicine Rotation. Acad Med 1993;68:674-80.

30. Butterfield PS, Libertin AG. Learning outcomes of an ambulatory care rotation in internal medicine for junior medical students. J Gen Intern Med 1993;8:189-92. 
31. Steinmetz CA, Litzelman DK, Woolliscroft JO. Effect of an ambulatory care rotation on third-year students' diagnostic problem-solving skills. Acad Med 1994;69:852-.

32. van der Vleuten CP, Swanson AG. Assessment of clinical skills with standardised patients: state of the art. Teaching and Learning in Medicine 1990;2:58-76.

33. Jolly B, Grant J, editors. The Good Assessment Guide. London: Joint Centre for Education in Medicine; 1997.

34. Newble D, Jolly B, Wakeford R. The Certification and Recertification of Doctors. Issues in the Assessment of Clinical Competence. Cambridge: Cambridge University Press; 1993.

35. Nyquist JG, Naylor AJ, Woodward LG, Dixon S. Use of performance-based assessment to evaluate the impact of a skill-oriented continuing education program. Acad Med 1994;69:S51-S53.

36. Hekelman FP, Vanek E, Kelly K, Alemagno S. Characteristics of Family Physicians' Clinical Teaching Behaviours in the Ambulatory Setting: A Descriptive Study. Teaching and Learning in Medicine 1993;5:18-23.

37. Sinclair S. Making Doctors: An Institutional Apprenticeship, Oxford: Berg; 1997.

38. Sheldon TA, Clarke M, Woods JR. The student diary survey: a method of monitoring hospital-based medical education. Med Educ 1991;25:213-23.

39. O'Sullivan PS, Weinberg E, Boll AG, Nelson TR. Students' educational activities during clerkship. Acad Med 1997;72:308-13.

40. London Economics. Allocating Medical SIFTR within Camberwell DHA. 1-38. London: London Economics; 1991.

41. Leese B, Bosanquet N. Changes in general practice organization: survey of general practitioners' views on the 1990 contract and fundholding. Br J Gen Pract 1996;46:959.

42. Kavanagh S, Knapp M. The impact on general practitioners of the changing balance of care for elderly people living in institutions. BMJ 1998;317:322-7.

43. Appleton K, House A, Dowell A. A survey of job satisfaction, sources of stress and psychological symptoms among general practitioners in Leeds. $\mathrm{Br} \mathrm{J} \mathrm{Gen} \mathrm{Pract}$ 1998;48:1059-63.

44. Department of Health. Statistics for General Medical Practitioners in England: 1988 1998. London: Department of Health Publications; 1999. p1-18. 


\section{Can general internal medicine be taught in general practice? A feasibility study}

\section{Summary}

There is national and international interest in increasing the community-based component of undergraduate medical education, but more research is needed on its potential, practicability and effectiveness. The objective of the study was to examine the feasibility and efficacy of general practitioners teaching basic clinical skills to first year clinical medical students in the community. The structure and methods of evaluation of the programme are described. Evaluation tools included semi-structured interviews of general practitioner tutors; student questionnaires; assessment of student performance; and costs of the programme. The great majority of the students found the programme enjoyable ( 81 out of $81,100 \%$ ) and educational (79 out of $81,97 \%$ ). Students' performance in the end of rotation Objective Structured Clinical Examination suggested that clinical skills are acquired at least as well in the community as in hospital. Tutors identified the personal benefits of this teaching as development of their own clinical skills and the stimulation of teaching. The programme has been successfully expanded from 24 students to 230 students annually and has demonstrated that community-based teaching can usefully contribute to undergraduate medical education in the area of clinical skills teaching. Key practical issues for schools contemplating similar initiatives are presented.

\section{Introduction}

There is an unusual degree of consensus on the improvements that are needed in undergraduate medical education in Britain. Both the General Medical Council' and the King's Fund ${ }^{2}$ have recommended far-reaching changes to existing curricula. Many of these are in line with world-wide trends in curriculum reform, as stated in the Edinburgh Declaration $^{3}$ and reiterated 5 years later at the World Summit ${ }^{4}$. A major proposal is that students should spend more time in the community and less in tertiary hospitals. The benefits of community-based teaching include: access to numerous patients representing the wide range of morbidity within the general population; an enhanced understanding of community health needs; the opportunity for students to enhance their diagnostic skills by studying patients presenting with undifferentiated symptoms; improvement of communication skills; and sensitisation to the social and environmental background of illness through meeting patients at home ${ }^{5}$.

In addition, there are pressing economic and technological forces driving a shift to community-based teaching. Clinical education based in teaching hospitals is becoming increasingly difficult with the increased emphasis on outpatients and day $\operatorname{cases}^{6}$, and short average in-patient stays ${ }^{7}$. The reduction in the number of beds in London has been particularly dramatic ${ }^{8}$. Moreover, much of the management of chronic disease is being transferred to primary health care following the 1990 contract $^{9}$. 
Many British medical schools are increasing the community-based component of their curricula, spearheaded by departments of primary care. A survey of the 28 academic departments in the United Kingdom and Eire showed that 14 contribute to the teaching of basic clinical skills ${ }^{10}$ - previously the exclusive domain of hospital doctors. For example, in the Kings College Medical School 'Medicine in the Community' firm 42 students per year spend 24 sessions over 8 weeks in a general practice ${ }^{11}$. Cambridge Medical School have introduced a parallel track curriculum based in one family practice for four students for the first 15 months of the clinical course ${ }^{12}$. At University College London Medical School (UCLMS) one entire first clinical year junior medical firm is now based in general practice. This is the largest such programme in the UK, with 230 students per year, over 30 general practitioners as part-time lecturers, and an annual budget of c. $£ 200,000$.

There is little research into the practicability and effectiveness of community-based teaching. In particular, the following important questions are, as yet, unanswered:

1. What is the potential contribution of community-based teaching to undergraduate medical education?

2. Can clinical skills be taught as effectively in the community as in the traditional hospital setting?

3. What are the key practical issues for medical schools who wish to teach clinical skills successfully in primary care?

In this paper we describe the key features of the development, implementation and evaluation of the UCLMS community-based programme. This begins to answer the questions raised above.

\section{The UCLMS "Medicine in the Community" Programme}

\section{The UCLMS curriculum}

The UCLMS curriculum is a traditional one; the first 2 years concentrate on the basic sciences. Over half the students take an intercalated B.Sc. before proceeding to the 3 year clinical course. The 'Medicine in the Community' firm takes place in the first clinical year, in rotation with junior medical and surgical firms. All first year firms share the common aims of teaching the basic clinical skills of history taking, physical examination and communication with patients. There is a specific family medicine rotation in the second clinical year.

\section{Structure of the programme}

The programme was piloted with 24 students in 1991 to determine the feasibility of teaching basic clinical skills in family practice. The initial programme was judged successful, and the number of students expanded exponentially year on year, until September 1994 when the entire annual intake of over 200 students per annum was included. The structure of the firm has been refined with experience, resulting in the model described below. The objectives of the firm were: 
- To give students an understanding of the symptoms, signs, investigation and management of a core group of common chronic medical conditions;

- To promote an understanding of both the impact of ill health on people's lives, and the contribution of lifestyle to ill health;

- To foster a problem-solving approach;

- To promote self-directed learning.

Most students were allocated in pairs to a GP part-time lecturer. They spent 2 days a week in the health centre, seeing patients at home and in the centre. The teaching had three main components:

(1) Carrying out and presenting a full medical history and physical examination on about four patients with common medical problems each week. The students' consultations took place either at the patient's home or in the health centre.

(2) 'Sitting in' with their tutor while s/he consulted, learning to take focused, problemorientated histories, and to examine individual systems.

(3) Participation in department-based seminars to develop diagnostic and communication skills - one half day per week.

Teaching each week focused on a particular theme, usually a symptom: chest pain; shortness of breath; abdominal pain and bowel disturbance; difficulty with mobility, and multi-system disorders - diabetes, drug and alcohol abuse. Tutors identified appropriate patients. For example, when the focus was 'shortness of breath' patients with heart failure, chronic bronchitis and asthma could have been selected.

In the early part of the year, tutors concentrated on ensuring that students were able to take a comprehensive history and perform a competent examination. As students' expertise and confidence increased, more emphasis was placed on differential diagnosis and problem solving.

For most students the primary health care component occupied 3 days per week. The remaining 2 days were spent on a linked specialty (oncology or public health medicine) and the pathology lecture course. In September 1994 we developed a third model for approximately one-quarter of the students whereby the students were entirely based in one general practice for the week.

Students' performance in the key areas of history taking, physical examination and communication skills was assessed by an Objective Structured Clinical Examination $(\mathrm{OSCE})^{13}$ at the end of the firm.

\section{General practice tutors}

Tutors were recruited through personal contacts, advertisements in the medical press and personalized letters to all local GPs. Short-listed candidates were interviewed and suitable tutors appointed. They were contracted to take one pair of students on alternate firms (20 weeks of teaching per year). In addition, tutors were required to attend regular staff development sessions, undertake some joint teaching with hospital doctors, and assist with the end of rotation OSCE. They were appointed on annually renewable contracts and paid the 
equivalent of two sessions (2/11ths of full time) starting on the mid-point of the clinical lecturer scale. This equated to about $£ 5,500$ per year. In addition, they received $£ 12.15$ per session from the Family Health Service Authority (FHSA). Total annual remuneration was therefore about $£ 6,500$. (For comparison, the annual payment for two sessions for GP hospital practitioners at the time was $£ 5,780-£ 7,760$.) Tutors who took more students were paid proportionately more ${ }^{14}$.

\section{Methods of evaluation}

Evaluation of the programme has been based on students' perceptions elicited by an end-ofrotation questionnaire; tutors' views obtained in semi-structured interviews; and the results of the OSCE. In 1992-3 questionnaire responses and OSCE performance of students on the community firm were compared with those of students on a concurrent hospital-based general internal medicine and oncology firm.

\section{Students' perceptions}

The anonymous student end-of-rotation questionnaire originally included only quantitative items (e.g. 'How many patients did you clerk?), but was modified over the years to include questions aimed at obtaining more qualitative data (e.g. 'What three things did you like best about the firm). Questionnaires were analysed (using Mann-Whitney test for non-parametric date) with the statistical package SPSS.

\section{Tutors' views}

In 1994 all 20 practice-based tutors were interviewed. These semi-structured interviews were conducted in the tutor's practice, by a single interviewer (CT) who was not associated with the development and organisation of the programme. Areas covered included reasons for being a first year tutor; perceived advantages and disadvantages of this form of teaching for the tutor, the practice, the patients and the students; details of how tutors organised their teaching; and their views on pay and long term sustainability of such a programme. Results were categorised post hoc.

\section{Students' performance}

Students' performance in the key areas of history taking, physical examination and communication skills was assessed by an OSCE at the end of each 6 week rotation. A bank of nine, 9 minute stations were developed, of which six were used at any one time, maintaining a balance between history taking and examination stations.

In the history taking stations, students were asked to obtain as much information as they needed to make a diagnosis, and assist with management of the problem. Examination stations required a complete examination of a specific system, to MBBS standard. In the communication skills station students were told that the daughter of a man terminally ill with lung cancer had asked to see them. The 'daughter' inquired about the patient's prognosis, the help available to her if she looked after him at home, and methods of pain control. In all cases standardised patients and structured marking sheets were used. Examiners were drawn from hospital oncologists and GP tutors. 


\section{Results}

\section{Students' views}

In 1992-3, 46 out of 48 students on the medicine in the community firm and 21 out of 24 hospital-based students completed the same questionnaire. Students on the community firm reported clerking a median of four patients per week and presented histories to their tutor three times a week, as compared to 2.5 per week and once, respectively, for the hospital-based firm ( $\mathrm{P}<0.005$ for both criteria Mann-Whitney $U$-test). In 1993-4, 81 students responded out of a possible 93 (Table 1). Forty-four students (54\%) found the firm 'very' enjoyable, and the remaining $37(46 \%)$ found it 'quite' enjoyable. Forty-four (54\%) found it 'very' educational, $35(43 \%)$ 'quite' and $2(3 \%)$ 'not very' educational. None found it 'not at all' educational.

Comments made by the students indicated that the 2 days in general practice were highly appreciated, both because of the number and variety of patients seen and the individual tuition from the GP tutor. Seeing patients in their homes was considered useful as it enabled students to understand the social and psychological impact of chronic illness. Many students found the division between general practice and oncology or public health medicine unsatisfactory and requested more time in general practice. The major problem encountered by the students was the cost and inconvenience of travelling to the practices and patients' homes.

\section{Table 1 Numbers (percentage) of students the Community Firm has helped (1993-4)}

\section{A lot A little Not at all}

In taking and presenting a thorough medical history In improving examination technique

$66(82) \quad 15(18) \quad 0$
In formulating differential diagnosis

$48(59) \quad 32(37) \quad 0$
In presenting written case reports $47(58) \quad 33(41) \quad 1(1)$

$29(36) \quad 47(58) \quad 5(6)$
In planning basic investigation

$35(43) \quad 36(14) \quad 10(12)$

\section{Tutors' views}

Twelve tutors were male and 8 female with a mean age of 38 years (range 30-54). Most had a postgraduate qualification (MRCGP 12; MRCP 3; FRCS 1; PhD 1). Four were single-handed practitioners. Only two were currently GP trainers (i.e. recognised by the Joint Committee on Postgraduate Training for General Practice as competent to supervise registrars in general practice during the final year of vocational training). Some expressed a specific interest in undergraduate rather than postgraduate teaching.

The tutors' most important aims were to promote students' acquisition of basic clinical skills and to improve their approach to patients. Most said they adhered to the departmental teaching guidelines, with nine having the students sitting in their consultations for one session per week, six for less than a full session and five for more. The rest of the time was spent seeing patients at home or in the surgery who were selected as having a 'good' history or 
physical signs and reflecting a variety of common chronic medical conditions. Many tutors also organised 'short cases' on an ad hoc basis.

Tutors identified the personal benefits of this teaching as development of their own clinical skills, and the stimulation and enjoyment of teaching - making a change from the grind of NHS work. Only two specifically mentioned financial rewards. There was a general sense of pride in the programme, and a feeling that it reflected a recognition of GPs' abilities as clinicians and being 'no longer treated as second class citizens'.

\section{Students' performance}

Forty-eight community and 20 hospital-based students took the OSCE. Stations were used with varying frequency, as shown in Table 2.

\section{Table 2 Students' scores in end of rotation OSCE}

Station

Community firm
mean scores
( $\mathrm{n}=$ number of
students given
each station)

Hospital firm mean scores ( $\mathrm{n}=$ number of students given each station)
A Abdominal Examination
$15.9(24)$
$16.5(13)$
$0.49 \quad-2.6-1.3$
B History of Breathlessness
$14.7(39)$
$14.1(18)$
$0.47 \quad-1.1-2.3$
C History of Alchoholic Gastritis
$17.5(48)$
D Examination of the Respiratory 18.5 (24) System
E Communication Skills
$13.3(40)$
$16.2(20)$
$0.11-0.3-2.9$
$16.7(9)$
$0.15 \quad-0.7-4.2$
F History of Chest Pain
$17.4(16)$
$10.5(16)$
$0.04 \quad 0.2-5.4$
$17.7(40)$
$13.9(9)$
$0.001 \quad 1.5-5.4$
G Examination of the Cardio Vascular System
$\mathrm{H}$ Examination of the Cranial
$17.5(40)$ Nerves
I History of Lymphoma
16.7 (15)
$0.26 \quad-0.7-2.7$
$15.6(15)$
0.02
$0.3-3.5$
16.0 (17)
$16.7(5)$
0.63 


\section{Discussion}

At UCLMS both the teaching programme and the evaluation instruments have evolved over the period under study. This has made presenting and interpreting the data a complex task. Logistics prevented us from maintaining a comparison with students taught in hospital for more than one academic year; and as students' experiences can vary widely between hospital firms, the validity of choosing only the oncology firm is questionable. We have attempted to minimise these shortcomings through complementing the quantitative work with qualitative techniques and through triangulation - combining methods to validate our conclusions. Despite these methodological limitations we feel confident that our data help answer the questions posed initially.

We have demonstrated that community-based teaching can usefully contribute to undergraduate medical education in the area of clinical skills teaching. This achievement is underlined by the commitment of the UCLMS to ensuring that all students experience the 'Medicine in the Community' firm, and to providing new recurrent funds of $£ 125,000$ per annum. The OSCE data suggest that, at the very least, clinical skills can be taught as effectively in the community as in the hospital setting. We are currently undertaking a much larger randomised cross-over trial of community versus hospital-based teaching of clinical skills to provide more information about the relative strengths and weaknesses of the two locations. Some consultant doctors and students feel concerned about the lack of acute medicine seen on this attachment. However, our response is that this is the job of acute hospital-based firms in the first clinical year. In the community, students learn about chronic disease and its impact on a person's life. Both community and hospital settings are needed for a rounded clinical education. We have not explored the wider potential contribution of the community to the curriculum; current curricular initiatives ${ }^{15}$ may help to define this.

\section{Practical issues and feasibility of community-based medical education}

This was the final question raised at the beginning of this paper, and the one to which we have the clearest answers.

\section{Issues for students}

Students are particularly appreciative of the structured nature of the programme, which allows them to focus their reading; the personalised, student-centred teaching provided by the tutors; and the opportunity to see patients in their homes.

Many students would have preferred not to link general practice to another specialty, but an inevitable challenge of community-based education is the geographically dispersed nature of GP tutors. By concentrating the general practice attachment into 2 whole days per week (rather than half day sessions scattered throughout the week) students spend less time travelling and transport fares have been reduced. The time taken and cost of travel remains one of the students' major irritations. Practices are located up to $15 \mathrm{~km}$ from University College Hospital, and expenses of up to $£ 14$ per week are incurred on public transport. These expenses are not met by the programme and many local authorities (who provide student grants) no longer reimburse travelling expenses. 
Committing 2 whole days per week to the programme allows tutors to use the middle of the day (a relatively quiet time for GPs) to teach. Not many GPs could provide more than four sessions of intensive teaching in a week. However, it may be possible for practices with a commitment to undergraduate education to appropriate extra resources and the space to expand, to employ extra staff and take on more students.

Issues for the medical school

Quality control is a further issue - given the geographical dispersal of the tutors it can be difficult to ascertain exactly how and what students are being taught. We have tackled this with a combination of staff development sessions, involving tutors in assessing the students at OSCEs using standardised marking schedules, and feeding back student end-of-firm comments. Persistent student dissatisfaction with a particular tutor would lead to non-renewal of contract.

The impact of this programme on future medical education depends on its sustainability and generalisability. Sustainability depends largely on adequate funding and recruiting, training and maintaining sufficient numbers of good tutors. The annually renewable part-time lecturer contract provides the tutors with status, and formalises their relationship with the department, requiring them to conform with the overall aims and objectives of the programme and attend staff development meetings.

Good teaching takes time so it is essential to pay tutors appropriately. The total costs of teaching 154 students in the community for 1993-4 was about $£ 190,000$ which equates to £50-60 per student per half day ${ }^{14}$. This includes the part-time lecturers salaries, costs of department-based teaching and organisation and development programme. The difference between the total cost and the recurrent funding from UCLMS is made up from departmental funds.

\section{Box 1 Prerequisites for success for teaching internal medicine in general practice}

- Appropriate remuneration

- Large pool of potential GP tutors

- Formal annually renewable teaching contracts

- Flexible practice arrangements

- On-going teachers' course

- Intensive 1:2 teaching only part of a week

- Slow start, flexible development adapted to local circumstances

- An experienced senior member of staff in control 
We believe that this model of community-based medical education is robust, versatile and widely applicable. Box 1 contains a list of the factors we believe are prerequisites for success for other schools contemplating this sort of venture.

There are, however, many unresolved questions. What (if any) are the long-term benefits to students of such a relatively short community-based attachment? Has the shift to more community-based teaching (which was perhaps largely driven by necessity) been accompanied by a shift to a more community-oriented curriculum? If this model were to be widely adopted, what are the implications for patients and their doctors (a more detailed assessment of their problems versus repeated student intrusion into the doctor-patient relationship)? Finally, will academic general practice use the opportunity of arriving late on the undergraduate teaching scene to set high professional standards for the recruitment and training of teachers? And, if so, might such standards be adopted by other medical disciplines? 


\section{References}

1. General Medical Council. Tomorrow's Doctors: Recommendations on Undergraduate Medical Education. London: General Medical Council; 1993.

2. Towle A. Critical Thinking: The Future of Undergraduate Medical Education. London: King's Fund Centre; 1991.

3. Metcalfe DH. The Edinburgh Declaration. Fam Pract 1989;6:165-7.

4. World Federation for Medical Education [editorial]. Med Educ 1997;31:305-6.

5. Lloyd MH, Rosenthal JJ. The contribution of general practice to medical education: expectations and fulfilment. Med Educ 1992;26:488-96.

6. Audit Commission for Local Authorities and National Health Service in England and Wales. A Short Cut to Better Services. Day Surgery in England and Wales. London: HMSO; 1992.

7. Audit Commission for Local Authorities and National Health Service in England and Wales. Lying in Wait: The Use of Medical Beds in Acute Hospitals. London: HMSO; 1992.

8. Jarman B. Is London overbedded?. BMJ 1993;306:979-82.

9. Leese B, Bosanquet $\mathrm{N}$. Changes in general practice organization: survey of general practitioners' views on the 1990 contract and fundholding. Br J Gen Pract 1996;46:959.

10. Robinson LA, Spencer JA, Jones RH. Contribution of academic departments of general practice to undergraduate teaching, and their plans for curriculum development. $\mathrm{Br} \mathrm{J}$ Gen Pract 1994;44:489-91.

11. Booton P. Teaching General Medicine in General Practice. In: Towle A, ed. Community Based Teaching - Sharing Ideas 1, London: King's Fund Centre; 1992.

12. Oswald N, Jones S, Date J, Hinds D. Long-term community-based attachments: the Cambridge course. Med Educ 1995;29:72-6.

13. Harden RM, Gleeson FA. Assessment of clinical competence using an objective structured clinical examination (OSCE). Med Educ 1979;13:41-54.

14. Murray E, Jinks V, Modell M. Community-based medical education: feasibility and cost. Med Educ 1995;29:66-71.

15. Whitehouse CR. Planning for Community-oriented Medical Education in Manchester. Education for Health 1996;9:45-59. 


\section{Can students learn clinical method in general practice? A randomised cross-over trial comparing student acquisition of clinical skills in general practice and in hospital}

\section{Summary}

The widespread adoption of general practice based teaching for skills and knowledge previously taught in hospital can only be supported if students learn these core skills as well in general practice as in hospital. The objective of the trial was to answer this question and to determine whether there was any difference in the acquisition of specific skills in the two environments. The trial used a randomised crossover design and involved the entire annual intake of first year clinical students at University College London Medical School (UCLMS). The intervention was a 10 week block of general internal medicine, of which one half was taught in general practice, and the other half in hospital. Students were randomly allocated to start in one location, and crossed over to the other location after five weeks. The outcome measures were students' performance in two equivalent nine station objective structured clinical examinations OSCEs administered at the mid and end points of the block, allowing a direct comparison of the two groups' performance at five weeks and an analysis of covariance, using their first examination scores as a covariate, to determine students' relative improvement over the second five weeks of their attachment. The results were that 225 students rotated through the block; all took at least one examination and $208(92 \%)$ took both. For the first half of the year there was no significant difference in the students' acquisition of clinical skills in the two environments; later, however, students taught in general practice improved slightly more than those taught in hospital $(\mathrm{P}=0.007)$. The conclusions were that students could learn clinical skills as well in general practice as in hospital; more work was needed to clarify where specific skills, knowledge, and attitudes were best learnt to allow rational planning of the undergraduate curriculum.

\section{Introduction}

There is an international move toward community-based undergraduate medical education ${ }^{1: 2}$. In Britain half of medical schools have some primary care input into teaching clinical skills ${ }^{3}$; most new curricula will have a substantial increase in community based teaching. This change reflects the "primary care led NHS" that is having a profound impact on delivery of health care" ${ }^{5: 6}$, and on undergraduate education ${ }^{7}$. However, community based teaching is no cheaper than hospital based teaching ${ }^{8}$, has some specific disadvantages including geographical dispersal of tutors making quality control difficult ${ }^{9}$, and results in considerable travel costs to students ${ }^{10}$.

Most evaluations of community based teaching have concentrated on ascertaining student or faculty perceptions of its educational value ${ }^{11-13}$. Using an objective structured clinical examination (OSCE), Satran et al found equal acquisition of clinical skills, ${ }^{14}$ but in their study both community and hospital based students were taught by paediatricians and only two of the examination stations were patient based. There is little evidence as to whether students taught in 
General Practice can acquire their clinical skills as well as those taught in hospital. This study was designed to address this question.

\begin{abstract}
Aims
The aims of the study were to determine whether students acquired their clinical skills as well in general practice as on the hospital attachment. In addition, we sought to determine whether there was any difference in the acquisition of specific skills in the two environments.
\end{abstract}

\title{
Methods
}

The subjects were all first year clinical students at University College London Medical School during the academic year 1995-6. The school has a traditional medical curriculum with two years of basic science followed by three years of clinical medicine. After a four week introductory course on clinical method, students were randomly divided into four groups. Each group started with a different 10 week block (covering general medicine; surgery; medical specialties; and geriatrics, rheumatology and orthopaedics) and rotated through all four blocks during the year. The block under study here (general medicine based at the Whittington Hospital) consisted of two five week attachments, one in general practice and one in hospital. Students were randomly allocated to start either in hospital or in the community and changed over after five weeks.

\section{Intervention: hospital and general practice based teaching}

The five weeks in general practice - the "Medicine in the Community" (MiC) clerkship - at the Whittington was designed to replace a traditional hospital clerkship and is described elsewhere. ${ }^{10}$ Both hospital and general practice attachments shared common aims but the teaching structure was different (see box). For example, as in most medical schools, the contracts of senior academic and NHS are unspecific about teaching commitments, whereas the general practitioners were paid specifically to provide protected teaching time.

\section{Trial design and Outcome Measures}

As well as determining whether students acquired their clinical skills as well in the Medicine in the Community attachment as in hospital we also wanted to see whether there was any difference in the acquisition of specific skills in the two environments.

The outcome measure was students' performance in two parallel nine station objective structured clinical examinations (OSCEs P and Q, Box 2), given to all students at five and ten weeks. In the first and third blocks students had P followed by Q, and in the second and fourth blocks they had $\mathrm{Q}$ followed by $\mathrm{P}$. Two different examinations were used to promote test security, to minimise learning effects within the design, and to maximise the number of cases used thus optimising the potential for detecting differential skill acquisition, overall, in the two environments. The disadvantage of using two examinations was that it was impossible to equate $P$ and $Q$ until after the first two blocks. 
Stations lasted 7 minutes and, except for two on data interpretation, each used a trained Standardised Patient. Stations were chosen to reflect problems found in both hospital medicine and general practice; all but two had been developed and validated over the previous five years. These two, on acute medical problems, were written by a consultant physician in consultation with a general practitioner. Examiners were drawn from senior hospital physicians and general practitioner tutors. Most were engaged in first year teaching; all others were experienced examiners in objective structured clinical examinations. Check lists, unavailable to students, were used for marking.

\section{Box 1 Aims of the attachment}

Both hospital and general practice attachments aim to enable students to acquire:

- the basic clinical skills of history taking, physical examination, and communication skills

- sufficient knowledge to understand and apply these clinical skills

- appropriate professional attitudes

\section{Structure of teaching in the two sites}

\section{Hospital}

- 4-6 students per firm

- 5 firms

- Firms had students throughout the year

- Students clerk and present available patients

- Patients seen on wards or in outpatients

- Teaching by senior NHS and academic staff and junior doctors

- $1: 1$ or $1: 2$ teaching in outpatients (once a week on average)

- $2 \times 1$ hour tutorials per week

- All senior staff offered five half days of training in teaching methods, variably taken up

- Teaching accepted part of job

\section{General Practice}

- 2 - 6 students per general practice tutor

- 20 tutors / practices

- Most tutors took students for alternate firms

- Students clerk and present specially selected patients

- Patients seen in their homes or in the surgery

- Teaching by tutor only

- 1:1 or 1:2 teaching in booked surgery (once a week on average)

- One 3 hour seminar per week

- All tutors offered rolling programme of training in teaching methods ( 6 evenings per year); $60 \%$ attendance in study year

- Tutors applied for teaching post; undertook to provide 4 - 6 hours protected teaching time per week

The performance of the students in hospital or MiC blocks could be directly compared at the five week point for each of the 4 rotations throughout the year; subsequently their improvement over the second five weeks could also be determined by subtracting the five week score from that at ten weeks. This was possible because the balanced design cancelled out any differences due to differential difficulty of the examinations.

Analysis of data from the first two blocks suggested that OSCE Q was slightly harder than OSCE P and that this was due to a hard station in Q and an easy one in P. In particular, all students scored so highly on the ascites station that there was no room for improvement. Therefore the same two examinations were used for the final two blocks, but with both photograph stations removed and the two blood test stations used each time. 


\section{Box 2 Contents of examinations $P$ and $Q$}

\begin{tabular}{|c|c|c|}
\hline Skill Domain & $\mathbf{P}$ & $\mathbf{Q}$ \\
\hline & Acute severe breathlessness & Acute severe chest pain \\
\hline History taking & Transient Ischaemic Attack & Chronic Obstructive \\
\hline & Rectal bleeding & Airways Disease \\
\hline & & Irritable Bowel syndrome \\
\hline & Respiratory System & Cardiovascular System \\
\hline Physical Examination & Peripheral Nervous System: & Peripheral Nervous System \\
\hline & Upper Limb & Lower Limb \\
\hline & Diabetic Foot & Cranial Nerves \\
\hline Communication Skills & Hypertension & Asthma Prophylaxis \\
\hline Data Interpretation & Ascites (photos) & $\begin{array}{l}\text { Rheumatoid and osteo } \\
\text { arthritis (photos) }\end{array}$ \\
\hline & $\begin{array}{l}\text { Thyroid Function Test } \\
\text { (hypothyroid patient) }\end{array}$ & $\begin{array}{l}\text { Full Blood Count } \\
\text { (Microcytic, hypochromic } \\
\text { Anaemia) }\end{array}$ \\
\hline
\end{tabular}

Results were analysed using SPSS 6.1 for Windows. Firstly, data from each of the four blocks were analysed to compare the effect of the two locations at the five week point. Total mean scores, and mean scores for each skill domain were compared using the t-test for unrelated groups. Subsequently improvements between ten week- and five week- scores were analysed using analysis of co-variance, a statistically equivalent variant of a design used by Ali et $\mathrm{al}^{15}$, and Nyquist et $\mathrm{al}^{16}$ to compare two groups in a balanced crossover design. In this analysis blocks 1 and 2 and blocks 3 and 4 are combined to fully utilise the balanced nature of the design.

\section{Results}

A total of 225 students rotated through the Medicine in the Community firm in the study year. Of these, all 225 took at least one OSCE, and $208(92 \%)$ took the OSCE at both the five week and the ten week point.

Table 1 shows the results of a direct comparison of mean scores for the hospital and MiC groups at the five week point for Blocks 1 and 2. Table 2 displays the equivalent data for Blocks 3 and 4. Table 3 shows the incremental improvement in the two groups over the second five weeks of the attachment for each of the 4 blocks. In Table 1 total OSCE scores are higher for hospital students on examination P1 and for community students on OSCE Q2, but only the latter reached statistical significance. These differences were due partly to performance on the interpretation domain and to isolated differences on individual stations, but not to other skill domains. There were no consistent differences between locations. There were no such differences for later groups, apart from one on data interpretation.

Further analysis combined the first two and last two blocks in separate analyses. This showed that students' improvement over the second five weeks, using the first examination as a co- 
variate, was not significantly different between learning locations for the first two blocks $(\mathrm{p}=$ 0.128 ), but was significantly better in the community than in hospital for the last two blocks: mean improvement in score $=6.6(95 \%$ CI $3.4-9.8)$ for the community attachment and $1.7(95 \%$ CI -1.3 - 4.7) for students studying in hospital $(p=0.007)$. Further analysis of scores broken down into skills showed that this was due to improved examination skills in the community students (mean improvement: community $=4.23(2.38-6.08)$, hospital $0.26(-1.5-1.94)$; $\mathrm{p}<0.002$ ). These data represent a difference between locations of about $3 \%-10 \%$ on 5 weeks experience as measured by performance in the examination.

In addition, mean scores for all students for each examination showed gradual improvement over the 40 weeks. After equation of the examinations, scores showed a significant monotonic linear trend ( $\mathrm{p}<0.001)$. The increase over the last 20 weeks is approximately $10 \%$. In other words, 5 weeks training in $\mathrm{MiC}$, for experienced first year clinical students, is worth about the equivalent of 10 to 20 weeks of average clinical experience in terms of performance in the examination.

Table 1 Comparison of mean OSCE scores of students taught for their first five weeks of blocks 1 and 2 either in general practice or in hospital.

\begin{tabular}{lllll}
\hline Skill domain & $\begin{array}{l}\text { OSCE } \\
\text { Block }\end{array}$ & GP mean $(95 \%$ CI $)$ & Hospital mean $(95 \%$ CI) & p value \\
\hline History taking & P1 & $37.8(36.2-39.4)$ & $39.9(38.2-41.6)$ & $\mathrm{ns}$ \\
Max score $=60$ & Q2 & $38.4(36.4-40.4)$ & $36.6(34.3-39)$ & $\mathrm{ns}$ \\
Physical Examination & P1 & $35.9(33.0-38.8)$ & $36.6(33.3-40.0)$ & $\mathrm{ns}$ \\
Max score =60 & Q2 & $45.0(41.8-48.2)$ & $41.7(39.9-43.5)$ & $\mathrm{ns}$ \\
Communication skills & P1 & $12.0(10.8-13.2)$ & $12.4(11.7-13.2)$ & $\mathrm{ns}$ \\
Max score $=20$ & Q2 & $10.2(9.4-11.0)$ & $10.1(9.3-10.9)$ & $\mathrm{ns}$ \\
Data Interpretation & P1 & $24.4(23.0-25.8)$ & $26.9(25.4-28.3)$ & .02 \\
Max score $=40$ & Q2 & $21.0(19.4-22.6)$ & $17.4(15.5-19.4)$ & .007 \\
Total score & P1 & $110.1(106.1-114.1)$ & $115.9(111.7-120)$ & $\mathrm{ns}$ \\
Max score $=180$ & $\mathrm{Q} 2$ & $114.6(109.2-120.1)$ & $105.9(101.3-110.6)$ & .02 \\
& & & & \\
\hline
\end{tabular}

Students who took OSCE Pl $(n=56)$ had had a four week introductory course prior to their medical attachment; students who took OSCE Q2 $(n=54)$ had had the four week introductory course plus ten weeks of a surgical attachment. 
Table 2 Comparison of mean OSCE scores of students taught for their first five weeks of blocks 3 and 4 in either general practice or in hospital.

\begin{tabular}{lllll}
\hline Skill domain & $\begin{array}{l}\text { OSCE } \\
\text { Block }\end{array}$ & GP mean $(95 \%$ CI $)$ & Hospital mean (95\% CI) & p value \\
& P3 & $40.5(38.4-42.6)$ & $39.9(38.2-41.6)$ & $\mathrm{ns}$ \\
History taking & Q4 & $41.1(38.9-43.3)$ & $42.0(40.0-44.0)$ & $\mathrm{ns}$ \\
max =60 & P3 & $42.9(40.3-45.5)$ & $41.0(38.9-43.1)$ & $\mathrm{ns}$ \\
Physical Examination & Q4 & $46.2(44.3-48.1)$ & $46.4(44.6-48.2)$ & $\mathrm{ns}$ \\
max =60 & P3 & $13.1(12.3-13.9)$ & $14.0(13.0-15.0)$ & $\mathrm{ns}$ \\
Communication Skills & Q4 & $13.4(12.4-14.4)$ & $13.3(12.2-14.4)$. & $\mathrm{ns}$ \\
max =20 & P3 & $19.3(17.5-21.1)$ & $22.0(20.1-23.9)$ & .04 \\
Data Interpretation & Q4 & $23.2(21.8-24.6)$ & $24.0(22.5-25.5)$ & $\mathrm{ns}$ \\
max =40 & P3 & $115.8(110.0-121.6)$ & $116.9(112.2-121.6)$ & $\mathrm{ns}$ \\
Total score & Q4 & $123.9(120.0-127.8)$ & $125.8(121.8-129.8)$ & $\mathrm{ns}$ \\
Max =180 & & & \\
\hline
\end{tabular}

Students on Block $3(n=57)$ had had 24 weeks of clinical experience (4 weeks Introductory course, 10 weeks surgery and 10 weeks Oncology or AIDS medicine) while students on Block 4 $(n=55)$ were on the last block of the year.

Table 3 Incremental improvement in total OSCE scores for the two groups over the second five weeks of their attachments

\begin{tabular}{lllll}
\hline Block & Basis of Improvement & $\begin{array}{l}\text { GP mean } \\
\text { improvement } \\
(95 \% \mathrm{CI})\end{array}$ & $\begin{array}{l}\text { Hospital } \\
\text { mean Improvement } \\
(95 \% \mathrm{CI})\end{array}$ & $\begin{array}{l}\mathrm{p} \\
\text { value }\end{array}$ \\
\hline 1 & Q1 - P1 (t-test) & $5.4(.12-10.8)$ & $2.0(-3.0-7.0)$ & $\mathrm{ns}$ \\
2 & P2 - Q2 (t-test) & $25.1(18.2-32)$ & $29.3(22.6-36)$ & $\mathrm{ns}$ \\
$1 \& 2$ & Balanced Analysis of covariance & $17.35(12.3522 .35)$ & $13.68(9.04-18.32)$ & $\mathrm{ns}$ \\
3 & *Q3 - *P3(t-test) & $7.4(2.4-12.4)$ & $3.5(-.7-7.7)$ & $\mathrm{ns}$ \\
4 & *P4 - *Q4(t-test) & $5.5(1.9-9.2)$ & $-.33(-4.4-3.8)$ & .041 \\
$3 \& 4$ & Balanced analysis of covariance & $6.61(3.4-9.8)$ & $1.7(-1.3-4.7)$ & .007 \\
\hline
\end{tabular}

*OSCEs P \& Q modified as described above. 


\section{Discussion}

The results suggest that, overall, students acquire their clinical skills as well, if not better, in General Practice as in hospital. This appears to be true for all the skill domains tested. In particular, examination skills improved more for experienced students in MiC locations. Generally, students' clinical skills continue to improve throughout the year. The spread of results around the mean diminishes throughout the year, hence it is possible that there is a ceiling effect; given the sort of experience provided in the first clinical year, students can only progress so far.

The method was specifically chosen to sample as wide a range of skills as possible within a balanced design. Its strengths include the randomisation of students both to the order in which they took the four blocks making up the first year, and once on the medicine block, to starting in either community or hospital. The cross-over design allowed both for direct comparisons of students taught in the two venues and for pre- and post-exposure testing, a design which has been widely favoured as a method of assessing efficacy of skills teaching ${ }^{15-19}$. The comparison group is both plausible and fair; the "Medicine in the Community" firm was expressly designed to replace a traditional hospital medical clerkship and its brief was to teach the same core clinical skills as those students learn in hospital. The outcome measure, an OSCE, is a recognised and widely used method for testing clinical skills ${ }^{20}$ in undergraduate and postgraduate settings. ${ }^{21: 22}$ The sample size in this study is large enough to detect educationally important differences. Although longer OSCEs are needed before inferences about a single student can be made, we were interested in group performance which is adequately determined by this number of stations.

Potential weaknesses in the design include the small number of stations in each skill domain which limits the power of the study to comprehensively determine whether specific skills are acquired better in either location. The cross-over design minimised the impact of varying ability in different groups, but it was not possible to control for this altogether. Previous work has demonstrated that test security is not necessarily a problem with OSCEs ${ }^{23-25}$, and that under appropriate circumstances, replicated in this study, repetition of stations throughout the year does not jeopardise the validity of the examination ${ }^{26: 27}$. Stations were chosen to reflect problems that the student might encounter in either hospital or General Practice, but it is possible that the problems tested favoured students who had learnt in one or other setting. Examiners were partially "blinded" as no information was given on students' prior experience. Any potential bias from examiners preferentially marking students known to them was minimised through drawing examiners from both settings, using structured marking sheets and would have been limited to scores from one station.

These data support current efforts to redistribute resources from traditional locations for student learning to the community. It is necessary to determine which specific knowledge, skills and attitudes are best acquired in the community, which are best acquired in hospital and which can be equally well acquired in either environment given appropriate, well structured and adequately resourced teaching. Further work is also needed on which teaching methods optimise student learning in all settings. Only then can we progress to rational planning of new curricula, and provide students with well structured teaching and an optimum balance between hospital based and community based learning. 


\section{References}

1. Whitehouse CR, Roland M, Campion P. Teaching Medicine in the Community: A guide for undergraduate education. Oxford: Oxford University Press; 1997.

2. World Federation for Medical Education [editorial]. Med Educ. 1997;31:305-6.

3. Robinson LA, Spencer JA, Jones RH. Contribution of academic departments of general practice to undergraduate teaching, and their plans for curriculum development. $\mathrm{Br} \mathrm{J}$ Gen Pract. 1994;44:489-91.

4. National Health Service Executive. Developing a primary care led NHS. London; HMSO; 1996.

5. Audit Commission for Local Authorities and National Health Service in England and Wales. Lying in Wait: The Use of Medical Beds in Acute Hospitals. London, HMSO 1992.

6. Audit Commission for Local Authorities and National Health Service in England and Wales. A Short Cut to Better Services. Day Surgery in England and Wales. London: HMSO; 1992.

7. Lowry S. Trends in health care and their effects on medical education. BMJ 1993;306:255-88.

8. Murray E, Jinks V, Modell M. Community-based medical education: feasibility and cost. Med Educ 1995;29:66-71.

9. Price DA, Miflin BM, Mudge PR, Jackson CL. The quality of medical teaching and learning in rural settings: the learner's perspective. Med Educ 1994;28:239-51.

10. Murray E, Todd C, Modell M. Can general internal medicine be taught in general practice? An evaluation of the University College London model. Med Educ 1997;36974.

11. Foldevi M,.Trell E. Learning the Basics of Medicine in General Practice in the Faculty of health Sciences, Linkoping, Sweden. Annals of Community-Oriented Education 1993;6:97-113.

12. Crebolder HFJM,.Metsemakers JFM. General Practice, Medical Education and Community-Based Teaching: the Maastricht Experience. Annals of CommunityOriented Education 1994;7:121-9.

13. Oswald N, Jones S, Date J, Hinds D. Long-term community-based attachments: the Cambridge course. Med Educ 1995;29:72-6.

14. Satran L, Harris IB, Allen S, Anderson DC, Poland GA, Miller WL. Hospital-based versus community-based clinical education: comparing performances and course evaluations by students in their second-year pediatrics rotation. Acad Med 1993;68:3802. 
15. Ali I, Cohen R, Reznick R. Demonstration of acquisition of trauma management skills by senior medical students completing the ATLS Program. J Trauma 1995;38:687-91.

16. Nyquist JG, Naylor AJ, Woodward LG, Dixon S. Use of performance-based assessment to evaluate the impact of a skill-oriented continuing education program. Acad Med 1994;69:S51-S53.

17. Kokotailo PK, Langhough R, Neary EJ, Matson SC, Fleming MF. Improving pediatric residents' alcohol and other drug use clinical skills: use of an experiential curriculum. Pediatrics 1995;96:99-104.

18. Berg D, Sebastian J, Heudebert G. Development, implementation, and evaluation of an advanced physical diagnosis course for senior medical students. Acad Med 1994;69:75864.

19. Rothman AI. Understanding the objective structured clinical examination. Aust $\mathrm{N} \mathrm{Z} \mathrm{J}$ Surg 1995;65:302-3.

20. van der Vleuten CP,.Swanson AG. Assessment of clinical skills with standardised patients: state of the art. Teaching and Learning in Medicine 1990;2:58-76.

21. McFaul PB, Taylor DJ, Howie PW. The assessment of clinical competence in obstetrics and gynaecology in two medical schools by an objective structured clinical examination. Br J Obstet Gynaecol 1993;100:842-6.

22. Sloan DA, Donnelly MB, Schwartz RW, Felts JL, Blue AV, Strodel WE. The use of objective structured clinical examination (OSCE) for evaluation and instruction in graduate medical education. J Surg Res 1996;63:225-30.

23. Colliver JA, Barrows HS, Vu NV, Verhulst SJ, Mast TA, Travis TA. Test security in examinations that use standardized-patient cases at one medical school. Acad Med 1991;66:279-82.

24. Rutala PJ, Witzke DB, Leko EO, Fulginiti JV, Taylor PJ. Sharing of information by students in an objective structured clinical examination. Arch Intern Med 1991;151:5414.

25. Stillman PL, Haley HL, Sutnick AI, Philbin MM, Smith SR, O'Donnell J et al. Is test security an issue in a multistation clinical assessment? A preliminary study. Acad Med 1991;66:S25-S27.

26. Jolly B, Cohen R, Newble D, Rothman A. Possible effects of reusing OSCE stations [letter]. Acad Med 1996;71:1023-4.

27. Niehaus AH, DaRosa DA, Markwell SJ, Folse R. Is test security a concern when OSCE stations are repeated across clerkship rotations? Acad Med 1996;71:287-9. 


\section{A comparison of the educational opportunities on junior medical attachments in general practice and in a teaching hospital: a questionnaire survey}

\section{Summary}

The objectives of the trial were to obtain students' perceptions of the educational quality of the general internal medicine teaching overall and to determine whether specific learning objectives were better addressed in general practice or in hospital. The study population was the entire annual intake $(n=225)$ of students into the first clinical year at one UK medical school. The survey was carried out after a 10 week block of general internal medicine, consisting of five weeks taught in general practice and five weeks taught in a teaching hospital. Students were randomly allocated to start in either general practice or hospital. The outcome measure was a questionnaire survey of students' perceptions of their learning on the two halves of the block. Each student completed the same questionnaire twice: one after their hospital experience and once after their general practice experience. Statistical analysis was carried out using the SPSS package for Windows 3.1. Group means were calculated for each response, and the mean differences for each student's responses for the two learning environments were analysed using $t$-tests for paired samples. Students perceived they learnt more about history taking and physical examination in the community, whereas they learnt more about writing up their clerkings, keeping progress notes and disease management in hospital. The conclusions were that the community and hospital environments appeared to have different strengths for the teaching of medical students. The data supported the judicious transfer of clinical skills teaching into general practice, when the circumstances achieved here could be duplicated. However, some aspects of the clinical attachment, particularly record keeping and disease management are probably better taught in hospital at present.

\section{Introduction}

Given the current and planned increase in community based teaching, both worldwide ${ }^{1 ; 2}$ and in the $\mathrm{UK}^{3 ; 4}$, it is vital to determine the relative strengths and weaknesses of hospital based and community based teaching. Until recently in the UK, community based teaching was equated with learning about primary care. Now, however, it increasingly involves learning subjects, such as clinical method and general internal medicine, that have previously been seen as the exclusive domain of hospital teachers ${ }^{5}$. Prior work has established that students can acquire clinical method as well in General Practice as in hospital ${ }^{6}$; questionnaire studies have elicited high student satisfaction with community attachments ${ }^{7-9}$, but there are fewer studies which provide a direct comparison of student perceptions of learning opportunities and achievements in the two settings.

University College London Medical School has run a junior medical firm in general practice since 1991. As this was specifically set up to replace a traditional hospital based firm, and 
shared common objectives with the remaining hospital firms, it is an appropriate model to study in order to answer this question.

The aim of the study was to obtain students' perceptions of the degree to which teaching of general internal medicine enabled them to achieve the medical school's objectives for the first clinical year; to obtain process data on the learning opportunities available to students; and to determine their views of the educational qualities of their attachments. In addition we sought to determine whether specific learning objectives were better addressed in general practice or in hospital, and whether students' stated clinical experience correlated with their views on their achievement of clinical objectives.

\section{Methods}

\section{The educational experience}

In the study year (1995-6), University College London Medical School (UCLMS) had a traditional curriculum: two years of biomedical sciences with little clinical contact followed by a three year clinical course. Approximately $10 \%$ of the intake into the clinical course came from Oxford or Cambridge, and about half the UCLMS students took a B.Sc before entering the clinical course. The first clinical year started with a four week introduction to clinical method for all students; after this the intake was divided into four groups which rotated through four ten week blocks (general medicine; surgery; medical specialties; and geriatrics, rheumatology and orthopaedics) during the year. All blocks shared common aims, written and agreed by the medical faculty, relating to mastery of clinical method and acquisition of knowledge pertaining to general internal medicine and surgery (Table 1).

\section{Table 1 Objectives of the first clinical year (common to all 4 blocks)}

\begin{tabular}{ll}
\hline & By the end of the year, students should be able to: \\
\hline 1 & take a thorough medical history \\
2 & present a history in a succinct and professional manner \\
3 & understand the significance and possible causes of common symptoms \\
4 & interview the patient to determine which cause is most likely \\
5 & conduct a competent, thorough clinical examination \\
6 & discern the significance of abnormal signs \\
7 & think deductively about the history and signs to reach a differential diagnosis \\
8 & write competent notes on the history and examination, including a problem list and \\
9 & differential diagnosis \\
10 & plan initial investigations \\
11 & plan disease management \\
\hline
\end{tabular}


The block under study consists of five weeks "Medicine in the Community" (a general practice based junior medical firm designed to replace a hospital attachment and described elsewhere ${ }^{10}$ ) and five weeks internal medicine in one of the teaching hospitals that contribute to the medical school. Students were allocated to one of three firms making up the "Medicine in the Community" (MiC) attachment (Box 1): one, "Medicine in the Community only" was a pure GP attachment with students in the practice for 4 days/ week. On the other two firms students were in practices for 2 days / week. For "Medicine in the Community / Oncology", they were also on the oncology wards or outpatients for 2 days / week. The third, "Medicine in the Community / Public Health Medicine", placed students in a community health service for two days a week, for example in a community drug team, a day hospital for the elderly, or a primary care service for homeless people. Students on all three attachments had a weekly half-day seminar in the department for formal teaching of diagnostic skills.

\begin{tabular}{|lll|}
\hline Box 1 Structure of the "Medicine in the Community" (MiC) firms. \\
$\begin{array}{l}\text { MiC only } \\
\mathbf{4 8} \text { students / year }\end{array}$ & $\begin{array}{l}\text { MiC / Oncology } \\
\mathbf{6 7} \text { students / year }\end{array}$ & $\begin{array}{l}\text { MiC / Public Health } \\
\mathbf{1 1 0} \text { students / year }\end{array}$ \\
6 students / firm & $8-9$ students / firm & $13-14$ students / firm \\
6 students / group & $2-4$ students / group & 2 students / group \\
1 practice & $\begin{array}{l}\text { each group attached to one } \\
\text { of } 6 \text { practices }\end{array}$ & $\begin{array}{l}\text { each group attached to one } \\
\text { of 12 practices }\end{array}$ \\
& $\begin{array}{l}\text { students in practice 2 days / } \\
\text { week + 2 days on oncology } \\
\text { wards and outpatients }\end{array}$ & $\begin{array}{l}\text { students in practice 2 days / } \\
\text { week + 2 days on public } \\
\text { health attachment }\end{array}$ \\
$\begin{array}{l}\text { students in practice 4 days / } \\
\text { week }\end{array}$ &
\end{tabular}

\section{On all MiC firms students:}

- clerk and present specially selected patients in their homes or in surgery

- have $1: 1$ or $1: 2$ teaching in booked surgery (once a week on average)

- have one 3 hour seminar for formal teaching of clinical method per week; students taught in groups of $6-8$ with one GP faculty member and one Simulated Patient

- have one afternoon of pathology lectures each week

The hospital attachments were subdivided into four: all had general medical in-patients and participated in the rota for admission of patients with acute medical problems. All also had a specialist interest which was reflected in planned admissions and outpatients. These were: diabetes and renal medicine; cardiology and neurology; gastro-enterology and endocrinology; and respiratory medicine and rheumatology. Students were attached in groups of $4-6$ to the hospital firms, all of which took students throughout the academic year. Teaching was largely 
ward based, with students clerking and presenting patients as they were admitted. Teaching was provided by senior NHS and academic staff as well as by junior doctors. Students also had individual teaching in out-patients, approximately once a week. Most firms provided two tutorials lasting an hour each week.

All students also attended a half day lecture course on pathology throughout the year.

\section{The questionnaire}

The questionnaire had been developed over the preceding three years ${ }^{10}$. It consisted of four parts: the first elicited qualitative data about the attachment; the second asked students to rate the extent to which the attachment helped them achieve the objectives of the first clinical year on a 4 point scale (very much, a lot, a little, not at all); the third asked whether they had found the attachment challenging, interesting, enjoyable and if it had made them want to learn more, also on a four point scale (very, quite, not very, not at all). The final section asked for information on the average numbers of patients per week that students had taken a full history from, and performed a physical examination on; and the number of times each week a history was presented to a doctor, their examinations observed and commented on, and their written clerkings commented on.

\section{Data analysis}

Questionnaire data were entered into an Excel spreadsheet and then read into SPSS (both for Windows 3.1) for analysis. Frequency counts and group means were calculated for each response to the objectives (Table 3 ), and for the categorical items relating to the environment (Tables 2 and 4), and means for the continuous data (Tables 2 and 4). The differences for each student's responses for the two learning environments were analysed using both nonparametric (Wilcoxon matched pairs signed rank test) and parametric tests (t-tests for paired samples) as appropriate. However, means, 95\% confidence limits, and probability values for t-test results are provided (Tables 2 - 4) for ease of presentation. In the categorical data a difference of +1.0 represents a difference of one category, e.g. from 'very' to 'quite', with positive values in favour of the community firms. In the continuous data a difference of +1.0 represents a mean difference, for example, of one patient examination, in favour of the community firms.

In the data from community attachments, subgroups were compared using both parametric (ANOVA) and non-parametric (Kruskal-Wallis 1-way) tests. Both tests found the same questions to yield significant differences. Means are provided in Table 4 and probability values using non-parametric tests are presented because the smaller sample sizes in each group rendered non-parametric significance testing more appropriate. 


\section{Results}

225 students rotated through the General Medicine block during the study year. $192(85 \%)$ completed the questionnaire after their GP attachment and $181(80 \%)$ did so after their hospital attachment. $181(80 \%)$ students completed two questionnaires, although not all students answered every question on both occasions.

Students had a high opinion of their attachments. The overall mean scores suggest that students found their medical attachments challenging, interesting, enjoyable and that they made them want to learn more (Table 2). This was true for both hospital and GP attachments, although students rated their GP attachment as significantly more enjoyable.

\section{Table 2 Comparison of perceptions of community and hospital environments}

\begin{tabular}{llllll}
\hline Descriptive & $\begin{array}{l}\mathrm{N} \text { of } \\
\text { paired } \\
\text { means }\end{array}$ & $\begin{array}{l}\text { GP mean } \\
(95 \% \mathrm{CI})\end{array}$ & $\begin{array}{l}\text { Hospital mean } \\
(95 \% \mathrm{CI})\end{array}$ & $\begin{array}{l}\text { Paired means } \\
\text { GP - Hospital } \\
(95 \% \mathrm{CI})\end{array}$ & $\begin{array}{l}\mathrm{p} \\
\text { value }\end{array}$ \\
\hline $\begin{array}{l}\text { Did you find the firm } \\
\text { challenging?* }\end{array}$ & 181 & $3.07(2.97-3.17)$ & $3.03(2.94-3.12)$ & $.04(-.09-.17)$ & $\mathrm{ns}$ \\
$\begin{array}{l}\text { Did you find the firm } \\
\text { interesting?* }\end{array}$ & 182 & $3.55(3.47-3.64)$ & $3.54(3.45-3.62)$ & $.02(-.10-.13)$ & $\mathrm{ns}$ \\
$\begin{array}{l}\text { Did you find the firm } \\
\text { enjoyable?* }\end{array}$ & 180 & $3.57(3.48-3.65)$ & $3.39(3.29-3.50)$ & $.17(.04-.31)$ & .014 \\
$\begin{array}{l}\text { Did the firm make you want } \\
\text { to learn more?* }\end{array}$ & 182 & $3.44(3.35-3.53)$ & $3.34(3.24-3.43)$ & $.1(-.01-.22)$ & $\mathrm{ns}$ \\
$\begin{array}{l}\text { How many histories did you } \\
\text { take each week? }\end{array}$ & 123 & $3.93(3.61-4.25)$ & $3.02(2.74-3.30)$ & $.91(.5-1.3)$ & $<.001$ \\
$\begin{array}{l}\text { How many physical } \\
\text { examinations did you do each } \\
\text { week? }\end{array}$ & 114 & $6.53(5.35-7.71)$ & $5.84(4.68-6.99)$ & $.69(-.71-2.09)$ & $\mathrm{ns}$ \\
$\begin{array}{l}\text { How many times did you } \\
\text { present each week? }\end{array}$ & 119 & $2.56(2.27-2.85)$ & $1.56(1.35-1.78)$ & $1.0(.65-1.35)$ & $<.001$ \\
$\begin{array}{l}\text { How many examinations were } \\
\text { observed each week? }\end{array}$ & 117 & $2.40(2.09-2.71)$ & $.85(.67-1.02)$ & $1.56(1.21-1.90)$ & $<.001$ \\
$\begin{array}{l}\text { How many written clerkings } \\
\text { were marked each week? }\end{array}$ & 105 & $1.17(.86-1.49)$ & $.72(.56-1.06)$ & $.45(.13-.78)$ & $<.01$ \\
\hline
\end{tabular}

T-tests for paired samples

*Scoring: 4 = "very", 3 = "quite", 2 = "not very" and 1 = "not at all"

Students were less positive about the degree to which the attachments enabled them to achieve the learning objectives for the first clinical year. Students perceived that their GP attachment helped them to achieve the objectives relating to history taking and physical examination significantly more than the hospital attachments did. The opposite was true for objectives relating to writing notes of a history and examination, progress notes and studying disease management (Table 3). 
Table 3 To what extent did your attachment to this firm help you to achieve the following objectives?

\begin{tabular}{|c|c|c|c|c|}
\hline OBJECTIVE & $\begin{array}{l}\text { Group Medicine in } \\
\text { the Community } \\
\text { mean }(95 \% \mathrm{CI})\end{array}$ & $\begin{array}{l}\text { Group Hospital } \\
\text { mean }(95 \% \mathrm{CI})\end{array}$ & $\begin{array}{l}\text { Difference in } \\
\text { paired means } \\
(95 \% \mathrm{CI})\end{array}$ & $\begin{array}{l}\mathrm{p} \\
\text { value }\end{array}$ \\
\hline $\begin{array}{l}\text { 1) To take a thorough medical } \\
\text { history }\end{array}$ & $3.23(3.12-3.35)$ & $2.76(2.65-2.88)$ & $.47(.32-.62)$ & $<.001$ \\
\hline 2) To present a history & $3.03(2.91-3.14)$ & $2.73(2.61-2.85)$ & $.30(.14-.45)$ & $<.001$ \\
\hline $\begin{array}{l}\text { 3) To understand significance of } \\
\text { symptoms }\end{array}$ & 2.96 & 2.85 & .11( & se \\
\hline $\begin{array}{l}\text { ew pt to determine } \\
\text { symptoms }\end{array}$ & $3.06(2.95-3.17)$ & $2.51(2.38-2.63)$ & $.56(.41-.70)$ & $<.001$ \\
\hline npetent & $3.17(3.05-3.23)$ & $2.64(2.54-2.74)$ & $.53(.38-.68)$ & $<.001$ \\
\hline significance of & $2.80(2.70-2.91)$ & $2.61(2.52-2.71)$ & $.19(.05-.33)$ & $<.01$ \\
\hline liagnosis & 2 & $3-2.93)$ & $.04(-.11-.18)$ & (100 \\
\hline nt notes of & $2.35(2.24-2.47)$ & $2.54(2.42-2.65)$ & $-.18(-.34--.03)$ & .02 \\
\hline estigations & 2.5 & 2.491 & $8-.22)$ & nos \\
\hline $\begin{array}{l}\text { 10) To study disease } \\
\text { management }\end{array}$ & $2.15(2.04-2.26)$ & $2.43(2.31-2.55)$ & $-.23(-.43-. .13)$ & $<.001$ \\
\hline 11) To write progress notes & $1.53(1.42-1.65)$ & $1.76(1.63-1.89)$ & $-.23(-.37--.08)$ & $<.01$ \\
\hline
\end{tabular}

T-tests for paired samples

$\mathrm{n}=181$, except for objectives 4 and 11 where $\mathrm{n}=180$, and objective 6 where $\mathrm{n}=178$.

Scoring: 4 = "very much", 3 = "a lot", 2 = "not very", 1 = "not at all".

Sub-group analysis was performed to see if it was possible to identify specific components of the GP attachments which were responsible for these results (Tables 4 and 5). There is a slight trend for students to claim that the GP only firm was more helpful in enabling students to achieve the objectives for the year, and was more challenging and interesting (though not more enjoyable) than the joint firms with oncology or public health. However students on the GP only firm reported presenting fewer histories and being observed examining patients less often by tutors, than students in the joint firms. 
Table 4 Description of sub-groups within Medicine in the Community (MiC)

\begin{tabular}{|c|c|c|c|c|}
\hline Descriptive & $\begin{array}{l}\text { MiC only mean } \\
(95 \% \mathrm{CI})\end{array}$ & $\begin{array}{l}\text { MiC / Oncology } \\
\text { mean }(95 \% \mathrm{CI})\end{array}$ & $\begin{array}{l}\text { MiC/ Public } \\
\text { Health mean } \\
(95 \% \mathrm{CI})\end{array}$ & $\mathrm{p}$ value \\
\hline $\begin{array}{l}\text { Did you find the firm } \\
\text { challenging?* }\end{array}$ & $\begin{array}{l}3.43 \\
(3.24-3.62)\end{array}$ & $\begin{array}{l}3.09 \\
(2.93-3.24)\end{array}$ & $\begin{array}{l}2.91 \\
(2.78-3.05)\end{array}$ & $<.0001$ \\
\hline $\begin{array}{l}\text { Did you find the firm } \\
\text { interesting?* }\end{array}$ & $\begin{array}{l}3.82 \\
(3.71-3.94)\end{array}$ & $\begin{array}{l}3.53 \\
(3.37-3.68)\end{array}$ & $\begin{array}{l}3.46 \\
(3.32-3.59)\end{array}$ & $<.01$ \\
\hline $\begin{array}{l}\text { Did you find the firm } \\
\text { enjoyable?* }\end{array}$ & $\begin{array}{l}3.69 \\
(3.53-3.84)\end{array}$ & $\begin{array}{l}3.56 \\
(3.41-3.71)\end{array}$ & $\begin{array}{l}3.53 \\
(3.40-3.67)\end{array}$ & ns \\
\hline $\begin{array}{l}\text { Did the firm make you want to } \\
\text { learn more?* }\end{array}$ & $\begin{array}{l}3.58 \\
(3.41-3.74)\end{array}$ & $\begin{array}{l}3.37 \\
(3.21-3.52)\end{array}$ & $\begin{array}{l}3.43 \\
(3.31-3.56)\end{array}$ & ns \\
\hline $\begin{array}{l}\text { How many histories did you } \\
\text { take each week? }\end{array}$ & $\begin{array}{l}3.69 \\
(3.30-4.08)\end{array}$ & $\begin{array}{l}3.92 \\
(3.54-4.30)\end{array}$ & $\begin{array}{l}3.68 \\
(3.21-4.15)\end{array}$ & ns \\
\hline $\begin{array}{l}\text { How many physical } \\
\text { examinations did you do each } \\
\text { week? }\end{array}$ & $\begin{array}{l}6.08 \\
(4.23-7.93)\end{array}$ & $\begin{array}{l}5.28 \\
(4.22-6.33)\end{array}$ & $\begin{array}{l}6.88 \\
(5.38-8.38)\end{array}$ & ns \\
\hline $\begin{array}{l}\text { How many times did you } \\
\text { present each week? }\end{array}$ & $\begin{array}{l}2.10 \\
(1.86-2.33)\end{array}$ & $\begin{array}{l}2.88 \\
(2.44-3.32)\end{array}$ & $\begin{array}{l}2.35 \\
(1.99-2.71)\end{array}$ & .02 \\
\hline $\begin{array}{l}\text { How many examinations were } \\
\text { observed each week? }\end{array}$ & $\begin{array}{l}1.24 \\
(0.96-1.52)\end{array}$ & $\begin{array}{l}2.80 \\
(2.32-3.27)\end{array}$ & $\begin{array}{l}2.72 \\
(2.37-3.07)\end{array}$ & $<.0001$ \\
\hline $\begin{array}{l}\text { How many written clerkings } \\
\text { weremarked each week? }\end{array}$ & $\begin{array}{l}0.76 \\
(0.53-1.00)\end{array}$ & $\begin{array}{l}1.49 \\
(0.91-2.07)\end{array}$ & $\begin{array}{l}1.00 \\
(0.69-1.31)\end{array}$ & ns \\
\hline
\end{tabular}

*Scoring: 4 = "very", 3 = "quite", 2 = "not very" and 1 = "not at all"

Table 5: Description of sub-groups within the Medicine in the Community (MiC)

To what extent did your attachment to this firm help you to achieve the following?

\begin{tabular}{|c|c|c|c|c|}
\hline Objective & $\begin{array}{l}\text { MiC only } \\
\text { mean } \\
(95 \% \mathrm{CI})\end{array}$ & $\begin{array}{l}\text { MiC / Oncology } \\
\text { mean } \\
(95 \% \mathrm{CI})\end{array}$ & $\begin{array}{l}\text { MiC / Public } \\
\text { health } \\
\text { mean } \\
(95 \% \mathrm{CI})\end{array}$ & $\begin{array}{l}\text { P (Kruskal } \\
\text {-Wallis 1- } \\
\text { Way } \\
\text { Anova) }\end{array}$ \\
\hline 1) To take a thorough & 3.60 & 3.30 & 3.04 & \\
\hline medical history & $(3.44-3.76)$ & $(3.09-3.50)$ & $(2.88-3.21)$ & $<.001$ \\
\hline \multirow[t]{2}{*}{ 2) To present a history } & 3.49 & 3.07 & 2.79 & \\
\hline & $(3.31-3.67)$ & $(2.88-3.26)$ & $(2.62-2.96)$ & $<.0001$ \\
\hline 3) To understand & 3.20 & 3.04 & 2.83 & \\
\hline significance of symptoms & $(3.0-3.40)$ & $(2.87-3.20)$ & $(2.69-2.98)$ & $<.01$ \\
\hline 4) Interview pt to determine & 3.07 & 3.11 & 3.07 & \\
\hline causes of symptoms & $(2.85-3.28)$ & $(2.90-3.32)$ & $(2.91-3.23)$ & ns \\
\hline 5) To conduct a competent & 3.56 & 3.25 & 2.98 & \\
\hline clinical examination & $(3.36-3.75)$ & $(3.06-3.44)$ & $(2.80-3.15)$ & $<.001$ \\
\hline 6) To discern significance of & 3.20 & 2.70 & 2.71 & \\
\hline abnormal signs & $(3.0-3.4)$ & $(2.56-2.86)$ & $(2.56-2.86)$ & $<.0001$ \\
\hline \multirow[t]{2}{*}{ 7) To reach a diagnosis } & 3.18 & 2.84 & 2.78 & \\
\hline & $(2.97-3.38)$ & $(2.65-3.03)$ & $(2.61-2.95)$ & .015 \\
\hline 8) To write competent notes & 2.51 & 2.35 & 2.29 & \\
\hline of history / examination & $(2.28-2.74)$ & $(2.15-2.55)$ & $(2.13-2.45)$ & ns \\
\hline 9) To plan initial & 3.09 & 2.63 & 2.28 & \\
\hline investigations & $(2.89-3.29)$ & $(2.43-2.83)$ & $(2.14-2.42)$ & $<.0001$ \\
\hline 10) To study disease & 2.31 & 2.30 & 1.98 & \\
\hline management & $(2.11-2.51)$ & $(2.09-2.50)$ & & .014 \\
\hline 11) To write progress notes & $\begin{array}{l}1.58 \\
(1.35-1.80)\end{array}$ & $\begin{array}{l}1.56 \\
(1.34-1.78)\end{array}$ & $\begin{array}{l}1.47 \\
(1.32-1.62)\end{array}$ & ns \\
\hline
\end{tabular}

Scoring: 4 = "very much", 3 = "a lot", 2 = "not very", 1 = "not at all". 


\section{Discussion}

These data are an important part of the evaluation of the UCLMS community based teaching of general internal medicine. The main strengths of this study lie in its balanced design with the collection of paired data and the randomisation of students. Students were randomly allocated both to the order in which they took the four blocks making up the first clinical year, and, once on the general medicine block, to starting in either community or hospital medicine. Each student experienced both a hospital-based and a general practice-based medical firm with half of them experiencing general practice first. This ensured that any differences found were unlikely to be due to either the novelty value of the medical firms, or the previous level of experience of the students, and suggests that any differences found reflected real differences in student perceptions of the two locations. Comparing each student's experience in one location, with their experience in the other location, controls for variation in qualities (e.g. enthusiasm) inherent in each student. Moreover, students completed the questionnaires in a neutral environment, at the joint assessment held at the end of each five week attachment, when they were examined by both GP tutors and hospital specialists.

GP tutors are contracted specifically to provide protected teaching time. This may be related to students' claims that, whilst on general practice attachments, they presented more histories and were observed examining more patients than in hospital. This in turn may have increased their perceived ability to achieve the objectives of taking and presenting a medical history and conducting a competent examination. However, students' acquisition of these clinical skills was largely similar in the two environments ${ }^{6}$. These students were relatively junior and needed much supervision; more senior students may benefit more from the opportunity to examine the large numbers of seriously ill patients, many of whom have abnormal signs, present in hospital.

The hospital attachments were better at helping students learn to write competent clerkings and progress notes and studying disease management. The latter is likely to include the evaluation of acutely and critically ill patients. However, students also claimed to have had more written clerkings commented on in general practice. On their hospital attachments students presumably read more full clerkings done by the junior doctors, including progress notes. GP notes bear little resemblance to traditional medical clerkings and despite GPs providing continuity of care, students may only see a patient once during their general practice attachment, compared to the daily review patients receive in hospital.

The dramatic increase in the amount of community based teaching is leading a number of medical schools to require "core" teaching practices to take several students at a time. It is therefore important to compare the educational experiences of the students in a practice which takes a group of 6 for four days a week all year, with the experiences of students in practices which take 2 at a time for two days a week, usually for half a year. The trend for the GP only firm to be more helpful than the joint firms in achieving the various objectives of the first clinical year does not appear to be due to greater clinical exposure, as determined by numbers of histories taken and examinations performed each week. In the informal feedback sessions students claimed to find the split firms disjointed and the continuity of the GP only firm may be one important factor in its apparent success. Practices which take larger numbers of students for longer periods attract more resources. Although this enables them to provide more dedicated teaching time, a more structured programme and better facilities including 
computer assisted learning, it may leave them less able to identify and focus on the needs of the individual student.

The results of this study are in line with a number of other studies examining the effects of community based teaching. Schwiebert \& Davis ${ }^{11}$ found that a family medicine clerkship had a positive impact on students confidence in a number of procedural and cognitive skills, including history taking and physical examination skills, while students taught in the university hospital had more confidence in procedures largely performed in hospital such as interpreting ECGs. Oswald ${ }^{12}$ found that students on an introduction to clinical skills course taught in general practice expressed a high degree of satisfaction with their learning of basic history taking and physical examination skills.

There are still a number of unanswered questions. What is it about GP teaching of clinical skills that makes it enjoyable for students? Is it the low tutor/student ratio, and if so, will the benefits diminish as the number of students attached to one practice at a time increases? To what extent do students' experiences determine their ability to learn clinical skills? Studies are currently underway to answer the first two questions, and we hope to answer the third through linking the questionnaire data presented here with data previously presented on student performance in two OSCEs. In the meantime these data strengthens the case for judicious transfer of some clinical skills teaching from the hospital sector to general practice, where the conditions achieved here (specially selected, enthusiastic, trained GP tutors who are paid to provide protected teaching time) can be duplicated. 


\section{References}

1. World Federation for Medical Education [editorial]. Med Educ 1997;31:305-6.

2. Southgate L, Brownell Anderson M, Boelen C, Chalmers A, des Marchais J, Schwenk TL. Implementing community oriented community-based medical education. In: Davis WK, Jolly B, Page GG, Rothman A, White BAC, editors. Ann Arbor: University of Michigan Medical School; 1997. p 87-92.

3. Whitehouse CR, Roland M, Campion P. Teaching Medicine in the Community: A guide for undergraduate education. Oxford: Oxford University Press; 1997.

4. Association for the Study of Medical Education. Curriculum Innovations: Descriptions of Undergraduate Medical Courses in the UK. London: Association for the Study of Medical Education; 1997.

5. Macfarlane F, McLennan E, Murray E, Wallace P. CeMENT (Community Based Medical Education in North Thames) Project Report. London: CeMENT; 1998.

6. Murray E, Jolly B, Modell M. Can students learn clinical method in general practice? A randomised crossover trial based on objective structured clinical examinations. $B M J$ 1997; 315:920-3.

7. Biddle B, Siska K, Erney S. A Description of Ambulatory Teaching in a Longitudinal Primary Care Program. Teaching and Learning in Medicine 1994;6:185-90.

8. Foldevi M. Undergraduate medical students' rating of clerkship in general practice. Fam Pract 1995;12:207-13.

9. Price DA, Miflin BM, Mudge PR, Jackson CL. The quality of medical teaching and learning in rural settings: the learner's perspective. Med Educ 1994;28:239-51.

10. Murray E, Todd C, Modell M. Can general internal medicine be taught in general practice? An evaluation of the University College London model. Med Educ 1997;36974.

11. Schwiebert LP, Davis A. Impact of a Required Third-Year Family Medicine Clerkship on Student Self-Assessment of Cognitive and Procedural Skills. Teaching and Learning in Medicine 1995;7:37-42.

12. Oswald NT. Teaching clinical methods to medical students. Med Educ 1993;27:351-4. 


\section{Students' perceptions of the relative advantages and disadvantages of general practice-based and hospital- based teaching: a qualitative study}

\section{Summary}

The aim of the study was to obtain the perceptions of first-year clinical medical students of the relative advantages and disadvantages of general practice-based and hospital-based clinical teaching. Qualitative methods were used. A purposive sample of first-year clinical medical students who had experienced both community-based and hospital-based teaching was invited to participate in individual semi-structured interviews or focus groups. Interviews and focus groups were audio-taped and transcribed to facilitate content analysis of the data. Twenty-four students participated in individual interviews and a further eighteen took part in focus groups. Respondents identified advantages and disadvantages specific to teaching in each setting. Chief advantages of hospital-based learning were perceived to include learning about specialties and the management of acute conditions, and gaining experience of procedures and investigations. Community-based learning was perceived as particularly appropriate for learning about psychosocial issues in medicine, for increasing students' awareness of patient autonomy and for improving communication skills. In addition, aspects of organisation and of teaching methods employed by community tutors were viewed as conducive to a positive educational experience. Students perceived some areas, such as clinical skills teaching, to be equally-well learned in either setting. The conclusions were that as general practice-based teaching forms a greater proportion of the undergraduate medical experience, medical educators must find ways of determining the specific advantages that general practice and hospital settings can contribute to undergraduate learning and using these resources effectively to develop comprehensive and integrated curricula. Innovations in teaching methods may also be necessary to provide an effective educational experience and promote active learning.

\section{Introduction}

Many British medical schools are increasing the community-based component of their undergraduate curricula', responding both to the changes in health-care provision following the recent reorganisation of the National Health Service and a world-wide consensus that medical education should have more relevance to the health needs of the community ${ }^{2}$. Traditional hospital-based curricula may not offer students the necessary range of educational experiences. Transferring more teaching into the community is seen as one solution.

A variety of community-, general practice- and ambulatory care- based courses have been introduced world-wide ${ }^{3-6}$. Early evaluations suggest that medical students can acquire clinical skills as well in the community as in hospital ${ }^{7: 8}$, that costs are equivalent and that students and faculty perceive community-based teaching to have specific educational advantages such as the opportunity to gain experience of common conditions ${ }^{5: 8}$, and a high level of supervision ${ }^{3}$. 
However, certain educational experiences are only available to students on the hospital ward ${ }^{9}$. One task facing medical educators is to achieve a balance between hospital and community sites.

Advocates of community-based teaching have suggested that it might have advantages in the following key areas which are considered ill-served by a traditional curriculum ${ }^{10}$ :

- psychosocial aspects of health

- awareness of and respect for patient autonomy

- communication skills

- continuity of care and management of chronic illness

- teamworking.

As yet there are few empirical data to support these claims ${ }^{3}$.

\section{The Educational Setting}

The medical undergraduate curriculum at UCLMS adheres to a traditional structure in which students spend two pre-clinical years studying basic medical sciences before embarking on a three-year clinical course. The first clinical year at UCLMS consists of four ten-week blocks: General Medicine; Specialist Medicine; Surgery; and Care of the Elderly/Rheumatology. All four blocks share common aims pertaining to the mastery of clinical method. The Medicine in the Community firm comprises half of the General Medicine block. The remainder of the year is hospital-based. There are approximately 200 students in the first clinical year and they rotate through all four blocks, so that at any time during the year there are approximately 50 students in each block. During the General Medicine block, half the students -approximately 25- are allocated to the Medicine in the Community firm, while the other half are taught in a hospital setting. The students change over after five weeks.

\section{The Medicine in the Community firm at UCLMS}

Students are taught in small groups and spend two or four days each week in general practice, attached to a GP tutor. GP tutors receive payment and have protected time for teaching. They are also offered regular training. The emphasis is on the teaching of basic clinical method and not general practice. Each week, all students attend a half-day seminar on clinical and diagnostic skills taught by the Department of Primary Care and Population Sciences as well as a Pathology lecture course (Box 1).

\section{Aims}

The purpose of this study was to determine students' views of the advantages and disadvantages of the community- and hospital-based teaching they had experienced in their first few months as clinical students. 


\begin{tabular}{|c|c|c|}
\hline MiC / Oncology & MiC / Public Health & MiC only \\
\hline $7-8$ students / firm & $11-12$ students / firm & 6 students / firm \\
\hline 2-4 students / group & 2 students / group & 6 students / group \\
\hline $\begin{array}{l}\text { each group attached to one } \\
\text { of } 6 \text { practices }\end{array}$ & $\begin{array}{l}\text { each group attached to one } \\
\text { of } 12 \text { practices }\end{array}$ & group attached to 1 practice \\
\hline $\begin{array}{l}\text { students in practice } 2 \text { days / } \\
\text { week }+2 \text { days on oncology } \\
\text { wards and outpatients }\end{array}$ & $\begin{array}{l}\text { students in practice } 2 \text { days } / \\
\text { week }+2 \text { days on public } \\
\text { health attachment }\end{array}$ & $\begin{array}{l}\text { students in practice } 4 \text { days } / \\
\text { week }\end{array}$ \\
\hline
\end{tabular}

\section{In all MiC firms, students:}

- clerk and present specially selected patients in their homes or in surgery

- have $1: 1$ or 1:2 teaching in booked surgery (once a week on average)

- have one 3 hour seminar for formal teaching of clinical method per week; students taught in groups of 6-8 with one GP faculty member and one simulated patient

- have one afternoon of pathology lectures per week

\section{Methods}

The evaluation took the form of a qualitative study using both semi-structured interviews with individual students and focus groups. The interviews aimed to obtain the students' perceptions of the advantages and disadvantages of a community-based firm when compared with their experiences of hospital-based firms. The use of focus groups in addition to individual interviews was intended to enhance data collection and to provide a validation of the analysis.

\section{Subjects and settings}

The respondents were first-year clinical students at University College London Medical School (UCLMS) who were approaching the end of their Medicine in the Community firm. All students had also completed a hospital-based firm prior to commencing the communitybased firm. The sample consisted of selected students from the population under study.

\section{Recruitment}

In order to ensure that all students had experience of both hospital- and community-based teaching, interviews did not commence until the second ten-week block. A purposive sample 
of students was selected to participate in the one-to-one interviews and/or the focus groups. We hypothesised that the following characteristics might influence students' perceptions of their learning experiences: age, gender, ethnicity, previous degree, previous occupational history. Accordingly, we used these characteristics to guide our selection in order to maximise the range of viewpoints and experiences.

The selected students were invited to participate in either a focus group or individual interview by letter at the beginning of the firm, non-responders being followed up by further letter, telephone or e-mail. Participants were assured of confidentiality and anonymity, and guaranteed that their views would have no impact on their grades for the firm. Interviews were conducted by two of the authors (MO and JM), using a previously-agreed format as a guide to ensure that both interviewers covered the same areas.

\section{The interview}

The interview was semi-structured and designed to encourage students to compare and contrast their learning experiences on the hospital wards and in the community (Box 2).

\section{Box 2 Issues addressed in the interview}

- perceived advantages and disadvantages of community-based teaching when compared with hospital teaching

- perceived advantages and disadvantages of hospital teaching when compared with community-based teaching

- areas considered to be more effectively learnt in the community

- areas considered to be more effectively learnt in hospital

The interview was also used as a template for facilitating the focus groups. These were run by one of the researchers while the second researcher observed and took notes. The interviews and focus groups were audio-taped and transcribed.

The interviews and the focus groups were piloted prior to commencing the main study. As a result, several significant modifications were made to the wording and content of the interview and for this reason the piloted interviews and focus group were excluded from the final analysis.

Both the interviewers came from a General Practice background, and one (JM) was involved in teaching some of the students from the population under study in the plenary sessions which form a part of the community firm. Interviews with any students whom he had taught were conducted by the other researcher $(\mathrm{MO})$.

In addition to the data collected from the interviews and focus groups, the following information was recorded for each respondent: age and gender; ethnic group; previous degree and work experience; and previous clinical experience. Sampling continued until the point of redundancy was reached and further data collection yielded no new information. 


\section{Data analysis}

The audio-taped interviews and focus groups were transcribed. The two researchers then developed a coding frame to facilitate a thematic analysis of the transcripts guided by grounded theory methodology ${ }^{11}$. The coding frame was repeatedly modified as further transcripts were analysed. Once the dominant themes had emerged, these were further analysed into sub-themes where this was appropriate to a deeper understanding of the data. Two authors (JM and MO) then analysed the data independently with no significant discrepancies in their results.

\section{Study sample}

Twenty-four students took part in individual interviews and another eighteen participated in focus groups. There were three focus groups, each consisting of six students. Five students failed to respond and six refused to participate. There were no significant differences in the demographic characteristics of those students who participated and those who refused to participate or failed to respond. The individual interviews lasted between thirty and sixty minutes, and the focus groups ran for one to one and a half hours.

\section{Results}

The dominant and subsidiary themes that emerged from the analysis are summarised in Box 3 . The students perceived advantages and disadvantages to both settings, and advantages perceived within one setting were often balanced by a corresponding disadvantage within the other (Box 4).

\section{Organisation of teaching and learning}

Structure: Respondents identified aspects of course organisation as important to their learning experiences. Within the community setting, they valued having explicit course objectives and teaching organised around set themes in order to fulfil these objectives. They contrasted this with hospital teaching which was often ad hoc, and where they sometimes felt unsure of what was expected of them.

\section{Box 3 Major themes which emerged from analysis of the interviews and focus groups \\ Organisation of teaching and learning \\ Teaching and learning relationships \\ Teaching content \\ - structure \\ - teaching methods \\ - student-teacher relationship \\ - learning/teaching environment \\ - "specialised" learning}

Relating to patients

Awareness of psychosocial issues 
Low student:tutor ratios, protected teaching time and allocated rooms for teaching were other features of community-based teaching which respondents cited as contributing to a satisfying learning experience. They felt that attention had been paid to their educational needs and that teaching was regarded as a valuable activity by their community tutors. This contrasted with hospital-based teaching, which often took place in large groups, which some participants felt was inhibiting, and where sessions were often cancelled without notice due to tutors' clinical commitments.

'here [in general practice] everything is very organised and there is teaching time for us to see patients, and we know who we are going to see, what we are going to do next.'

(Interview, Student 19)

Teaching style: Respondents noted features of teaching style which they felt impacted upon their learning, either positively or negatively. In the community they were encouraged to take an active approach to their learning, for example, by preparing and presenting seminars. Students felt that they learnt from the guidance given in preparing such seminars, and from the ample feedback on their presentations.

Learning on the ward could sometimes be a passive experience. Students often felt they received too little supervision and constructive feedback. Many spoke of their lack of confidence in their basic clinical skills prior to entering the community-based firm.

In contrast, they felt they received a high level of supervision and feedback during their community teaching, particularly in the areas of history-taking and physical examination. This was supplemented by revision and reinforcement. They judged this to be important in increasing their confidence and feelings of competence.

Furthermore, small group teaching was viewed as a strength of community teaching. The students generally felt less inhibited about participating in teaching, there were opportunities for all group members to take an active part in teaching sessions, and several respondents noted that their tutors seemed to be skilled in identifying the students' particular learning needs and then adapting their teaching accordingly.

'the GP actually watches you taking history, and examine a patient, and I think my examination skills have improved hugely because of that and that's something which I didn't get on the wards at all.' (Interview, Student 21)

'Because [in the community] it's one-to-one or one-to-two or whatever, they can pick up what you're bad at, what you're good at and you're taught specifically on what you need to be taught on.' (Focus Group 3, Student 39)

\section{Teaching and learning relationships}

Student/teacher relationship: Students highlighted the importance of the tutor having a positive, approachable attitude, of the tutor's acceptance of the learner status of the student and of the enthusiasm which tutors manifested for teaching. Interviewees associated these attributes with positive learning experiences both on the wards and in the community, but overall seemed to view them as more prevalent and more highly-developed among tutors in 
the community. Furthermore, respondents valued the personal approach of their community tutors who they felt made an effort to get to know them as people.

I feel that I know [our GP tutor] far more personally than anyone of a senior level in hospital environment...has made an effort to get to know us...I feel able to open up and approach him with any problem however minor and with no fear of humiliation.' (Interview, Student 1)

'the first [hospital] firm I did was brilliant because you got to know the consultant and everybody, the registrars, house officers, they were all involved in teaching us and we really felt part of the team, you know, valued.' (Interview, Student 52)

Learning/teaching environment: Students commented on the effect of the immediate environment upon their learning. Many felt that the atmosphere on the wards was competitive and that this made learning difficult. In contrast, general practice was viewed as more relaxed, and with the need to impress or to conceal areas of weakness removed, it became easier to learn.

However, many students found the ward atmosphere could be stimulating and enjoyable. Several had positive experiences where they were made to feel part of the team, and they learned important lessons about their future roles as junior hospital doctors and the interactions of health professionals within the ward environment.

\section{Teaching Content}

This theme included aspects of the undergraduate curriculum perceived to be better learned in certain environments.

"Specialised" learning: Students recognised the importance of the opportunities provided by each setting: the hospital for seeing acute illness, early management and diagnostic procedures; the community for communication skills and learning about chronic illness and minor illness. They did not appear to regard one setting as more important than the other but appreciated that both settings offered valuable learning experiences.

'in the hospital you have people with disease concentrated in one place, so I mean as far as seeing...physical signs, you know seeing ill people and seeing how they are investigated and managed, you know lec aing in the hospital's great. But for learning patient communication it's possibly not, I mean, you see examples of bad communication between doctors and patients....' (Interview, Student 21)

The issue of continuity of care was raised, but in the context of an acute illness rather than in chronic conditions. Students recognised the importance of the opportunity within hospitals to follow a patient through an illness and noted the absence of such experiences during their community attachment. 


\section{Relating to patients}

Students noted differences in how they approached patients in the two settings. In the hospital setting, they were aware that the patients were often ill and uncomfortable, and had already been examined by several other doctors and students. They often felt awkward in approaching patients as they felt they might be causing the patients unnecessary discomfort by examining them. Balancing this was the students' need to practise examination skills and to gain experience of the physical signs of a wide range of illnesses.

In the community patients were recruited by the tutors. They were usually not acutely ill; most had chronic health problems. As the patients were "volunteers", students perceived them as approachable, and were less likely to feel uncomfortable or guilty about putting them through a physical examination. However, some students found it difficult to take a history from patients who did not have an acute problem. Some also commented that they found it more difficult to perform a full physical examination on patients who were fully dressed than patients on the ward: asking the patient to undress could be awkward or embarrassing, and if the patient had health problems such as arthritis which made undressing difficult, the students were less likely to perform a full examination. Patients examined in the community were also less likely to have physical signs for the students to elicit.

'somebody wouldn't be in hospital unless there was something wrong and therefore it's clearly frequently something that you can see, a symptom or a sign that you can elicit, so that's great.' (Interview, Student 52)

Several respondents commented that the patients they saw in the community seemed to relate to students and doctors in a far more confident way than those in hospital. For example, they were far more likely to voice criticisms of the care they had received. The students felt that they responded to the patients much more as autonomous individuals in the community setting, seemingly in response to the patients' higher levels of confidence and security outside the hospital setting.

\section{Awareness of psychosocial issues}

Respondents were almost unanimous in their opinion that their community firm had heightened their awareness of psychosocial issues in relation to health and illness. They attributed this to three factors. Firstly, their tutors raised the issues during formal teaching sessions. Secondly, they observed their tutors dealing with these issues when the students sat in on consultations. Thirdly, and most importantly, students felt that having an hour or more with patients to take a history enabled them to ask about these issues in depth. This was particularly the case for the patients they visited at home. They were surrounded by visual prompts, and were able to see at first hand the ways that illness could impact upon the individual and the family. There was however one student who felt that his hospital attachments had given him a more profound understanding of this area. It is noteworthy that several students were doubtful that this awareness would persist once they immersed in hospital life again. 
'[In the community] you definitely get to see the patients more as proper people rather than just lying in a bed...you go and see their house, you see how they're living...showed us all the adaptations that she has in her home to allow her to function which was really eye-opening because it makes you see how bad it actually is.' (Interview, Student 7)

'[In the community] you have a better insight into what causes health problems...you get to know the person better which has a huge impact on a person's health generally and his response to treatment, whether he takes his treatment, things like that... a more realistic attitude...in a hospital you're sheltered from the outside world in your citadel with other doctors.' (Interview, Student 52) 
Box 4 Students' perceptions of the advantages and disadvantages of hospital-based and community-based learning

Advantages of hospital-based learning

- specialist teaching

Disadvantages of hospital-based learning

- lack of clear learning objectives

- availability of patients with clinical

- patients sometimes unwilling or too ill for students to clerk

- first-hand experience of acute presentation of illness

- learning the management of acute illness

- following patients from admission to discharge

- observing and learning practical procedures and investigations

- feeling included in the medical team

- gaining insight into the reality of life as a junior doctor

- friendliness of junior doctors

- being involved in the social life of the hospital

Advantages of community-based learning

- learning about common conditions

- seeing conditions at an early stage of presentation

- gaining insight into the psychosocial context of health and illness

- gaining an awareness of the patient as a person

- patients were approachable and generous with their time

- observing good communication skills

- clear learning objectives

- high level of supervision and feedback

- skilled, enthusiastic tutors who were friendly and approachable

- protected teaching time

Disadvantages of community-based learning

- travel to community sites could be expensive and time-consuming

- fewer physical signs to elicit

- fewer opportunities to practice procedures

- lack of associated social activities

- inadequate supervision and feedback on occasion

- hierarchical nature of hospital life sometimes inhibiting or uncomfortable

- use of outdated teaching methods by some tutors

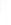

- teaching cancelled at short notice due to tutors' service commitments

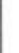




\section{Discussion}

There are some limitations to this study which may affect its transferability. The students' experiences of both community- and hospital-based teaching was relatively short and by no means homogeneous. Both interviewers were general practitioners which may have inhibited the interviewees from commenting negatively about general practice-based teaching. Finally, the UCLMS joint junior medical firm may differ from community-based courses and modules at other medical schools although it does have features in common with community-based initiatives elsewhere in the United Kingdom ${ }^{6: 12}$.

Despite these limitations, this study adds to the sparse empirical data addressing the theoretical advantages of community-based teaching. The findings are broadly in line with questionnaire studies of students' views on the efficacy and the enjoyability of learning clinical skills in the community ${ }^{5: 13}$. The majority of our subjects perceived that their community teaching had enabled them to grow in confidence and competence. Particularly striking was the remarkable consistency in the students' responses, despite the use of purposive sampling.

The students identified ways in which their community and hospital teaching complemented each other: they recognised that while areas such as basic clinical skills could be learned in either setting, there were some areas that seemed to be more appropriately learned in one rather than the other. Some of these are predictable: for example, they perceived an advantage of hospital-based teaching as the opportunity to learn practical skills and observe investigations and procedures; while the community offered them greater opportunity to observe and practice communication skills and to learn about psychosocial issues. But some of the assumptions about community-based teaching - for example that it provides an ideal setting for learning about chronic illness, continuity of care and multidisciplinary teamwork are not supported by our results. However, our respondents were at a very early stage of their clinical education; senior students might have rather different perceptions.

Students highlighted the consistently high quality of teaching in the community as one of the chief advantages of the community firm. The aspects of teaching that they felt contributed to this, such as the attitude of the tutors towards their teaching and their students, the teaching methods employed and the organisation of the course, are all factors identified in previous research as being associated with positive learning experiences ${ }^{3: 14}$. While the students also identified positive experiences during their hospital attachments, these were less consistent. This perhaps reflects the fact that while hospital doctors are expected to participate in undergraduate teaching regardless of enthusiasm or ability, the GP tutors volunteered to teach and had the additional benefits of protected teaching time and regular training sessions. It may be that hospital staff engaged in teaching undergraduates would benefit from at least some of these advantages as a way of improving the effectiveness of their teaching.

More empirical data is needed to enable curriculum planners to accurately identify the relative strengths and weaknesses of the different sites available for undergraduate medical teaching. Our data suggest that potential advantages of learning in general practice are not always fulfilled unless specifically addressed in the course objectives. 
1. Association for the Study of Medical Education. Curriculum Innovations: Descriptions of Undergraduate Medical Courses in the UK. Dundee: Association for the Study of Medical Education;1997.

2. World Federation for Medical Education [editorial]. Med Educ 1997;31:305-6.

3. Irby DM. Teaching and Learning in Ambulatory Care Settings: A Thematic Review of the Literature. Acad Med 1995;70:898-931.

4. Crebolder HFJM, Metsemakers JFM. General Practice, Medical Education and Community-Based Teaching: the Maastricht Experience. Annals of CommunityOriented Education 1994;7:121-9.

5. Foldevi M, Trell E. Learning the Basics of Medicine in General Practice in the Faculty of health Sciences, Linkoping, Sweden. Annals of Community-Oriented Education 1993;6:97-113.

6. Macfarlane F, McLennan E, Murray, E, Wallace P. CeMENT (Community Based Medical Education in North Thames) Project Report. London: CeMENT; 1998

7. Murray E, Jolly B, Modell M. Can students learn clinical method in general practice? A randomised crossover trial based on objective structured clinical examinations. $B M J$ 1997; 315:920-3.

8. Satran L, Harris IB, Allen S, Anderson DC, Poland GA, Miller WL. Hospital-based versus community-based clinical education: comparing performances and course evaluations by students in their second-year pediatrics rotation. Acad Med 1993;68:3802.

9. Grum CM, Richards PJ, Woolliscroft JO. Shifting medical student education to the outpatient setting: what are we losing? Acad Med 1995;70:447.

10. Whitehouse CR, Roland M, Campion P. Teaching Medicine in the Community: A guide for undergraduate education. Oxford: Oxford University Press; 1997.

11. Glaser B, Strauss A. The discovery of grounded theory. New York: Aldine; 1967.

12. Parle J, Greenfield S, Thomas C, Ross N, Lester H, Skelton J et al. Community-based clinical education at the University of Birmingham Medical School. Acad Med 1999;74:248-53.

13. Murray E, Jolly B, Modell M. A comparison of the educational opportunities on junior medical attachments in general practice and in a teaching hospital: a questionnaire survey. Med Educ 1999;33:170-6.

14. Metcalfe DH, Matharu M. Students' perception of good and bad teaching: report of a critical incident study. Med Educ 1995;29:193-7. 


\section{What do students actually do on an internal medicine clerkship: a log diary study}

\section{Summary}

There are limited data on the amount of time students spend on teaching and learning while on internal medicine clerkships, and what there are suggest a wide international variation. Community based teaching of internal medicine is now widespread; but its strengths and weaknesses compared to traditional hospital based teaching is still unclear. The aim of the study was to determine the proportion of time students spend on different activities on an internal medicine clerkship, and to determine whether this differs in general practice and in hospital. In addition we aimed to determine students views on the educational value and enjoyment of various activities. Data was collected by prospectively completed log diaries recording student activities. Each student was asked to complete the diary for two separate weeks of their internal medicine clerkship: one week of general practice based and one week of hospital based teaching. The response rate was $68 \%(88 / 130)$. Students spent approximately 5.5 hours per day on teaching and learning activities in both environments, with more time ( 50 minutes vs 30 minutes, $\mathrm{p}=.007$ ) on unsupervised interaction with patients in hospital than in general practice, and more time $(53$ minutes vs 21 minutes, $\mathrm{p}<.001$ ) undergoing assessment in general practice than in hospital. Standard deviations were wide, demonstrating the heterogeneous nature of the data. Students perceived supervised interaction with patients and teaching by doctor as the most educational activities in both environments, but found it even more educationally valuable and enjoyable in general practice than in hospital (mean score for educational value: 4.27 in general practice, 3.88 in hospital, $\mathrm{p}=.048$; mean score for enjoyment 4.13 in general practice, 3.66 in hospital, $p=.03$ ). The conclusions were that students greatly value interactions with patients, perceiving these as both educational and enjoyable. Curriculum planners must continue to place patient based learning at the centre of undergraduate medical education. The heterogeneity of the data suggests that individual students have very different experiences, despite apparently similar timetables.

\section{Introduction}

A consistent feature of the current developments in undergraduate medical education is the increase in teaching taking place in general practice. This shift of student learning from the traditional teaching hospital environment to general practice is being driven both by educational factors, and by changes in patterns of health care delivery.

Given the importance of learning in an authentic environment ${ }^{1: 2}$, i.e. an environment similar to the one where the skills and knowledge learned will be eventually applied, there is a strong theoretical argument for ensuring that clinical skills teaching is done in a clinical environment. Traditionally, the clinical environment chosen has been a teaching hospital, but for the reasons detailed below, students are increasingly learning their clinical skills in general practice. 
Reform of the National Health Service in the UK has led to a massive shift of care from the secondary to the primary care sector ${ }^{3-5}$. This has resulted not only in fewer patients available for students to learn from, but also those that are available, tend to be at the severe end of the illness spectrum, and hence possibly less able to assist students with learning basic clinical skills. Students' clinical experience in a traditional hospital setting has been shown to be very variable, with a significant number not encountering important clinical problems during their training ${ }^{6}$. This problem may be exacerbated if there is a reduction in overall clinical contact with patients as has been suggested by McManus ${ }^{7}$. Junior students in particular, need a more structured experience and considerable supervision.

Overall, clinical skills teaching in general practice has been shown to be as effective as teaching in hospital ${ }^{8}$. Some skills (writing up clerkings, keeping progress notes, disease management and management of acute conditions) were perceived by students as better acquired in hospital while history taking, understanding of psycho-social issues and communication skills were better acquired in general practice ${ }^{9: 10}$. These studies have all treated community based clerkships as a "black box", concentrating on outcomes or perceived outcomes. Our understanding of the process, or what goes on inside the "black box" is extremely limited. Parle has provided some preliminary data on the type of clinical problems students encounter during clinical skills teaching in general practice ${ }^{11}$ but we have little idea what students are actually doing and how they spend their time.

Log diaries have been used in educational research to determine a range of outcomes. They have been used to document learner's experience of clinical encounters at both undergraduate ${ }^{12 ; 13}$ and postgraduate ${ }^{14}$ level. This information has been used as a method of quality assurance (are students having appropriate clinical encounters to enable them to achieve the learning objectives of the curriculum? ${ }^{15: 16}$ ) and to compare learning opportunities at different sites ${ }^{17: 18}$. Less commonly, log diaries have been used to compare the amount of time students spend on various activities at different $\operatorname{sites}^{19}$. It has been suggested the data from student completed log diaries could be used to inform resource allocation to clinical teaching sites ${ }^{20}$.

The medical school at University College London (UCL) has a 10 week internal medicine clerkship which is divided into five weeks in hospital and five weeks in general practice. This provides a unique opportunity to undertake studies comparing learning in the two environments. We therefore decided to determine the time spent by students on a general internal medicine clerkship on various learning activities, student perceptions of the value of these activities, and whether either the amount of time or perceptions of value varied between hospital based and community based clerkships. We expected that these data would help "unpack" the black box of general practice based teaching, providing more information about the process of the clerkship.

\section{Aim:}

To determine the actual activities of first year clinical students on an internal medicine clerkship taught half in hospital and half in general practice, and to compare the two settings in terms of use of time and student perceptions of educational value. 


\section{Methods:}

\section{Educational experience}

At the time the study was undertaken University College London Medical School had a traditional curriculum. After two years of basic medical sciences, with little or no clinical content, students progress to a three year clinical course.

The clinical course starts with a three week introduction to clinical method for all 240 students, after which students are divided into four groups and rotate through four ten week blocks (General internal medicine; Specialist medicine; General Surgery; and Care of the Older Person / Rheumatology / Orthopaedics). All students have a common assessment (OSCE and MCQ) at the end of the first year. The block under study is the general internal medicine block, of which five weeks is taught in a teaching hospital and five weeks in general practice, known as Medicine in the Community (MiC). Both parts share common aims pertaining to mastery of clinical method. The teaching attachments are described in detail elsewhere ${ }^{8}$.

In the second clinical year students rotate through the major specialties, including general practice and sit the written final examinations. The third clinical year concentrates on the transition to professional practice with electives, special study modules, senior medicine and surgery, and shadow house officer attachments. Clinical finals are at the end of this final year.

\section{Subjects and setting}

During the study year (1997 - 98) 240 students rotated through the 10 week general internal medicine block. Once on the 10 week internal medicine block, students were randomly allocated to start in either general practice or hospital, and changed over after five weeks. Students on the first block of the year participated in the pilot; data generated from this was not entered into final study. 180 students rotated through the general internal medicine block during the study period.

\section{Recruitment}

One investigator (PA) met with groups of students attending teaching sessions during their hospital and general practice based clerkships. The investigator explained that the purpose of the study was to determine student activities during the two clerkships, participation was entirely voluntary, individuals would not be identified either during analysis or in reporting, and that the study had no relationship to any assessment procedures. Students were offered a $£ 5$ book voucher for returning a diary. 130 diaries were distributed as logistic reasons prevented the investigator from meeting up with all students.

\section{Sampling strategy}

We expected the first and last weeks of each five week attachment to have different characteristics to the middle three weeks as week 1 was expected to have some time dedicated to orientation and introduction of students, while the final week would have time set aside for assessment. We therefore sampled across the five weeks, with each rotation of students asked to complete diaries for a different week. As we wanted to compare activities in hospital and in general practice, students were asked to complete diaries for the equivalent week of both 
attachments (e.g. students who completed a diary for week 2 of their GP attachment were asked to complete one for week 2 of their hospital attachment).

\section{Instrument development}

A log diary was developed following a review of the literature and discussion with students and faculty. We were interested in the period from 7 am to $7 \mathrm{pm}$, Monday - Friday as we wanted to include all structured teaching time, travel to and from attachments, and obtain an estimate of free time during these hours. Anecdotal evidence suggested that students' main complaints were about waiting for teaching sessions that were delayed or cancelled without notice in hospital, and time spent travelling in general practice. We therefore specifically enquired into these activities. Students were also asked how much time they spent on self directed learning outside these hours.

Initially we were uncertain as to whether to use pre-coded diaries or free text. We hypothesised that completion rates would be better with pre-coded diaries, but that free text would yield more information. Piloting revealed that completion rates were higher for precoded diaries, and that free text did not yield more information. We therefore used pre-coded diaries for the main study. Codes were derived from the learning activities that students reported, and included travelling and waiting for teaching as these last two activities caused students much concern. Students were also asked to rate each activity for enjoyment and educational value, where 1 was of no value and 5 was of great value.

Piloting also revealed that students perceived that one week was a reasonable time frame to keep the diary, and that the A5 size $(148 \mathrm{~mm} \times 210 \mathrm{~mm})$ made the diary easy to carry around, easy to fill in, and that students had no trouble understanding any of the instructions or codes. (Appendix)

The diaries were validated in the pilot stage by comparing students stated activities with those time-tabled, and ascertaining whether students on the same attachments entered similar activities for each time period. Students were asked to put their name on a detachable portion of the front page.

\section{Analysis}

Student names on the diaries were used to differentiate responders from non-responders and were then removed and destroyed before the data was double entered onto an Excel spread sheet. Data were then transferred to SPSS 9 for windows for the analysis. The time spent on different activities was determined as the sum of the half-hour segments marked on the diaries. Histograms of the data were examined, and as the data appeared normally distributed, differences between locations were compared with unpaired t-tests, based on all data. Nonparametric (Mann-Whitney U) tests were also run, but as there were no differences in the significance of the findings, the parametric tests are presented for ease of comprehension. Variability of results were expressed as standard deviations. Ratings of enjoyment and educational value were analysed as continuous variables. The mean rating for each student was determined for each activity, and these data were then used to compare the overall mean ratings for each activity in the two locations with two-tailed unpaired t-tests. 


\section{Results}

\section{Response rate:}

Of the 130 diaries distributed $96(74 \%)$ were returned, and $88(68 \%)$ had been partially or wholly completed. Of these $60(46.2 \%)$ consisted of paired data, where the same student had completed a diary for the same week of both the hospital and community firms.

Responders and non-responders were compared for gender, age and academic performance. There was no difference in age or gender between responders and non-responders but responders performed significantly better in the end of year assessment procedures (OSCE and MCQ) than non-responders. In the MCQ, mean scores for responders were $43.8 \%$ ompared to $40.5 \%$ for non-responders $(p=.015)$. Mean scores for the OSCE were $88.5 \%$ for responders and $83.4 \%$ for non-responders $(\mathrm{p}<.001)$. In case this introduced systematic bias into the results, we analysed the paired data from students who had completed diaries both for their hospital and their community attachments separately. As there was no difference in the results from these paired data, and from the data generated by all responders, data from all responders is presented.

Data from the different weeks of the attachments were compared, and as there was no significant difference in time allocation between weeks in either environment, all paired data were pooled and analysed together.

\section{Time on each activity:}

The amount of time in minutes students spent on each activity in the two environments is shown in Table 1. Students spent about 5.5 hours on teaching and learning activities in both environments, with the only significant differences in use of time being that students in hospital spent more time on unsupervised interaction with patients than students in general practice, while the latter spent more time undergoing assessment. Student perceptions that they spent more time in hospital than in general practice waiting for teaching were confirmed, but the time spent on travel in both environments was the same. 
Table 1 Time (minutes) spent on various activities in hospital and in general practice per day.

\begin{tabular}{|c|c|c|c|c|c|}
\hline & $\begin{array}{l}\text { General } \\
\text { Practice } \\
\text { mean } \\
\text { (SD) }\end{array}$ & $\begin{array}{l}\text { Hospital } \\
\text { mean } \\
\text { (SD) }\end{array}$ & $\begin{array}{l}\text { mean } \\
\text { difference }\end{array}$ & $\begin{array}{l}95 \% \mathrm{CI} \text { for } \\
\text { mean } \\
\text { difference }\end{array}$ & $\mathrm{p}$ \\
\hline Teaching by doctor * & $\begin{array}{l}147 \\
(61)\end{array}$ & $\begin{array}{l}137 \\
(56)\end{array}$ & 10 & -15 to 35 & ns \\
\hline $\begin{array}{l}\text { Teaching by staff other than doctors } \\
\text { (e.g. nurses)* }\end{array}$ & $\begin{array}{l}43 \\
(33)\end{array}$ & $\begin{array}{l}31 \\
(21)\end{array}$ & 12 & -4 to 29 & ns \\
\hline Supervised interaction with patients* & $\begin{array}{l}52 \\
(38)\end{array}$ & $\begin{array}{l}46 \\
(46)\end{array}$ & 6 & -17 to 28 & ns \\
\hline $\begin{array}{l}\text { Unsupervised interaction with } \\
\text { patients* }\end{array}$ & $\begin{array}{l}30 \\
(14)\end{array}$ & $\begin{array}{l}50 \\
(39)\end{array}$ & -20 & -33 to -6 & .007 \\
\hline Self directed learning* & $\begin{array}{l}98 \\
(69)\end{array}$ & $\begin{array}{l}88 \\
(50)\end{array}$ & 10 & -17 to 36 & ns \\
\hline Assessment* & $\begin{array}{l}53 \\
(22)\end{array}$ & $\begin{array}{l}21 \\
(8)\end{array}$ & 32 & 21 to 44 & .000 \\
\hline Waiting for teaching & $\begin{array}{l}12 \\
(6)\end{array}$ & $\begin{array}{l}18 \\
(10)\end{array}$ & -6 & -11 to -2 & .008 \\
\hline Travel & $\begin{array}{l}81 \\
(38)\end{array}$ & $\begin{array}{l}81 \\
(35)\end{array}$ & 0 & -15 to 16 & ns \\
\hline Non-clinical / recreation & $\begin{array}{l}263 \\
(84)\end{array}$ & $\begin{array}{l}217 \\
(83)\end{array}$ & 46 & 10 to 81 & .012 \\
\hline Subtotal for teaching and learning & 330 & 324 & 6 & -21 to 32 & NS \\
\hline
\end{tabular}

*activities included in the subtotal for teaching and learning

as not all students undertook each activity, the overall mean is not the sum of the contributing means.

Unpaired data, independent t test

Perceived educational value and enjoyment of each activity:

Students had clear views about the value of the different activities (Table 2). Supervised interaction with patients was perceived as by far the most educationally valuable activity, followed by teaching by doctor. Supervised interaction with patients was seen as even more educationally valuable in general practice than in hospital. Students in hospital found unsupervised interaction with patients the least educationally valuable activity, whereas in general practice, teaching by staff other than a doctor was perceived as the least valuable activity.

Students were clearly able to distinguish between the educational value and the enjoyment of different activities. Unsupervised interaction with patients was the most enjoyable activity in hospital, despite its low ranking for educational value (Table 2). Overall, interacting with patients, either supervised or unsupervised was seen as most enjoyable, with supervised interaction being significantly more enjoyable in general practice than in hospital. Assessment and self-directed learning, although perceived to be educationally valuable, were not seen as enjoyable. 
Table 2 Students' perceptions of the educational value and enjoyment of various activities.

Educational Value

\begin{tabular}{llllll}
\hline & $\begin{array}{l}\text { General } \\
\text { Practice } \\
\text { mean }\end{array}$ & $\begin{array}{l}\text { Hospital } \\
\text { mean }\end{array}$ & $\begin{array}{l}\text { mean } \\
\text { difference }\end{array}$ & $\begin{array}{l}95 \% \text { CI for } \\
\text { mean } \\
\text { difference }\end{array}$ & $\mathrm{p}$ \\
\hline Supervised interaction with patients & 4.27 & 3.88 & .39 & 0 to .78 & .048 \\
Teaching by doctor & 3.87 & 3.87 & 0.0 & -.25 to .26 & $\mathrm{~ns}$ \\
undergoing assessment & 3.81 & 3.71 & .10 & -.59 to .77 & $\mathrm{~ns}$ \\
self-directed learning & 3.70 & 3.71 & .01 & -.33 to .30 & $\mathrm{~ns}$ \\
unsupervised interaction with patients & 3.53 & 3.56 & -.03 & -.42 to .36 & $\mathrm{~ns}$ \\
teaching by staff other than a doctor & 3.31 & 3.71 & -.39 & -.91 to .13 & $\mathrm{~ns}$ \\
& & & & & \\
\hline
\end{tabular}

\section{Enjoyment}

\begin{tabular}{llllll}
\hline & $\begin{array}{l}\text { General } \\
\text { Practice } \\
\text { mean }\end{array}$ & $\begin{array}{l}\text { Hospital } \\
\text { mean }\end{array}$ & $\begin{array}{l}\text { mean } \\
\text { difference }\end{array}$ & $\begin{array}{l}\text { 95\% CI for } \\
\text { mean } \\
\text { difference }\end{array}$ & p \\
\hline Supervised interaction with patients & 4.13 & 3.66 & .47 & .05 to .9 & .03 \\
unsupervised interaction with patients & 3.75 & 3.85 & .10 & -.51 to .31 & $\mathrm{~ns}$ \\
Teaching by doctor & 3.62 & 3.56 & .06 & -.22 to .33 & $\mathrm{~ns}$ \\
teaching by staff other than a doctor & 3.21 & 3.57 & -.35 & -.87 to .16 & $\mathrm{~ns}$ \\
self-directed learning & 3.13 & 3.04 & .09 & -.23 to .41 & $\mathrm{~ns}$ \\
undergoing assessment & 2.86 & 2.72 & .14 & -.47 to .75 & $\mathrm{~ns}$ \\
& & & & & \\
\hline
\end{tabular}

Unpaired data, independent t-tests. 


\section{Discussion}

The main findings of the study were that students spent approximately five and a half hours on educational activities each day. There was very little difference in time spent on the various activities in the two environments, with the exception of students spending less time on unsupervised interaction with patients, waiting for teaching and more on assessment in general practice compared to in hospital. Supervised interaction with patients was seen as the most educational activity, and students perceived this as significantly more educational and more enjoyable in general practice than in hospital. Overall, interaction with patients was seen as the most educational and most enjoyable part of the day - a finding which will come as no surprise to most clinical teachers, and one which should sound a note of caution for anyone considering reducing the clinical content of an undergraduate curriculum. The data were very heterogeneous with students reporting widely differing amounts of time spent on each activity. This was a contributing factor to the lack of statistically significant differences, as demonstrated by the very wide standard deviations. The suggestion is that students are creating very different experiences for themselves, despite apparently similar timetables.

These relatively junior (first year clinical) students received considerable teaching and supervision: 3.5 to 4 hours / day. This compares with a US study where students spent about 13 hours a day on teaching and learning activities of which they received teaching and supervision for about 6.5 hours ${ }^{21}$. A log diary study from Maastricht found $5^{\text {th }}$ year students spent about 35 hours a week on teaching and learning activities, but it is not clear how much of that time involved direct supervision ${ }^{22}$. The only comparable data on hospital based teaching from the UK suggested students received approximately 5 - 10 hours teaching per week $^{20}$. The UK data were gathered from students from all three clinical years; students in the first clinical year $\left(3^{\text {rd }}\right.$ year) received 3.47 hours / week while on their medical clerkships. Those students were only on the wards in the afternoons, unlike the UCL students who were on the wards full time. Log diary data from fourth year students on a traditional apprenticeship-style general practice attachment, also done at UCL, found that students received a mean of 4 hours per week of teaching from a GP tutor, and a further 2.3 hours per week from other members of the primary health care team ${ }^{23}$.

Travel is clearly a burden for students, with a mean of 80 minutes / day spent travelling. Surprisingly, there was no difference in time spent travelling during general practice attachments and hospital attachments, although the travel involved in community based teaching has been a consistent complaint of students at $\mathrm{UCL}^{24}$. The reality is that $\mathrm{UCL}$ is a multi-site medical school in a large metropolitan area, with very limited amounts of student accommodation. Most students find their own accommodation, and inevitably, this is likely to be away from the expensive centre of the city where the medical school is sited.

The opportunity to obtain comparative data from hospital and general practice attachments with similar educational aims and objectives is rare. There was a reasonable response rate $(68 \%)$, and although responders appeared to be more academically able than non-responders, comparison of the data from students who had completed two diaries, one for hospital and one for general practice, with the rest of the responders showed no difference. Thus although more able students may well spend more time overall on educational activities than colleagues who performed less well in end of year exams, this response bias does not appear to have biased the data comparing the hospital and general practice attachments. The study was designed to collect paired data to control for individual student factors, such as enthusiasm. However, we 
decided not to discard the unpaired data, but to present all the data obtained, as analysis of the paired data alone did not yield any different findings. The accuracy of student recording of activities was confirmed in the pilot phase of the study, when student records were compared with firm time-tables and with other students on the same firms. As students received their $£ 5$ book token for returning a log diary whether it had been completed or not, there was no incentive to enter fictitious data. Although the specific time allocation to various activities will vary according to different course timetables, the value that students place on the activities is likely to be generalisable to other schools.

Part of the rationale for the study was to try and unpack the "black box" of community based teaching. It appears as if the emphasis in general practice on supervised interaction with patients makes a substantial contribution to the success of the clerkship, in terms of student enjoyment and achievement of the learning objectives. Students in the hospital environment spend more time with patients, but as so much of this time is unsupervised, it is not perceived as meeting students' educational demands. Overall, the very strong value students place on interactions with patients provides a clear message to curriculum planners. Patient based learning must remain at the centre of undergraduate medical education. 


\section{References}

1. Brown J, Collins A, Duguid P. Situated cognition and the culture of learning. Educational Researcher 1989;18:32-42.

2. Monti EJ, Wren K, Haas R, Lupien AE. The use of an anesthesia simulator in graduate and undergraduate education. CRNA. 1998;9:59-66.

3. National Health Service Executive. Developing a primary care led NHS. London: HMSO; 1996.

4. Leese B, Bosanquet $\mathrm{N}$. Changes in general practice organization: survey of general practitioners' views on the 1990 contract and fundholding. Br J Gen Pract 1996;46:959.

5. Scott A, Wordsworth $\mathrm{S}$. The effects of shifts in the balance of care on general practice workload. Fam Pract 1999;16:12-7.

6. Jolly B, Macdonald MM. Practical experience in the pre-registration year in relation to undergraduate preparation. Proc Annu Conf Res Med Educ 1986;25:171-6.

7. McManus IC, Richards P, Winda BC, Sproston KA, Vincent CA. The change in clinical experience of British medical students. Lancet 1992;341:941-3.

8. Murray E, Jolly B, Modell M. Can students learn clinical method in general practice? A randomised crossover trial based on objective structured clinical examinations. BMJ. 1997; 315:920-3.

9. Murray E, Jolly B, Modell M. A comparison of the educational opportunities on junior medical attachments in general practice and in a teaching hospital: a questionnaire survey. Med Educ 1999;33:170-6.

10. O'Sullivan M, Martin J, Murray E. Students' perceptions of the relative advantages and disadvantages of community-based and hospital-based teaching: a qualitative study. Med Educ 2000;34:648-55.

11. Parle JV, Greenfield SM, Skelton J, Lester H, Hobbs FD. Acquisition of basic clinical skills in the general practice setting. Med Educ 1997;31:99-104.

12. McLeod PJ, Snell L. Casemix in an internal medicine clerkship: educational value of the clinical problems seen. J Gen Intern.Med 1991;6:455-9.

13. Alderson TS, Oswald NT. Clinical experience of medical students in primary care: use of an electronic log in monitoring experience and in guiding education in the Cambridge Community Based Clinical Course. Med Educ 1999;33:429-33.

14. Kay L, Pless T, Brearley S. Survey of surgical training in Europe. Med Educ 1996;30 :201-7.

15. McGraw R, Lord JA. Clinical activities during a clerkship rotation in emergency medicine. J Emerg Med 1997;15:557-62. 
16. Snell LM, Battles JB, Bedford JA, Washington ET. Verifying the curriculum of a family medicine clerkship. Med Educ 1998;32:370-5.

17. Dent JA, Davis MH. Role of ambulatory care for student-patient interaction: the EPITOME model. Med Educ 1995;29:58-60.

18. Davis MH, Dent JA. Comparison of student learning in the out-patient clinic and ward round. Med Educ 1994;28:208-12.

19. Calhoun JG, Davis WK, Erlandson EE, Maxim BR. A multisite comparison of student activities in the surgery clerkship. Surgery 1982;91:622-7.

20. Sheldon TA, Clarke M, Woods JR. The student diary survey: a method of monitoring hospital-based medical education. Med Educ 1991;25:213-23.

21. Calhoun J, Davies WK, Erlandson EE, Maxim BR. A multisite comparison of student activities in the surgery clerkship. Surgery 1982;91(6):622-7.

22. van de Weg N, Visser K, Seuren M, Scherpbier A, Wolffenbuttel B, Wolfhagen H. Tijdsbesteding van co-assistenten nader bekeken. Bulletin Medisch Onderwijs 1993;12:173-9.

23. Schamroth AJ, Haines AP, Gallivan S. Medical student experience of London general practice teaching attachments. Med Educ 1990;24:354-8.

24. Murray E, Todd C, Modell M. Can general internal medicine be taught in general practice? An evaluation of the University College London model. Med Educ 1997;36974. 


\section{Appendix Sample page of log diary.}

\section{MONDAY AM}

Please apply the following coding for the activity section:

1. = Non clinical / recreation

2. = Waiting for clinical activity / teaching

3. = Travel to or from surgery / hospital / patient's home

4. = Self directed learning (e.g.: library / computer assisted learning / discussion with fellow students

5. = Teaching by doctor (please specify grade of doctor)

6. $=$ Teaching by other staff (please specify: e.g. nurse etc)

7. = Interaction with patient supervised by clinical teacher

8. = Interaction with patient not supervised by clinical teacher

\begin{tabular}{|l|l|l|l|}
\hline Time & $\begin{array}{l}\text { Activity } \\
\text { Please enter number } \\
\text { from scale }\end{array}$ & $\begin{array}{l}\text { Educational Value } \\
\text { Please grade from } \\
1 \text { to 5 where: } \\
1=\text { no value, to: } \\
5=\text { great value }\end{array}$ & $\begin{array}{l}\text { Enjoyable? } \\
\text { Please grade from } \\
1 \text { to 5 where: } \\
1=\text { not enjoyed, to } \\
5=\text { greatly enjoyed }\end{array}$ \\
\hline $7.00-7.30$ & & & \\
\hline $7.30-8.00$ & & & \\
\hline $8.00-8.30$ & & & \\
\hline $8.30-9.00$ & & & \\
\hline $9.00-9.30$ & & & \\
\hline $9.30-10.00$ & & & \\
\hline $10.00-10.30$ & & & \\
\hline $10.30-11.00$ & & & \\
\hline $11.00-11.30$ & & & \\
\hline $11.30-12.00$ & & & \\
\hline $12.00-12.30$ & & & \\
\hline $12.30-13.00$ & & & \\
\hline
\end{tabular}

The afternoon (13.00 to 19.00) was displayed on the facing page; each page had the codes displayed. 


\section{Costs of teaching internal medicine in general practice}

\section{Summary}

The General Medical Council has issued a call for an increase in community-based medical education, and many medical schools are enhancing the community component of their curricula. This paper uses the experience of a community-based junior medical firm to explore the potential costs, and highlight some of the unresolved problems, which a major transfer of education to the community might engender. Community-based medical education is not a cheap option. The cost of this programme for the academic year 1992-93 was £266 494 , or $£ 60$ per student session. This compares with the Service Increment for Teaching and Research (SIFTR) provision of $£ 41140$ per student per annum, or (excluding the $25 \%$ of SIFTR which is supposed to cover research costs), £64 per student session. There are a number of possible ways of funding community-based education, including a diversion of SIFTR toward departments of primary health care. As this would have serious implications for the financial viability of some medical schools, an urgent discussion about the future funding of medical education is required.

\section{Introduction}

There is international agreement that the traditional model of undergraduate medical education, which relies almost exclusively on teaching hospitals, has outlived its usefulness. The Edinburgh Declaration' called for a substantial transfer of undergraduate medical education from teaching hospitals to the community. The World Summit, 5 years later, recommended the use of wider settings to enlarge and enrich the hospital experience ${ }^{2}$. The true costs of undergraduate medical education are often unknown. However, in many countries, including Britain, the bulk of the funds dedicated to undergraduate medical education are given to teaching hospitals. There is no system for directing a proportion to the community, which thus lacks the necessary resources to maintain a substantial role in undergraduate teaching. This paper uses the University College London Medical School (UCLMS) experience of one community-based junior medical firm as an example to explore the potential costs, and highlight some of the unresolved problems which a major transfer of education to the community might engender. We believe that our experience will be relevant for other schools attempting a similar development of community-based medical education.

\section{What is community-based education?}

Community-based medical education has been defined as consisting of 'learning activities that use the community extensively as a learning environment ${ }^{3}$.

There is considerable international experience in developing community-based medical education. The Network of Community-Orientated Educational Institutions for Health Sciences includes medical schools from the five continents. Some have introduced a large community-based component into the course ${ }^{3: 4}$; others have converted their entire course into 
a problem-based, community-orientated medical course ${ }^{5}$. The more successful innovative courses tend to have been started with a clean slate - either a new medical school (e.g. Newcastle, Australia) ${ }^{6}$ or a parallel track which subsequently leads to a combined curriculum (e.g. Harvard University, USA) ${ }^{7}$.

In Britain, general practice plays a central role in the provision of health care to the population. Moreover, Departments of Primary Health Care/General Practice have a strong tradition of educational development ${ }^{8}$, often leading the way in teaching communication skills $^{9}$, and staff training ${ }^{8}$. Despite this, there has been little attempt to explore the possibilities of developing community-based medical education. Most medical schools have concentrated on a 3-6 week attachment to general practice ${ }^{10}$; this attachment usually aims to teach students about the discipline of general practice, rather than utilizing the resources of the community to teach students basic clinical skills. In contrast, the initiative described here, along with a similar initiative at Kings College London Medical School ${ }^{11}$, and a pilot project at Cambridge Medical School where students will spend 15 months of a 27 -month clinical course in a general practice ${ }^{12}$, aim to teach skills and knowledge that have traditionally been the province of hospital-based education.

In common with many developed countries, Britain is exploring ways of containing the costs of providing health care for its population. Simultaneously, developments in medical technology resulting in an ever shorter average length of stay ${ }^{13}$ and more people being treated as out-patients or as day $\operatorname{cases}^{14}$, have resulted in fewer hospital in-patients available for students to clerk and learn from in the traditional way. These pressures, together with the growing realization that traditional medical education fails to provide students with the skills and attitudes that will equip them for medicine in the $21^{\text {st }}$ century ${ }^{15: 16}$, have encouraged British medical schools to explore new methods and locations for teaching medical students. Community-based teaching is one option under consideration.

\section{The UCLMS initiative}

Although each medical school will inevitably wish to construct its own community-based programme, the UCLMS experience can be used as an example of a successful development of a community-based programme from scratch. Nearly all the staff employed on this programme have been recruited for this purpose, and those few that were already part of the department tend to have had their sessions increased to reflect their extra commitments. This has allowed a reasonably accurate costing of the programme undertaken. This implies that other British medical school will incur broadly similar costs if similar programmes are implemented. Although the manpower costs will be different for medical schools in other countries, this analysis provides the framework for each school to estimate the costs of starting a similar programme.

UCLMS has a traditional undergraduate medical curriculum which starts with two years basic science with little or no clinical content. About half the students take an intercalated B.Sc before progressing to a three year clinical course. The first clinical year concentrates on teaching basic clinical skills on junior medical and surgical firms; the second consists of rotations through the major specialties (including general practice) and the third is preparation for practice, with electives and district general hospital attachments. Since September 1991 a community-based general medical firm has replaced a hospital-based junior medical firm for first-year clinical students. It has the same objectives of teaching students the basic clinical skills of history-taking, physical examination and communication skills. The success of the 
initial pilot has allowed for rapid expansion of this initiative; since September 1993, 154 of the total annual intake of 210 students have some community-based experience in their first clinical year. Continued expansion is planned for the next academic year to cater for all firstyear clinical students.

\section{Structure of the firm}

UCLMS runs two models for community-based general medical firms. The one that we favour, and have chosen to develop, is a full 6-week firm, as detailed below. The alternative model has a similar structure for the time in the community, but students are only attached to a general practitioner (GP) lecturer for 2 weeks out of a 6-week firm.

Students are allocated in pairs to a teaching general practice, with a GP who holds a part-time lecturer's contract with UCLMS. Students spend 2 days a week in the practice, seeing patients at home and in the surgery. They are asked to take a full medical history and, wherever possible, perform a full physical examination of the patient. The GP tutor will supervise part of the examination, and ask students to present the history. On average, students see and discuss approximately six 'long cases' per week. Students also sit in on one surgery with the tutor to learn to take focused, problem-orientated histories, and to perform system examinations. Early in the academic year, students need substantial help and supervision.

Seminars organized by the Department of Primary Health Care on communication and physical examination skills account for one half-day a week. The rest of the week is divided between traditional hospital-based teaching, and the pathology lecture course which runs throughout the first clinical year.

\section{Recurrent costs}

The 1990 GP contract ${ }^{17}$ firmly established the principle that for GPs, time is money, and that if extra work is undertaken, it should be properly remunerated. For the first time, GPs received a sessional payment from the Family Health Service Authority (FHSA) for teaching students. There are significant opportunity costs of teaching for GPs, in that time spent teaching may prevent their undertaking potentially revenue-earning work. For these reasons, the historic pattern of GPs undertaking unpaid teaching, because of the personal satisfaction engendered, is no longer viable. Moreover, if initiatives in community-based education are to be both generalizable and sustainable, they cannot be based on a handful of enthusiasts.

It was estimated that payment of the equivalent of two lecturer sessions per week ( $£ 5000$ per annum) would be appropriate starting payment for GPs undertaking to teach on this first-year firm. Tutors move up the incremental scale annually, reaching the top of the scale ( $£ 6000$ per annum for two sessions) in 5 years. This estimate was arrived at by considering both the amount of time GPs would need to give to this programme, and the value of this time. The tutors spend, on average, 4-6 hours a week teaching students outside surgery hours (for 21 weeks a year). In addition, time is spent compiling and maintaining a list of suitable 'teaching' patients, arranging for students to visit them, attending meetings and leading departmental seminars. The current annual payment per session for GP Hospital Practitioners is $£ 3286$ ( $£ 63.20$ per session), and the BMA guidelines for payment of a locum tenens are $£ 25-£ 28$ per hour. 
In addition to the lecturer's salary, GPs receive $£ 12.00$ per student session from the FHSA for taking students. This contribution to the total cost is presented in Table 2.

Additional lecturer time has been needed for student assessment, course development and evaluation, department-based teaching and organization of the staff development sessions. A senior member of the department (MM) takes overall responsibility for the firm, including recruitment of new tutors.

Staffing costs are presented in Table 2. For ease of comparison the cost per student session has also been calculated. A student session is defined as a half-day teaching of one student. If eight students attend one 3-hour seminar, that is eight student sessions. As each student has 4 weeks' holiday per year, there are 48 weeks of tuition, or 480 student sessions per student per year. In the 6-week firm, each student has 24 sessions in general practice, and a further six in the Department of Primary Care. The 2-week model provides each student with 10 sessions in general practice (Box).

These costs do not include incidental expenditure on stationery, photocopying, telephone and payment of simulated patients needed for student assessment. Neither do they include the costs to the students of the increased travelling entailed.

\section{Box Numbers of student sessions}

112 students spend 6 weeks on the community-based junior medical firm. Four sessions per week are in practice (i.e. 2688 sessions are eligible for the FHSA payment), and a further one session per week is in the Department of Primary Care. (Subtotal 3360 sessions)

In addition, 42 students spend five sessions per week for 2 weeks in the community. As all these sessions are in practices, all 420 receive the FHSA payment. (Subtotal 420 sessions.)

Thus the total number of student sessions for the combined community-based firms is 3780 . 
Lecturer sessions

course development, student assessment, evaluation (4/11ths) skills, plenary sessions (3/11ths)

practice based teaching (38/11ths)

Educational input (1 session/week from a medical educationalist)

Subtotal

(3108 sessions, see Table 3 )

Total

Total number of student sessions* per annum (see Box)

Salaries correct at 1 April 1994 (to nearest $£ 10$ ) including London weighting (LW) and oncosts for superannuation and National Insurance. Costs calculated using the incremental point of $£ 28,025$ for lecturer's salary. (GPs appointed at $£ 25,675$, annual incremental rise to maximum of $£ 33,720$ after 5 years. $\mathrm{LW}=£ 1,448$ per annum, on-costs at $26 \%$, except for secretarial staff where $\mathrm{LW}=£ 2,134$ per annum, on-costs at $21 \%$.

*See text for definition of student session (i.e. including FHSA payment).

\section{Capital costs}

Ideally, any attempt to examine the costs of community-based education would include the capital costs. This paper does not attempt to do this, partly because the capital costs have been negligible to date, and partly because the future capital costs are difficult to ascertain. Ideally, practices need a separate consulting room for students to see and examine patients without disrupting the service work, and a library in which students can read and reflect between seeing patients. Establishing these capital costs would require a survey, not only of the practices currently involved in first-year teaching, but also of the practices which may become involved in the future. We see this as a separate, but important, piece of work which remains to be done and could be linked with plans for service development. 


\section{Discussion}

\section{What are the advantages of community-based medical education?}

This analysis shows that teaching basic clinical skills in the community is not a cheap option. It is therefore worth reviewing the benefits of the approach which include: (1) patients seen in the community have a range of common medical conditions which more accurately reflect the morbidity of the population than patients seen in hospital; (2) students can refine their diagnostic skill by seeing large numbers of patients presenting with undifferentiated symptoms ${ }^{18}$; (3) students have the opportunity to learn about chronic disease management, which is now largely done in general practice; (4) students gain a much greater insight into the lives of the patients, enabling them to understand the interaction between lifestyle and ill health ${ }^{19} ;(5)$ GPs are well placed to help students come to terms with the uncertainty at the heart of clinical medicine ${ }^{19}$; and (6) tuition provided by experienced clinicians, who spend 4-6 hours per week with each pair of students.

The intensive, one-to-two approach allows teaching to be tailored to the individual needs of each student, and together with the structured approach of the firms, with nominated topics for each week, allows the student to study effectively. Advice from an educationalist, while adding little to the total costs, has added significantly to the quality of the education. As well as benefits to students, there are also potential benefits to patients of having a thorough review of their clinical problems.

Nearly half of all medical students will pursue a career in general practice ${ }^{20}$, and all doctors who continue in clinical medicine will need to liaise with GPs. This liaison may be easier if students gain a better understanding of working conditions in the community.

\section{Comparison with the costs of hospital-based teaching}

Unfortunately, there are no reliable figures for costs of hospital-based teaching of these basic clinical skills. It is likely that some parts of the hospital-based curriculum are more expensive than others. In particular, teaching basic clinical skills to first-year students is labour intensive. The costs of junior medical teaching in teaching hospitals include the extra time spent on teaching ward rounds, the extra time taken by teaching in out-patients, and the time taken by junior staff to provide ad-hoc teaching on the wards and in casualty. More senior students need less intensive tuition, take more responsibility and, in hospital medicine, may contribute to the service needs of a firm.

In recognition of the extra costs incurred by teaching hospitals, the Department of Health provides extra money in the form of the Service Increment for Teaching and Research (SIFTR). SIFTR is a notional amount derived from the median excess costs of teaching hospitals over District General hospitals ${ }^{21}$, and currently equals $£ 41,140$ (including $9 \%$ London weighting) per student per annum. $75 \%$ is intended to cover teaching costs - equal to an average of $£ 64$ per student session, compared to the recurrent costs of community-based teaching of clinical skill of $c . £ 60$ per session.

Allocations of SIFTR within teaching hospitals tends not to reflect the increased intensity of teaching required by junior students compared to senior students. Indeed, it is not clear how 
teaching hospitals spend SIFTR - much of it may not be spent on undergraduate educational activities and there are difficulties in ensuring that it is used for its stated purpose. Only a few medical schools ${ }^{12: 22}$ have attempted to allocate SIFTR according to the amount of teaching undertaken by each department.

\section{The Way forward?}

Although to date SIFTR has been a purely notional amount it is intended to cover the costs of teaching and research. As such, it is possible to argue that it should be targeted towards those that actually do the teaching: in other words, that the money should follow the student just as it is supposed to follow the patient in the new market-style National Health Service. Indeed, it is possible to imagine the introduction of a purchaser-provider split in medical education. In such a case the providers would be everyone who teaches medical students, including basic scientists, hospital-based departments, and departments of primary care. The dean of each medical school could act as purchaser, commissioning educational modules from providers. There are two hypothetical advantages to such an approach. The first is that if teaching were to attract specific funds, it is likely that it would rapidly achieve higher status and greater priority than is currently the case; a necessary prerequisite to improving the quality of education on offer. The second is that it could take control over the curriculum away from departments - which have a vested interest in their specialty - and place it in the hands of those that have responsibility for the curriculum as a whole. This might allow construction of a more unified curriculum. There is, however, the real anxiety that removing part of SIFTR would render many teaching hospitals unviable in to day's market-style NHS.

The Government has established three funding schemes in recognition of the potential loss of revenue faced by GPs who undertake teaching and research activity. Two have primarily been used for the developments of infrastructure within academic departments of primary health care. The third, the sessional payment of $£ 12$ already referred to, is for general practitioners who undertake undergraduate teaching within their practice. In addition, a working party at the Department of Health is considering whether SIFTR, or a GP equivalent, would be appropriate to cover any excess service costs in general practices resulting from teaching and research activity. If adopted this would be likely to replace the other funding schemes which are not, in themselves, enough to sustain a shift towards community-based medical education.

In conclusion, the current discussion about restructuring medical education requires simultaneous consideration of the funding requirements of the new curricula. If the initiatives described above are deemed educationally desirable, adequate resources will have to be found. 


\section{References}

1. Metcalfe DH. The Edinburgh Declaration. Fam Pract 1989;6:165-7.

2. World Federation for Medical Education [editorial]. Med Educ 1997;31:305-6.

3. Hamad B. Community-oriented medical education: what is it? Med Educ1991;25:16-22.

4. Magzoub MEMA, Magzoub MMA, Saeed AA. The rural residency course. Annals of Community-Oriented Education. 1992;5:105-10.

5. Des-Marchais JE, Bureau MA, Dumais B, Pigeon G. From traditional to problem-based learning: a case report of complete curriculum reform. Med Educ 1992;26:190-9.

6. Clarke RM, Feletti GI, Engel CE. Student perceptions of the learning environment in a new medical school. Med Educ 1984;18:321-5.

7. Moore GT, Block SD, Style CB, Mitchell R. The influence of the New Pathway curriculum on Harvard medical students. Acad Med 1994;69:983-9.

8. Fraser RC, Preston Whyte E. The contribution of academic general practice to undergraduate medical education. Occas Pap R Coll Gen Pract 1988;1-40.

9. Whitehouse CR. The teaching of communication skills in United Kingdom medical schools. Med Educ 1991;25:311-8.

10. McCrorie P, Lefford F, Perrin F. Medical Undergraduate Community-based Teaching: A Survey for ASME on Current and Proposed Teaching in the Community and in General Practice in U.K. Universities. Dundee: Association for the Study of Medical Education; 1993.

11. Booton P. Teaching General Medicine in General Practice. In: Towle A, editor. Community Based Teaching - Sharing Ideas 1. London: King's Fund Centre; 1992.

12. Lowry $\mathrm{S}$. Trends in health care and their effects on medical education. $B M J$ 1993;306:255-88.

13. Audit Commission for Local Authorities and National Health Service in England and Wales. Lying in Wait: The Use of Medical Beds in Acute Hospitals. London: HMSO; 1992

14. Audit Commission for Local Authorities and National Health Service in England and Wales. A Short Cut to Better Services. Day Surgery in England and Wales. London: HMSO; 1992.

15. Towle A. Critical Thinking: The Future of Undergraduate Medical Education. London: King's Fund Centre; 1991.

16. General Medical Council. Tomorrow's Doctors: Recommendations on Undergraduate Medical Education. London: General Medical Council; 1993. 
17. Department of Health. Statement of Fees and Allowances payable to General Medical Practitioners in England and Wales from 1 April 1990. London: HMSO; 1990.

18. Association of University Teachers in General Practice, United Kingdom and Republic of Ireland. Undergraduate medical education in general practice. $J R$ Coll Gen Pract Occas Pap 1984;1-25.

19. Iliffe S. All that is solid melts into air--the implications of community based undergraduate medical education. Br J Gen Pract 1992;42:390-3.

20. Department of Health. Statistics for General Medical Practitioners in England: 1988 1998. 1-18. London: Department of Health Publications; 1999.

21. London Economics. Allocating Medical SIFTR within Camberwell DHA. 1-38. London: London Economics; 1991.

22. Clack GB, Bevan G, Peters TJ, Eddleston AL. King's model for allocating service increment for teaching and research (SIFTR). BMJ 1992;305:95-6. 


\section{Influence on general practitioners of teaching undergraduates: qualitative study of London general practitioner teachers}

\section{Summary}

The objective was to examine the perceived effect of teaching clinical skills and associated teacher training programmes on general practitioners' morale and clinical practice. 30 North London general practitioners who taught clinical skills were asked about the effect of teaching and teacher training on their morale, confidence in clinical and teaching skills, and clinical practice using a qualitative semi-structured interview. The main theme was a positive effect on morale. Within teacher training this was attributed to developing peer and professional support; improved teaching skills; and revision of clinical knowledge and skills. Within teaching this was attributed to a broadening of horizons; contact with enthusiastic students; increased time with patients; improved clinical practice; improved teaching skills; and an improved image of the practice. Problems with teaching were due to external factors such as lack of time and space and anxieties about adequacy of clinical cover while teaching. It was concluded that teaching clinical skills can have a positive effect on the morale of general practitioner teachers as a result of contact with students and peers, as long as logistic and funding issues are adequately dealt with.

\section{Introduction}

The past decade has seen a revolution in the delivery of undergraduate medical education. Medical schools nationally ${ }^{1 ; 2}$ and internationally ${ }^{3 ; 4}$ are increasing the amount of community teaching, most of which is done by the increasing number of general practitioner teachers ${ }^{5-8}$. General practitioner teachers have developed from their original role as teachers of behavioural science and general practice into teachers of clinical skills, with excellent access to a wide range of patients s:10. $^{\text {. }}$

This development has occurred at a difficult time in general practice. Changes within the profession have led to increased workload ${ }^{11}$ and low morale ${ }^{12}$, with falling recruitment to general practice and difficulty in filling once oversubscribed vocational training schemes ${ }^{13: 14}$. Low morale among established general practitioners has been associated with an increase in early retirement and difficulties in recruitment ${ }^{15: 16}$.

Many of the changes within general practice have had particular impact in London, and concern about primary care services led to the creation of London Initiative Zone Educational Incentives. The aims of these incentives were to refresh, recruit, and retain general practitioners within inner city practices ${ }^{17}$. One of the projects funded was the Community based Medical Education in North Thames (CeMENT) project. This collaborative project promoted community based teaching of clinical skills at north London medical schools ${ }^{18}$. There were concerns about the impact on general practice of a sustained and substantial 
increase in community based teaching ${ }^{19}$. Little information was available on the effects of teaching or teacher training on general practitioners' morale, clinical skills, and clinical practice.

\section{Participants and methods}

\section{The CeMENT project}

The CeMENT project was set up in 1994. It involved all of the north London medical schools, with a total annual intake of about 800 medical students. At the time of this study in 1997, 233 general practitioners were actively involved in CeMENT teaching; 37836 student sessions (one student session = one student for one half day) had been held in the community; and student evaluations of the project were positive across all sites. Teacher training courses were a key feature of CeMENT. They aimed to enhance teaching ability and refresh clinical skills. All courses had input from general practitioners and educationalists, were learner centred, involved collaboration with hospital clinicians, and were adapted to the needs of each school.

\section{Undergraduate teaching programmes}

Traditionally general practitioner teachers have used the apprenticeship model, in which students observe the general practitioner during routine clinical work. In CeMENT teaching general practitioners teach in paid protected time, not during clinical work. CeMENT teaching focuses on teaching clinical method, that is history taking, examination skills, and the management of problems. Collaborative teaching programmes specific to each school include internal medicine, dermatology, clinical introductory courses, obstetrics and gynaecology, otorhinolaryngology, paediatrics, rheumatology, and cardiology ${ }^{6}$. Courses varied in length from 3 half days in the community during a 1 week otorhinolaryngology rotation to a 5 week full time internal medicine attachment. All programmes shared some common features (Box 1). After the CeMENT project all of the projects have continued using funding from the medical schools and the Service Increment For Teaching (SIFT).

\section{Box 1 Common features of CeMENT teaching programmes}

- General practitioner teachers

- Teach clinical method

- Small groups of medical students

- Take place in protected time (that is, no clinical commitment)

- Take place in the general practitioner teacher's practice

- Involve volunteer patients drawn from the practice list

\section{Study population and sample}

The sample was designed to achieve the maximum range of views and experiences of teachers. On the basis of the researchers' experiences in recruitment, training, and teaching, a sampling framework was constructed that included practices from inside and outside the 
London Initiative Zone; experienced and inexperienced teachers; small and large practices; an ethnic mix of teachers of both sexes; a geographical and socioeconomic mix of practice population; and practices with positive and negative attitudes to teaching.

Teachers selected were contacted initially by the medical school CeMENT teaching coordinators to inform them about the study and to seek their collaboration with the interview process. Thirty one active CeMENT teachers were contacted, and all agreed to participate. The interviewer (FM) then arranged and conducted 30 interviews. One teacher was not interviewed as a suitable time could not be arranged.

\section{The interview}

A semi-structured interview was designed to cover all the issues that might be affected by either teacher training or teaching. Themes explored in the interview included the positive and negative effects of teacher training and teaching on teachers' morale, confidence in teaching, confidence in clinical practice, and delivery of service. These issues were selected from the researchers' experience; a literature review; discussion with participating teachers; and input from others involved with community based teaching nationally.

An independent, non-medical researcher with wide experience in health services research (FM) interviewed teachers to encourage frankness in their assessment of teaching. Piloting did not result in any changes as the interview adequately covered all topics of interest for the participants. The interview took place in the teachers' surgeries.

\section{Data analysis}

Interviews were audiotaped, and field notes were made by the interviewer. All replies were recorded on a Microsoft Access database and an analytical framework derived from the data with the method of constant comparison ${ }^{20: 21}$. Two authors (FM and SLH) independently analysed the data. There were no notable discrepancies in their conclusions.

\section{Results}

The unifying theme that emerged from respondents' experience of teaching and training was a boost to their morale. The data are presented in terms of the two dimensions of teaching and training. Respondents mentioned several issues that were perceived as uniformly negative for morale and that hindered successful teaching. These issues are presented separately as organisational problems.

\section{Effects of teacher training}

Support and feedback from peers: teacher training boosted morale because of networking with peers and sharing problems. Teachers who had suffered from isolation within general practice and teaching developed a peer group of fellow teachers with whom they could develop a new identity as general practitioner teachers. 


\section{Box 2 The effects of training for teaching}

"It has improved this [morale][---]the sessions prevent isolation" (GP 26)

"Getting together with peer group[---]challenges of students can be shared" (GP 12)

"I was worried about whether I was up to date[---]would I teach the right material. The sessions reassured me. It helped calibrate me" (GP 21)

"It has renewed and refreshed my clinical skills[---]I now examine patients without cutting corners" (GP 23)

"Learned more about obstetrics[---]feedback from the hospital consultants has helped" (GP 4)

"I felt much more confident[---] this is the first time that I have had real training for teaching, although I am an experienced teacher" (GP 27)

Developing clinical skills: anxiety about the adequacy of clinical skills was common. Teachers thought that "short cuts" in their clinical examination of patients were not appropriate for students to learn. Performing examinations and discussing clinical problems with other teachers and hospital specialists allowed participants to compare, contrast, and improve skills. Improvements in clinical knowledge, skills, and clinical practice led to an improvement in morale and were most often cited in neurology and otorhinolaryngology, which had been targeted by several of the training programmes. Seven teachers reported no changes.

Developing teaching skills: teachers who were not postgraduate trainers were insecure about teaching skills. Training reassured teachers that it was appropriate for them to teach, allowed them to calibrate their skills against those of their peer group, and gave them additional skills to deal with students. The improvement in skills noted was empowering and improved morale. Some experienced teachers noted that they did not gain much from the sessions, but they recognised the usefulness for others.

\section{Effects of teaching}

Broadening horizons: the experience of teaching added variety to the week, and teachers felt they were involved in an activity that transcended usual practice routine. Isolation was reduced by the presence of keen students, with improved morale for the whole practice. 


\section{Box 3 The effects of teaching}

"There is a whole world outside general practice and other options for a GP....has sustained me" (GP 28)

"It is fun[---] students keep you young, stimulated and they are non-cynical. Renews my enthusiasm for medicine" (GP 9)

"Student questions (unknowingly perceptive) have changed my approach to managing diabetes in antenatal patients" (GP 6)

"Explaining issues to students helps me re-evaluate my practice" (GP 29)

"I am more methodical, less generalised, neater at note taking, more rigorous, and can justify what I am doing" (GP 8)

"I see more patients with ENT and dermatology problems[---]my partners refer them to me" (GP 20)

"It has helped me to be more selective with my referrals" (GP 4)

"When I am teaching I am only available for dire emergencies[---]it is hard to balance conflicting priorities for a single handed GP" (GP 15)

"[Problems are] patient fatigue. Finding suitable patients. It is important to manage the doctor-patient relationship" (GP 7)

Contact with students: positive feedback from students was important for teachers' morale, and sessions that were not well attended or were poorly received led to anxiety.

Contact with patients: longer contact with selected patients during teaching was positive for teachers, and patients were thought to benefit from this in addition to a thorough clinical review, learning more about their condition, and revealing new personal information to students.

Improving clinical practice: a renewed enthusiasm for clinical work was attributed to three factors: the contact with enthusiastic students; an increase in time spent with patients; and greater confidence in clinical skills and knowledge. Changes in clinical skills and practice were reported as a result of teaching and were attributed to increased reading and reflection on practice; information from students; challenging questions from students; and more time with patients. Changes in practice included being more methodical in clinical examination; specific changes in patient management; developing a clinical subspecialty role within the practice; and disseminating information through the practice.

Improving teaching skills: teaching led to improvements in confidence and morale as the preparation time for sessions reduced and teachers felt able to cope with challenging students. 
Improving the image of the practice: the image of the practice was positively affected by teaching, influencing practice staff and general practitioner colleagues. Some practices invested in their premises to provide extra teaching facilities and most bought extra equipment, ranging from textbooks to improved information technology links.

\section{Organisational problems}

Time pressures led to anxiety for teachers because of loss of clinical time due to teaching and preparation. Assistants or locums were employed by some practices to do clinical work but this caused concern. Some premises lacked space, and in group practices some partners were not supportive. Six teachers found that funding for teaching was inadequate, although most concluded that it was cost neutral.

Finding appropriate patients was time consuming, and patient fatigue and effects on the doctor-patient relationship were mentioned by experienced teachers. Many teachers had hoped that teaching would result in better communication with hospital specialists from teaching. This was realised in some cases, particularly when teachers had both clinical and teaching contact with a hospital. Many thought that relationships were unchanged on the clinical front but were disappointed by insufficient feedback about their teaching, possibly indicating a search for affirmation of the teachers role.

\section{Discussion}

\section{Methodological considerations}

This qualitative study shows that the teachers sampled perceived benefits from being involved in undergraduate education. We explicitly looked for negative effects of teaching on doctors and their practices and found very few despite using an independent researcher to facilitate disclosure of negative feelings. The sample interviewed, however, was a specific group of general practitioners who had agreed successively to attending a teacher training course, teaching students in their practices, and then being interviewed.

There was a striking homogeneity of responses, despite planned sampling for maximum variability. Length of teaching experience, being a postgraduate trainer, time since qualification, sex, practice characteristics, location (urban or suburban), or medical school did not affect the results. The study took place within a well organised and well funded project and may represent a best case scenario. Similar positive attitudes towards teaching among general practitioners, however, have been found in previous studies ${ }^{22-24}$, suggesting that our results may be transferable to other groups of general practitioners.

\section{Changes in clinical practice}

The isolated nature of general practice means that general practitioners' clinical skills are not displayed to their colleagues. Deterioration of clinical skills is feared, and both calibration of skills with a peer group and perceived improvement boosted morale. Changes in clinical practice seemed to be due to reflection prompted by new information, echoing Kolb's "learning cycle," ${ }^{25}$ where experience prompts reflection, leading to generalisation (hypothesis formation) and testing. Further studies are needed to quantify these changes, which may have important implications for the role of teaching in continuing medical education. 
The opportunity for improving communication between hospital specialists and general practitioners did not fully emerge, remaining one of the challenges facing those who develop community based teaching.

\section{Sustainability of teaching}

To sustain teaching of clinical skills general practitioner teachers need help to overcome external (workload and infrastructure related) and internal (confidence related) restraints to teaching ${ }^{24}$. Within CeMENT, innovative solutions to service provision problems such as employing additional medical staff were assisted by the reimbursement for teaching, while issues of confidence were covered by training courses. Teaching of skills in the community and the provision of relevant training are recent innovations that may have increased enthusiasm, although no differences were found between well established and new teachers. The increase in morale attributed to teaching may prove important for the sustainability of teaching of clinical skills and for the current recruitment problems within general practice.

\section{Conclusion}

Community based teaching of clinical skills can have a positive impact on general practitioners, improving morale, confidence in clinical skills, and clinical practice. These positive outcomes rely on providing good quality teacher training to novice teachers, ongoing support and networking opportunities to all teachers, adequate funding to permit teachers to reduce their clinical commitments, and the commitment of all the doctors within a practice to teaching. 


\section{References}

1. Association for the Study of Medical Education. Curriculum Innovations: Descriptions of Undergraduate Medical Courses in the UK. Dundee: Association for the Study of Medical Education; 1997.

2. Lefford F, McCrorie P, Perrin F. A survey of medical undergraduate community-based teaching: taking undergraduate teaching into the community. Med Educ 1994;28:312-5.

3. Southgate, L, Brownell Anderson, M, Boelen, C, Chalmers, A, des Marchais, J, and Schwenk, T. L. Implementing community oriented community-based medical education. In: Davis W K, Jolly B, Page GG, Rothman A, White BAC. Moving Medical Education from the Hospital to the Community. Ann Arbor: University of Michigan Medical School; 1997. p 87-92.

4. Inui TS, Williams WT, Jr., Goode L, Anderson RJ, Bhak KN, Forsyth JD et al. Sustaining the development of primary care in academic medicine. Working Group on Sustaining the Development of Academic Primary Care. Acad Med 1998;73:245-57.

5. Whitehouse CR. Planning for Community-oriented Medical Education in Manchester. Education for Health 1996;9:45-59.

6. Macfarlane F, McLennan E, Murray E, Wallace P. CeMENT (Community Based Medical Education in North Thames) Project Report. London: CeMENT; 1998.

7. Martens FM, van der Vleuten CP, Grol RP, op 't Root JM, Crebolder HF, Rethans JJ. Educational objectives and requirements of an undergraduate clerkship in general practice. The outcome of a consensus procedure. Fam Pract 1997;14:153-9.

8. Fields SA, Usatine R, Stearns JA, Toffler WL, Vinson DC. The use and compensation of community preceptors in U.S. medical schools. Acad Med 1998;73:95-7.

9. Parle J, Greenfield S, Thomas C, Ross N, Lester H, Skelton J et al. Community-based clinical education at the University of Birmingham Medical School. Acad Med 1999;74:248-53.

10. Oswald NT,.Alderson TS. A core curriculum in general practice. Med Educ 1997;31:352-3.

11. Scott A,. Wordsworth S. The effects of shifts in the balance of care on general practice workload. Fam Pract 1999;16:12-7.

12. Appleton K, House A, Dowell A. A survey of job satisfaction, sources of stress and psychological symptoms among general practitioners in Leeds. Br J Gen Pract 1998;48:1059-63.

13. BMA Health Policy and Economic Research Unit. BMA cohort study of 1995 medical graduates. Third report: career intentions of first year senior house officers. London: British Medical Association; 1998. 
14. Baker M, Williams J, Petchey R. GPs in principle but not in practice: a study of vocationally trained doctors not currently working as principals. BMJ 1995;310:1301-4.

15. Mathie T. The primary care workforce crisis: a time for decisive action. Br J Gen Pract 1997;47:3-4.

16. Medical Workforce Standing Advisory Committee. Third report planning the medical workforce. London: Department of Health; 1997.

17. North Thames NHS Executive. The three Rs: recruitment, retention, refreshment and reflection. London initiative zone educational incentives (LIZ EI). Annual report 19967. London: NHSE Publications; 1997.

18. Wallace P, Berlin A, Murray E, Southgate L. CeMENT: evaluation of a regional development programme integrating hospital and general practice clinical teaching for medical undergraduates. Med Educ 2001;35:160-6.

19. Wilson A, Fraser R, McKinley RK, Preston Whyte E, Wynn A. Undergraduate teaching in the community: can general practice deliver? Br J Gen Pract 1996;46:457-60.

20. Ruston A, Clayton J, Calnan M. Patients' action during their cardiac event: qualitative study exploring differences and modifiable factors. BMJ 1998;316:1060-4.

21. Green J. Commentary: grounded theory and the constant comparative method. $B M J$ 1998;316:1064-5.

22. Murray E, Todd C, Modell M. Can general internal medicine be taught in general practice? An evaluation of the University College London model. Med Educ 1997;36974.

23. Gray J,.Fine B. General practitioner teaching in the community: a study of their teaching experience and interest in undergraduate teaching in the future. Br J Gen Pract 1997; 47:623-6.

24. Fine B, Seabrook M. GPs' attitudes towards increased medical education in the community. Education for General Practice 1996;7:42-7.

25. Kolb D, Fry R. Towards an applied theory of experiential learning. In Cooper C. ed. Theories of group processes. London: Wiley; 1975. 


\section{Patients' views and feelings on the Community based teaching of undergraduate medical students: qualitative study}

\section{Summary}

The objective was to determine the patients' views and feelings on community based teaching, in order to discover both the positive and negative aspects for participating patients. Patients participating in general practice based teaching in North London were interviewed, using a semi-structured interview format. Respondents felt very positive about participating in the community based teaching programme. There were two underlying components to this: altruism and personal gain. Within altruism reasons included: provision of a service to the community and repaying the system. Aspects of personal gain included: improved knowledge, improved self-esteem and companionship. Patient concerns included: embarrassment, reinforcement of the sick role and concerns about student access to notes. The conclusions were that patients enjoyed their involvement in community based teaching and perceived themselves as making a valuable contribution. The findings of the research will be reassuring for doctors who are presently involved and those who plan to be involved in the future. Doctors need to be aware of the possible shifts in the doctor-patient relationship when actively seeking patients' help in the teaching.

\section{Introduction}

In response to the General Medical Council's directive, Tomorrow's Doctors' most medical schools are increasing the amount of community based teaching. This directive recognised that the community offers a wealth of teaching opportunities for medical students, since patients with chronic diseases and significant clinical signs, previously managed in the hospital setting, are increasingly being supported and cared for in the community. This move has also been supported by the findings that community based teaching is as effective as hospital based teaching of basic clinical skills ${ }^{2-4}$. One feature common to these new programmes is the change from the traditional model of General Practice based teaching, of one student sitting in with the doctor while s/he consults, to pairs or groups of students being taught their basic clinical skills with the help of patients, who have been specifically asked by their doctors to assist in teaching.

The sustainability of community based teaching is dependent on the on-going willingness of all participants i.e. patients, GP tutors and students to participate ${ }^{5}$. Previous work has demonstrated that GP tutors perceive substantial personal advantages from teaching ${ }^{6: 7}$ and the popularity of community based teaching amongst medical students has been well demonstrated $^{8}$.

Research looking at the traditional teaching methods in General Practice suggests that patients are happy to have a student present during a consultation with their GP:10. In Newcastle, 
patients involved in a Medicine in Society course, where a pair of students visited the patient at home several times over six months, were positive about this initiative, seeing themselves as active teachers of the students ${ }^{11}$. However, the UCL model requires more intensive input by patients who may give up half a day per month for many years to participate in student teaching. GP Tutors involved in this model have expressed concerns that patients will become fed up (or "fatigued") by their repeated prolonged exposure to medical students and will eventually refuse to have further contact with them so jeopardising the future of community based teaching.

The University College London Medical School has been running a community based teaching programme of basic clinical skills for a number of years. The programme consists of a 5-week general medicine firm taught entirely in General Practice. Most of the time is spent in the general practice, where the GP tutors concentrate on teaching the basic clinical skills of history taking and physical examination. The students see a wide range of patients with common medical conditions. GPs within the teaching practices identify these patients, who are then contacted either by their own GP or by a nominated member of the practice staff. This person then advises the patient of what the teaching involves i.e. one to two medical students asking them questions and examining them either in their own home or in the practice. The patient is advised that each session will last approximately 2 hours and that they are not attending for routine medical care. If the patient agrees to become involved in the community based teaching their names are held by the practice and they are then contacted a few weeks prior to the teaching session.

\section{Aims}

This study aimed to determine the patients' views and feelings on community based teaching, in order to discover both the positive and negative aspects for the patients participating and develop systems to ensure the teaching benefits all the participants.

\section{Method}

\section{Recruitment}

Approval from the local research ethics committee was gained. Patients were recruited from four practices involved in the community based teaching of basic clinical skills, each had large intake of clinical medical students i.e. four to six students every five weeks for twenty to forty weeks of the year.

GP tutors were asked to identify a maximum variety sample of patients (Box 1). Once selected the patients were sent a letter from their own GP, informing them of the nature of the project and inviting them to be involved. If they agreed to be interviewed they were asked to return a reply slip to $\mathrm{KC}$. On receipt of the reply slip, the patients were contacted by telephone. Tape-recorded interviews were organised and a consent form to be completed prior to the interview was sent to the patient.

Each of the 4 practices sent out six letters. Fifteen patients responded of whom thirteen were currently involved and two had previously been involved in the teaching and then stopped. Fourteen were interviewed in their own homes and one was interviewed at their GPs practice 
at their own request. No patients who had declined to be involved in the teaching responded to the invitation to take part in the project. The two patients the GP tutors had identified as having stopped their involvement in the community based teaching believed they were still involved.

\section{Box 1 Sampling strategy}

GP tutors were asked to recruit:

- Patients actively involved in the community based teaching

- Patients who had declined to be involved in the community based teaching

- Patients previously involved in the community based teaching and now stopped

And to try to maximise the variability of the sample with respect to:

- Gender

- Age group

- Employment status

- Ethnicity

\section{The interview}

A semi-structured interview schedule was designed to address GP tutors' concerns about the sustainability of the community based teaching programme as well as perceived patient concerns. These concerns had been identified during a focus group, which had been held at the tutors' request after expressing concerns about the sustainability of the programme (Box 2).

The interviews were carried out by KC. Patients were told that she was a doctor working in the department of primary care at the medical school who organised the community based teaching programme. Patients were advised that any information generated during the interviews would not be passed to their GP.

Pilot interviews were carried out and did not result in any changes as the interview adequately covered all areas of interest and no new areas arose. After the first five interviews the interview schedule was modified in order to cover a new emergent theme based on patients' feelings about their notes being used in the teaching. This topic was then included in all the following interviews.

\section{Data analysis}

Interviews were audio taped, and on one occasion when this method failed the interviewer took extensive field notes. All interviews were transcribed in full. A thematic framework was generated from the emergent data based on recurrent themes and issues. This was then applied to the textual data. The indexed text was then lifted and put into charts ${ }^{12}$ with the same themes allowing comparisons to be made within and between the data. In order to ensure the accuracy of the analysis, the transcripts were read, charts checked and discussions were held with EM. Two patients were interviewed with their spouses. These are identified by number (of respondent) and letter e.g. 10a. 


\section{Box 2 Interview schedule}

Areas explored:

- What patients felt about their involvement in the teaching with prompts for positive and negative aspects.

- How the teaching affected the patients' relationship with their doctor.

- What the patients thought the doctors and students got out of the teaching

- How long the patients felt they may want to go on with the teaching

- Whether the patients would find it difficult to stop their involvement in the teaching and if stopping would affect their relationship with their doctor

\section{Results}

The overwhelming theme that emerged from the respondents' experience of the community based teaching was that they felt extremely positive about the teaching and given the opportunity would be willing to participate indefinitely. Two quite distinct underlying incentives for participating, altruism and personal gain, were identified, and the data is presented in terms of these two dimensions. In addition, a number of other interesting themes regarding the teaching were generated and these are presented separately as patient concerns regarding the teaching.

\section{Altruism}

\section{(i) Providing a service to the community through training better doctors}

Patients believed that their involvement with medical student teaching provided a service to the wider community as it broadened students' experience, enabling the students to become better doctors in the future. They also felt that their doctors would become better doctors as they were getting the opportunity to learn more about patients' feelings and experience of illness.

"makes me feel good that I'm putting something back into the community"(1)

"I think they'll be more aware of the fact that what they suggest as a course of treatment is not necessarily viable for the person concerned. They may bear that in mind next time they have to make a diagnosis" (9)

(ii) Repaying the system

Patients saw it as a way of repaying the NHS, as well as assisting their doctor who provides on-going care. Many of the patients would not be able to contribute financially to the NHS, and were pleased to be able to help.

"I feel sort of slightly as if I'm giving a bit back, because I've had a lot out of the health service" (11) 
(iii) Providing a service for no financial reward

In line with the altruistic motivation, patients were against being paid for their help in teaching as they felt that:

- Patients expecting compensation would be doing it for the wrong reasons.

- The NHS is already financially challenged

- The service i.e. involvement in community based teaching, being provided is voluntary

- The teaching programme is for the good of the wider community

- Payment would make it more difficult to refuse future involvement

Some patients felt that refunding travel expenses would be acceptable.

\section{Personal Gain}

\section{(i) Improved knowledge}

The close contact with the doctor and the medical students offered the patient the opportunity to learn more about their disease. This empowered the patients, making them more confident in the ability to cope with their own medical problem.

"Even I can learn something from the students. It's not just a one way system" (15)

"I know when something is wrong and I can do something about it" (1)

(ii) Enhanced self-esteem.

A number of patients involved with the community based teaching suffered with chronic diseases, which had left them unable to work, with ensuing feelings of worthlessness. Involvement in teaching gave patients a sense of worth and pleasure.

"It's given him another outlet when he's at home all the time and he's got something else to think about" (10a)

"I just love doing it actually"(1)

"I felt I had something to offer as I was very unwell"

(iii) Relief from social isolation/opportunity for companionship

Many patients involved in the community based teaching were elderly and lived alone. A visit from medical students and their doctor helped ease their isolation.

"I have a visitor for half a morning; somebody different to talk to" (9)

"I'm always happy when they're here" (12)

(iv) Reassurance of well -being ("a good going over")

Having agreed to participate in the community based teaching, patients discovered that their involvement provided them with the opportunity to have frequent thorough examinations, which in turn provided them with a sense of reassurance of their well being, and improved the chances of any new problem being identified earlier.

"when they take your pulse and your blood pressure you know how you are getting on" (2) "these kids they come along, and I'm undressed entirely, may find some little thing that's not normally spoke about" (12) 
(v) A perceived better service

The patients believed the teaching provided them with a direct improvement in their care through their general practitioner gaining a better understanding of their medical condition. Patients also judged their doctor's involvement in teaching as evidence of excellence. Moreover, they felt that this involvement would be of benefit to their doctor, as a way of keeping them up to date.

"his doctors have got more understanding of him because he has multiple problems and where before he says he couldn't relate, he couldn't express himself, he can now a lot more easier and they understand him a lot" (10a)

"it would help them (the doctors) to keep more up-to-date with things going on in the hospital" (5)

\section{(vi) Anticipated better service}

GP tutors had expressed concerns that their involvement in the teaching might make patients feel that they have a special relationship with the doctor that entitled them to out of-the ordinary care. The general consensus from respondents was that this would not happen, however the potential for this to occur was also apparent.

"we're just another patient really, aren't we? I don't see how we should have any priority" (7a)

"I do think maybe, if you need to see a doctor and you had to wait a long time, that they ought to be able to fit you in " (5)

\section{Patients' concerns regarding the community based teaching}

Having received no responses from patients who had declined to be involved in the community based teaching it was difficult to identify the underlying reasons for not wanting to take part in the teaching. However, comments made during interviews with patients who were involved, as well as those patients whom the GP tutors had identified as having stopped their involvement provided some insight into possible reasons for declining involvement.

\section{(i) Source of embarrassment and anxiety}

Patients implied that the teaching generated feelings of anxiety and embarrassment particularly during intimate examinations. This may have been prevented if the consulting doctor had asked the patient to re-consent to the student to be present during the examination.

"It was embarrassing on one occasion when I went there - I had trouble going to the toilet and he thought I might have piles or something like that, and there was a woman student there and I thought this was a bit embarrassing, but he did pull the screen back, though I'd rather he'd done it on his own you know." (3)

"I know some people have refused. I suppose it's just that they feel a bit embarrassed" (7a) 
(ii) Reinforcing the sick role

Patients expressed concerns that repeated contact with doctors and medical students reinforced their feelings of ill health and that this would be a reason for not increasing their involvement further.

"I wouldn't want to increase my involvement. I have so many medical problems anyway, and I'm constantly needing to go up to the hospital and to the doctors surgery, I'd like to get away from it all - you know try to be well" (13)

(iii) Providing a service as often as required

GP tutors had expressed concerns that patients may have felt unable to refuse to do the teaching. The responses given during the interviews indicated that this was not a problem and patients where happy to do it if and when asked, providing they did not have any other arrangements that took priority.

"as long as I don't have anywhere to go, if I have somewhere to go I'd have to cancel it" (2) "as long as the day is free I don't mind" (6)

"send them round the same day if you want" (9)

\section{(iv) Consent and confidentiality}

Patient did not expect that consenting to see students is taken as consenting for students to have access to their medical notes. Indeed several patients specifically commented when asked about students' access to their notes, that they did not want this to occur.

"I think the patient should have some say in it, because that's supposed to be private and confidential between my doctor and me, so the student's aren't allowed. I wouldn't stop, but I would like them to stop using my notes." (15)

\section{Discussion}

The main finding of this study is that patients enjoyed participating in this form of community based teaching. They perceived both altruistic and personally beneficial reasons for involvement, and identified few detrimental effects from participating. Most would continue their involvement indefinitely if invited to do so.

There was a remarkable consistency of results, with few new themes emerging after the first five interviews, and none after the thirteenth, suggesting that we had sampled to the point of redundancy. Respondents felt able to raise new topics (e.g. access of students to their notes) during the interview confirming that they perceived the interviewer as independent.

In order to address the concerns of the ethics committee, and respect patients' confidentiality, recruitment was by "opting in". Although this method tends to recruit fewer participants as it involves active consent, $62 \%$ of those approached agreed to be interviewed, echoing their altruistic motivation in participating in teaching. Unfortunately, no patients who had declined to participate in teaching were prepared to be interviewed, and the two patients who had been identified by their GP as no longer participating in teaching, perceived themselves as still 
involved. This prevented the study determining what prevented patients from initially becoming involved, or why they wanted to stop. Reassuringly, no interviewees felt that it would be difficult to cease their involvement and there were no suggestions that patients had initially felt coerced into participating.

There is an increasing body of evidence supporting active patient involvement in medical education ${ }^{13-15}$. In our study patients saw themselves as making a specific contribution to medical student education and deriving a number of personal benefits as a result of their involvement. This echoes Stacy and Spencer's ${ }^{11}$ finding that patients involved in a different model of community based teaching saw themselves as active teachers of students and also felt that they derived similar personal benefits. The similarity of our results suggests transferability to other environments, given that the nature of the educational initiative, both in terms of the amount of time patients committed, and the objectives of the attachment was very different in the two studies, as was the geographical location.

However, patients appear to have real concerns about student access to notes ${ }^{16: 17}$. Clinical teachers must note this, and consent for student access to notes can no longer be assumed. There may also be a broader issue here: to what extent are patients aware that information, and hence notes, are shared between the entire primary health care team on a need to know basis?

The relationship experienced between a GP tutor and his/her patient is unique. GP tutors, who have to actively seek help from patients, may feel indebted to the patient with a resultant shift in their relationship ${ }^{18}$. If so, could the real issue be "tutor fatigue" rather than "patient fatigue"? Is "tutor fatigue" a manifestation of some GPs discomfort with the potential shift in power toward the patient within the doctor-patient relationship? There is evidence that some GP registrars are still more comfortable with a model based on benign paternalism, rather than an egalitarian relationship ${ }^{19: 20}$

The findings will reassure doctors already involved in teaching as well as those who are considering getting involved in the future. They have highlighted training issues for GP tutors including recruitment of patients; strategies for clarifying patients' desired level of involvement; and methods to ensure that patient consent for student access to notes is not assumed. A more fundamental problem is the difficulty some tutors appear to have with the change in the doctor-patient relationship inherent in this type of teaching. This may be a part of the wider changes occurring with better-informed patients choosing to play a more active role in their health care. In the long term, will students who learn in primary care, with autonomous patients $\mathrm{s}^{21}$ feel more at ease with an increasingly egalitarian doctor-patient relationship? 


\section{References}

1. General Medical Council. Tomorrow's Doctors: Recommendations on Undergraduate Medical Education. London: General Medical Council; 1993.

2. Murray E, Jolly B, Modell M. Can students learn clinical method in general practice? A randomised crossover trial based on objective structured clinical examinations. BMJ. 1997; 315:920-3.

3. Berg D, Sebastian J, Heudebert G. Development, implementation, and evaluation of an advanced physical diagnosis course for senior medical students. Acad Med 1994;69 :758-64.

4. Satran L, Harris IB, Allen S, Anderson DC, Poland GA, Miller WL. Hospital-based versus community-based clinical education: comparing performances and course evaluations by students in their second-year pediatrics rotation. Acad Med 1993;68:3802.

5. Murray E,.Modell M. Community-based teaching: the challenges. Br J Gen Pract 1999;49:395-8.

6. Hartley S, Macfarlane F, Gantley M, Murray E. Influence on general practitioners of teaching undergraduates: qualitative study of London general practitioner teachers. BMJ 1999; 319:1168-71.

7. Gray J,.Fine B. General practitioner teaching in the community: a study of their teaching experience and interest in undergraduate teaching in the future. Br J Gen Pract 1997;47:623-6.

8. Parle JV, Greenfield SM, Skelton J, Lester H, Hobbs FD. Acquisition of basic clinical skills in the general practice setting. Med Educ 1997;31:99-104.

9. Cooke F, Galasko G, Ramrakha V, Richards D, Rose A, Watkins J. Medical students in general practice: how do patients feel? Br J Gen Pract 1996;46:361-2.

10. Jones S, Oswald N, Date J, Hinds D. Attitudes of patients to medical student participation: general practice consultations on the Cambridge community-based clinical course. Med Educ 1996;30:14-7.

11. Stacy R,.Spencer J. Patients as teachers: a qualitative study of patients' views on their role in a community-based undergraduate project. Med Educ 1999;33:688-94.

12. Bryman A, Burgess R, Ritchie J. Analysing Qualitative Data: Qualitative data analysis for applied policy research. London: Routledge; 1994.

13. Hendry GD, Schrieber L, Bryce D. Patients teach students: partners in arthritis education. Med Educ 1999;33:674-7.

14. Pill RM,.Tapper Jones LM. An unwelcome visitor? The opinions of mothers involved in a community-based undergraduate teaching project. Med Educ 1993;27:238-44. 
15. Wykurz G. Patients in medical education: from passive participants to active partners. Med Educ 1999;33:634-6.

16. O'Flynn N, Spencer J, Jones R. Consent and confidentiality in general practice: survey of patients' views on presence of students. BMJ 1997;315:1142.

17. Williamson $\mathrm{C}$,.Wilkie $\mathrm{P}$. Teaching medical students in general practice: respecting patients' rights. BMJ. 1997;315:1108-9.

18. Gantley M, Rickets M, Sheldon M, Carter Y. Patients in east London seem happy to give GPs consent for training [letter]. BMJ 1998;316:1391.

19. Elwyn G, Edwards A, Kinnersley P. Shared decision-making in primary care: The neglected second half of the consultation. Br J Gen Pract 1999;49/443:-482.

20. Elwyn G, Edwards A, Gwyn R, Grol R. Towards a feasible model for shared decision making: focus group study with general practice registrars. BMJ 1999;319:753-6.

21. Thistlethwaite JE, Jordan JJ. Patient-centred consultations: a comparison of student experience and understanding in two clinical environments. Med Educ 1999;33:678-85. 


\section{Discussion and Conclusions}

\section{Introduction}

This thesis presents a multi-faceted evaluation of a new, and increasingly widespread, form of teaching, namely teaching clinical skills in general practice. The research questions posed in Chapter 1 were:

- Was it feasible to develop an internal medicine clerkship in general practice?

- Did students acquire clinical skills as well on the general practice based clerkship as on the hospital based clerkship?

- What were the relative strengths and weaknesses of teaching internal medicine in hospital and in general practice?

- What were students actually doing on internal medicine clerkships taught in general practice and in hospital?

- What were the costs of teaching internal medicine in general practice?

- What was the impact of teaching internal medicine on the GP tutors?

- What were the reactions of patients to this type of teaching?

This chapter starts by examining problems in educational research in general and then considers the methodological issues specific to answering the questions posed in the thesis. Finally, I draw on the results of this work and other published research to provide guidance for those interested in developing similar initiatives.

\section{Challenges in Educational Research}

\section{The need for evidence based education:}

I welcome the establishment of Best Evidence Medical Education (BEME) - a movement which has grown out of the Evidence Based Medicine movement. BEME has been defined as: "the implementation, by teachers and educational bodies in their practice, of methods and approaches to education based on the best evidence available"1. In my view the reasons for trying to make educational practice more evidence based are overwhelming. The first is that medical education is expensive. The Service Increment for Teaching (SIFT) budget (which supports undergraduate medical education) in England and Wales was £431 million in 1998 $99^{2}$. In countries where medical education is not publicly funded, students (or their parents) make considerable financial investment in their education. Educators must be accountable for spending such sums, and must be able to demonstrate that educational programmes achieve the desired outcomes ${ }^{3}$. Secondly, the rationale for spending time, effort and money on medical education is that we believe that it has an impact on the way doctors practice in the future, and hence on health care. This puts medical education in the same position as any other health technology. In these days of evidence based medicine, where all new health technologies are rigorously evaluated before widespread implementation, educational changes must also be evaluated equally rigorously. 
Unfortunately, much educational research is still at a relatively early stage of development. I do not wish to recap the current vigorous debate amongst the founder members of BEME as to what constitutes evidence in education, how educational research should be assessed, and to what extent the criteria of evidence based medicine can be transferred to educational research. What is clear, is that much of the current work in educational journals is descriptive and frequently the evaluation is limited to determining student satisfaction with the new course. This is unsatisfactory. There are a number of reasons contributing to this, which I discuss below along with some potential solutions.

\section{a) Educational interventions are complex interventions.}

Educational research shares many similarities with health services research in that the intervention under study is often complex and multi-factorial. The environment in which the intervention occurs is the real world, and as such, subject to multiple economic, political and social factors, outwith the control of the investigator, which may change during the study period, making interpretation of results more difficult. As the interventions are complex, it is often difficult to know which part of the intervention is responsible for which effect - and to what extent the intervention can be adapted to fit local circumstances without losing its effectiveness. However, health service researchers are developing methodologies to deal with complex interventions, and I urge educational researchers to follow their lead.

The experience of evaluating complex interventions in health services research suggests that both quantitative and qualitative approaches are necessary. Campbell et al have suggested a phased approach to both development and evaluation of complex interventions ${ }^{4}$ which I believe is highly applicable to educational research. They suggest that the first phase is a theoretical phase, identifying the evidence that the intervention might have the desired effect. Subsequently the different components of an intervention must be defined, and their interrelationships considered. This can be done through qualitative testing with focus groups, preliminary surveys or case studies. Qualitative research can also determine how the intervention works, and potential barriers to implementation. The next phase is defining the trial and intervention design and considering the methodological issues for the main trial (randomisation, blinding, recruitment etc). The final phase is promoting effective implementation.

Thus although the randomised controlled trial was initially developed to determine the effects of a single intervention, such as a drug, the methodology, particularly of pragmatic trials ${ }^{5}$ can be transferred to complex interventions such as educational innovations. As RCTs tend to treat the intervention under study as a "black box", qualitative methods are needed to explore the relative importance of the various components of the intervention and to provide meaning and explanation of the findings ${ }^{67: 8}$.

Health service researchers are developing new methodologies for situations where a randomised controlled trial is not possible. Examples of these new methodologies include the balanced incomplete block design which allows comparison of multiple treatments or interventions with a relatively small sample size. Patients are randomised to receive different treatment sequences, so that all possible combinations are included ${ }^{9}$.

\section{b) problems with randomisation}

There are significant practical problems facing researchers who wish to randomise students, whether at the level of whole curricula, or individual courses. In most countries, students 
apply for specific schools, and have an expectation of which curriculum they will follow. Within any one curriculum, the combination of ethical and logistical difficulties in randomising allocation to a new course can seem almost insuperable. Do you obtain formal consent from students before randomising them to a new or conventional course and what happens to students who decline to enter the trial? Given the complexity of most medical school timetables, these questions can deter all but the most committed researchers.

Despite this, the ethical and intellectual basis for encouraging schools to promote RCTs of new courses is clear. It is ethical to randomise students when there is genuine uncertainty about the relative benefits of a new and traditional course ${ }^{10}$. Students should be encouraged to contribute to the research culture within the medical school, and adoption of "patient preference" methodologies ${ }^{11}$ within randomisation is likely to accommodate the anxieties of most students.

There have been some notable successes in randomisation of students, particularly at the level of the whole curriculum ${ }^{12}$. These have demonstrated that the difficulties are not insuperable, where there is a strong political will to undertake the research. It may be that a cultural unwillingness to prioritise educational research is at least a contributory factor to the scarcity of RCTs in medical education. Health service researchers face comparable difficulties with designing and implementing RCTs, but have been determined to overcome them ${ }^{13}$.

\section{c) problems with funding}

One vivid manifestation of the low priority placed on educational research amongst the research community is the paucity of funds available for educational research, and the difficulty in obtaining funding for evaluation of educational initiatives. Thus, in the UK, despite the pressure from the General Medical Council which has resulted in almost every medical school introducing a new curriculum, there are no dedicated funds for evaluating the impact of these new curricula.

\section{d) problems with defining outcomes}

An issue common to much educational research is the difficulty in defining desirable outcomes of an educational intervention. Moreover, even when desirable outcomes have been defined, there is a real lack of assessment tools for most outcomes other than knowledge and clinical skills ${ }^{3}$. Thus it is almost impossible to determine whether different educational methods have any impact on traits currently considered desirable, such as team working, respect for patients and colleagues, or cross-cultural competency.

\section{e) cultural problems.}

In my view this is the single most important issue. Able and eminent clinicians who actively participate in creating the evidence based for their clinical discipline, do not, as yet, apply the same intellectual rigor to their teaching or curriculum change ${ }^{14}$. Educational research is still a relatively low status field, at least in the UK, so that it can be difficult to attract high calibre applicants. As a result, research capacity is low in many places, and many of the academic staff involved in medical education are overloaded with service development and implementation.

This situation is not inevitable. Thirty years ago academic general practice faced many of the problems faced by educational researchers today. The intervening decades have demonstrated that change is possible; the recent review of funding of research and development identified the development of research and research capacity in primary care as a priority ${ }^{15}$. New chairs 
in primary care research are available, and departments of primary care have become thriving contributors to the academic output of major universities ${ }^{16}$.

\section{Specific methodological issues in this thesis}

\section{(i) Was it feasible to develop an internal medicine clerkship in general practice?}

The answer to this question is clearly a resounding "yes". Chapter 2 presented the early attempts at evaluating the UCL model of teaching internal medicine in general practice. As the model was developing constantly in response to student and tutor feedback, formal evaluation was difficult. Therefore a number of pilot studies were undertaken, to provide triangulation of data on student performance, student perceptions and tutor perceptions. These pilots provided reassurance for the medical school, allowing continuation of the programme, as well as allowing refinement of the research questions and development of research tools for subsequent use.

(ii) Did students acquire clinical skills as well on the general practice based clerkship as on a traditional hospital based clerkship?

The results of this randomised cross-over trial reported in chapter 3 suggested that students acquired their clinical skills at least as well in general practice as in hospital. This appeared to be true for all the skill domains (history taking, physical examination, communication skills, data interpretation) tested.

The method was specifically chosen to sample as wide a range of skills as possible within a balanced design. Its strengths included the randomisation of students both to the order in which they took the four blocks making up the first year and, once on the medicine block, to starting in either general practice or hospital medicine. The crossover design allowed both for direct comparison of the students taught in the two venues and for pre- and post-exposure testing; a design which has been widely favoured as a method of assessing efficacy of skills teaching ${ }^{17-20}$. The comparison group was both plausible and fair: the clerkship in general practice was expressly designed to replace a traditional hospital clerkship and both sites shared common aims and objectives for the clerkship. The outcome measure, an objective structured clinical examination (OSCE) was widely favoured for testing clinical skills in both undergraduate and postgraduate settings ${ }^{21: 22}$

Potential weaknesses included the small number of stations in each skill domain, which limited the power of the study to determine whether specific skills were acquired better in either location. The crossover design minimised the impact of varying ability in different groups, but it was not possible to control for this altogether. Previous work had shown that test security is not necessarily a problem with OSCEs, and that under appropriate circumstances, replicated in this study, repetition of stations throughout the year does not jeopardise the validity of the examination ${ }^{23 ; 24}$. Stations were chosen to reflect problems that the students might encounter in either general practice or hospital, but it is possible the problems tested favoured students who had learnt in one or other setting. The apparent validity of the examination is enhanced by the steady improvement of student performance throughout the year. Examiners were partially "blinded" as no information was given on 
students' prior experience. Any potential bias from examiners preferentially marking students known to them was minimised through drawing examiners from both settings and using structured marking sheets and would have been limited to scores from one station.

(iii) What were the relative strengths and weaknesses of teaching internal medicine in hospital and in general practice.

The pair of studies addressing this question reported in chapters 4 and 5 used different methodologies to approach the same question. In the questionnaire study, students reported that they learnt more about history taking and physical examination in general practice, whereas they learnt more about writing up clerkings, keeping progress notes and disease management in hospital. In the interview study, students felt that they learnt more about psychosocial issues in health, communication skills and patient autonomy in general practice, and more about investigations, procedures, management of acute illness and specialties in hospital.

The questionnaire study in chapter 4 benefited from the randomised crossover design used in chapter 3 . This ensured that any differences found were unlikely to due to either the novelty value of the medical firms, or the previous level of experience of the students. Comparing each student's experience in one location, with their experience in the other location controlled for variation in attributes (such as enthusiasm) in each student. Moreover, students completed the questionnaires in a neutral environment - the joint assessment held at the end of each five week attachment, where they were examined by both GPs and hospital doctors. This also resulted in a high response rate $(>80 \%)$. Although questionnaire studies are at best only a proxy for outcome, medical students are intelligent mature consumers of an educational process in which they have considerable investment and therefore their perceptions have value.

Qualitative research can complement quantitative research, by providing an understanding of the meaning behind a finding from a quantitative study ${ }^{6}$. It can allows the investigator to explore how, and why, certain outcomes occur. Methods of achieving rigour in qualitative studies have been well described ${ }^{25}$. The study reported in chapter 5 used purposive sampling to try to maximise the breadth of student views, audiotaped all interviews and focus groups, used interviewers who were not personally known to the students, and involved an external independent reviewer in data analysis.

The value of having empirical evidence on strengths and weaknesses of teaching in general practice is demonstrated by the difference between many of the claims made, such as general practice being the best place to learn both about rational use of investigations, and management of common problems ${ }^{26-29}$ and the data presented here where students perceived themselves as learning more about these objectives in hospital than in general practice.

(iv) What were students actually doing on internal medicine clerkships taught in general practice and in hospital?

In chapter 6, a log diary methodology was used to determine student activities on internal medicine clerkships in hospital and in general practice. Students were also asked to ascribe a 
value to the various activities undertaken, rating them for both educational value and enjoyment.

In both environments, students spent approximately 5.5 . hours on teaching and learning activities. The main differences in the two environments were that students spent more time on unsupervised interaction with patients and less time on assessment in hospital than in general practice. Standard deviations for time spent on each activity were wide, suggesting that individual students had widely differing experiences. Students perceived supervised interaction with patients and teaching by doctor as the most educational activities. The most enjoyable activity was interaction with patients, whether supervised or unsupervised.

Once again, this study benefited from the opportunity to obtain comparative data from hospital and general practice attachments with similar educational aims and objectives. There was a reasonable response rate $(68 \%)$, and although responders appeared to be more academically able than non-responders, comparison of the data from students who had completed two diaries, one for hospital and one for general practice, with the rest of the responders showed no difference. Thus although more able students may well spend more time overall on educational activities than colleagues who performed less well in end of year exams, this response bias does not appear to have biased the data comparing the hospital and general practice attachments. It was also difficult to hypothesise why this response bias should introduce systematic bias into the results. The accuracy of student recording of activities was confirmed in the pilot phase of the study, when student records were compared with firm time-tables and with other students on the same firms. As students received their $£ 5$ book token for returning a log diary whether it had been completed or not, there was no incentive to enter fictitious data. Although the specific time allocation to various activities will vary according to different course timetables, the value that students place on the activities is likely to be generalisable to other schools. The value placed on supervised interaction with patients in general practice was extremely high, and the reasons for this need further exploration.

\section{(v) What were the costs of teaching internal medicine in general practice?}

The study on costs presented in chapter 7 was the first one undertaken as part of this thesis. It suggested that the UCL model of teaching internal medicine in general practice was affordable within the context of SIFT (Service Increment for Teaching). SIFT was initially designed to level the playing field between teaching hospitals and district general hospitals, and was defined as the median difference in cost for a basket of common hospital procedures $^{30}$. Subsequently it became a dedicated funding stream to cover the reprovision costs of service to the NHS of undergraduate teaching, and general practice became eligible for SIFT funding ${ }^{31}$. It would have been a stronger study if it had been possible to determine the costs of teaching in hospital; however at that time few hospitals had even begun to consider these $\mathrm{e}^{32}$.

\section{(vi) What was the impact of teaching internal medicine on the GP tutors?}

This study of GP tutors involved in a pan North London project to increase the amount of general practice based teaching used a semi-structured interview to determine the impact of clinical skills teaching on the tutors (chapter 8). The main finding was that the teaching 
improved morale, both through the teacher training courses and through the teaching itself. Within teacher training, the improved morale was attributed to developing peer and professional support; improved teaching skills; and revision of clinical knowledge and skills. Within teaching it was attributed to a broadening of horizons; contact with enthusiastic students; increased time with patients; improved clinical practice; improved teaching skills; and an improved image of the practice. Problems with teaching were due to external factors such as lack of time and space and anxieties about adequacy of clinical cover while teaching.

The study used an independent researcher, not associated with the teaching programme, to facilitate disclosure of negative feelings by the tutors. Despite this, the study elicited very few negative effects. The sample interviewed, however, was a specific group of general practitioners who had agreed successively to attending a teacher training course, teaching students in their practices, and then being interviewed. The analysis was performed separately by two researchers from different professional backgrounds, and was reviewed by all authors to maximise rigor. There was a striking homogeneity of responses, despite planned sampling for maximum variability. Length of teaching experience, being a postgraduate trainer, time since qualification, sex, practice characteristics, location (urban or suburban) or medical school did not affect the results. However, the study took place within a well organised and well funded project and may represent a best case scenario.

\section{(vi) What were the reactions of patients to this type of teaching?}

This interview study explored patients response to regularly giving up a half day to assist with student teaching (chapter 9). Respondents felt very positive about it, for two underlying reasons: altruism and personal gain. Within altruism reasons included provision of a service to the community and repaying the system. Aspects of personal gain included improved knowledge, improved self-esteem and companionship. Patient concerns included: embarrassment, reinforcement of the sick role and concerns about student access to notes. They identified few detrimental effects from participating and most said they would continue their involvement indefinitely if invited to do so.

There was a remarkable consistency of results, with few new themes emerging after the first five interviews, and none after the thirteenth, suggesting that we had sampled to the point of redundancy. Respondents felt able to raise new topics (e.g. access of students to their notes) during the interview confirming that they perceived the interviewer as independent.

In order to address the concerns of the ethics committee, and respect patients' confidentiality, recruitment was by "opting in". Although this method tends to recruit fewer participants as it involves active consent, $62 \%$ of those approached agreed to be interviewed, echoing their altruistic motivation in participating in teaching. Unfortunately, no patients who had declined to participate in teaching were prepared to be interviewed, and the two patients who had been identified by their GP as no longer participating in teaching, perceived themselves as still involved. This prevented the study determining what prevented patients from initially becoming involved, or why they wanted to stop. Reassuringly, no interviewees felt that it would be difficult to cease their involvement and there were no suggestions that patients had initially felt coerced into participating. 

teaching

Lessons for the future: challenges and sustainability of general practice based

It is not inevitable that the shortage of available patients in teaching hospitals and the recommendations of the General Medical Council will continue to lead to more teaching in general practice. An alternative is a substantial increase in the use of district general hospitals. Although general practice based teaching has many potential advantages (Box 1), many important challenges (Box 2) must be met for a sustained increase to be achievable.

\section{Box 1 Potential advantages of community-based teaching}

\section{Advantages to students:}

- large number of patients,

- undifferentiated symptoms assist development of diagnostic skills,

- clinical experience reflecting morbidity of local population,

- exposure to long-term management of chronic illnesses,

- understanding of psychosocial issues in medicine,

- increases awareness of the health needs of a population,

- low student-teacher ratios facilitate a tutorial relationship and student-centred teaching.

\section{Advantages to general practice :}

- enhanced status,

- may encourage students into career in general practice,

- teaching is revitalized and may enhance clinical skills of tutors,

- enriched career paths for GPs

- patients may benefit from regular in-depth review.

\section{Advantages to medical schools:}

- overcomes problems of shortage of patients for students to clerk because of reduced average length of hospital admissions and increased use of day surgery and outpatient procedures; schools can maintain or increase student intake,

- enhanced collaboration between hospital specialists and GPs,

- broadens the spectrum of student learning in line with General Medical Council recommendations,

- reflects shift of service delivery within the NHS.

\section{The challenges}

\section{Numbers of teaching practices}

Increased learning in the community requires additional teaching practices ${ }^{33}$. There have been fears that the recent increase in general practice workload resulting from the 1990 GP Contract and the shift of care from hospital to community may have a negative effect on GPs willingness to take on additional tasks, including undergraduate teaching ${ }^{34}$. However, only a small proportion of the circa 35,000 GPs in the UK need to be involved to meet the needs of 4,500 students annually. Gray and Fine found considerable enthusiasm for teaching undergraduates among south London GPs, if the practical issues could be satisfactorily 
addressed. The most important of these was the need for adequate resources, so that an increase in time spent on teaching, can be matched by a decrease in time spent on other $\operatorname{tasks}^{35}$. Chapter 8 in this thesis provided further evidence that GPs experience teaching as having a positive effect on morale, providing the practical problems, including resources, are adequately addressed.

\section{Box 2 Challenges facing community-based teaching}

- numbers of teaching practices,

- resources,

- perceived weaknesses of GP teaching,

- impact on service delivery (including patients),

- quality control,

- burn out,

- effect on academic departments,

- research and evaluation.

\section{Resources}

Good teaching requires the resources to provide protected time. This principle has been widely accepted in the UK, with the diversion of Service Increment for Teaching (SIFT) funds toward general practice, usually via academic departments of primary care. SIFT is not a payment for teaching; it is intended to meet National Health Service (NHS) reprovision $\operatorname{costs}^{2}$. If a GP takes a morning to teach, she / he must meet the cost of another clinician to see the patients. Costs also include the expense of maintaining premises for educational purposes, providing books, journals, information technology and appropriate teaching equipment, and the staff costs of administering the programme. Students incur travel expenses and may need to be accommodated on distant attachments.

Many teaching hospital trusts rely on SIFT for survival: for a London medical school with 200 clinical students in each of three clinical years, SIFT amounts to approximately $£ 25$ million per annum. Given that there is no new SIFT money, if student learning, (and hence funding) is diverted elsewhere, then there is a fall in the equivalent teaching hospital budget. This is a very real dilemma, as destabilization of a local hospital trust is against everyone's interest, including the GP recipients of diverted SIFT. Financial imperatives, rather than educational principles may drive decisions on where students are taught. Resolution of the potential conflict between trusts and departments of primary care over resources requires goodwill; dialogue between representatives of schools, trusts and primary care; and phased change, giving trusts time to adjust.

Dialogue is also vital for educational reasons. In most specialties, some learning objectives are best achieved in hospital, others in the community. Hospital-based teachers must be involved in the debate about the movement of student learning away from traditional settings, and changes in the curriculum need planning to enhance, rather than diminish, collaboration between primary and secondary care. 


\section{Perceived deficiencies in general practice based teaching}

There is some concern that a move toward general practice based teaching will lower academic standards. Most hospital physicians practise in a culture where research takes precedence over teaching. While general practice has led in training its postgraduate teachers $^{36}$, it has only relatively recently entered the research scene. New curricula stress the integration of basic and clinical sciences: will GPs have sufficient scientific background for this purpose? Hospital specialists usually have a deep understanding of a relatively narrow area facilitating vertical integration of scientific and clinical information. GPs are generalists, experts in early diagnosis, with a relatively superficial but wide knowledge across the whole field of medicine. They integrate horizontally, aiming to combine an understanding of the psychological and social components of illness with the identification of a physical problem ${ }^{36}$. High quality medical care requires both approaches, and it can be argued that many GPs would benefit from refreshing their understanding of the science underpinning practice. Community based teaching can assist student learning of basic sciences; for example, learning about nutrition linked to community concerns has been well described in Nigeria ${ }^{37}$. Good course design, with clear learning objectives, coupled with a rolling programme of staff development for all - basic scientists, hospital doctors and GPs - will facilitate integrated teaching in all settings ${ }^{38: 39}$.

\section{Impact on service general practice}

As practices adapt to changes in teaching patterns and take on more students (e.g. some London practices take six students at a time for 40 weeks a year) they will need to consider the following three impacts on service general practice.

(i) Clinical and administrative staff The whole primary care team is affected by the presence of a large number of students. More medical staff are needed to cover service demands and provide protected teaching time. Accordingly, some practices may employ an assistant or clinical lecturer; some may increase the number of partners, leading to a lower list size per partner, and opening alternative career pathways combining clinical with academic work. Discussion will be needed with local medical committees and health authorities, and negotiation at a national level with the medical practices committee, who govern the number of GP principals permitted in any area.

This level of teaching also affects the administrative and support staff involved in organising student timetables and contacting patients for students to see. This has implications for the health authority and primary care groups: staff budgets for partial reimbursement of practice staff are for provision of general medical services ${ }^{40}$ only, and extra administrative costs will need to be met from SIFT payments. There is also the issue of recompensing attached or aligned community nursing staff, whose original terms of service did not include teaching medical students.

(ii) Space Students need room to see and examine patients, they need access to library and IT facilities and somewhere to pursue independent study, and space for seminars. Many innercity practices, often the nearest to medical schools and most accessible for students, will have great difficulty obtaining extra space. The cost of premises for providing general medical services is met by the health authority, according to strict guidelines laid down by the Department of Health ${ }^{40}$. GPs must meet the cost of additional space. A guaranteed teaching income over a number of years, including the revenue costs of teaching accommodation, will 
be an essential prerequisite to taking on the financial risk of renting or buying space surplus to clinical needs.

(iii) Patients Patients tend to react favourably to the attendance of students in GP consultations $\mathrm{s}^{41 ; 4}$ but their response to the on-going presence of large numbers of students is not yet known. We are also unsure of patients' willingness to attend the surgery regularly for clinical skills teaching, rather than for clinical care. Confidentiality must be considered: many patients are concerned at the prospect of students accessing their records ${ }^{43}$. Will patients view practices heavily engaged in teaching as centres of excellence, like teaching hospitals, with benefits outweighing potential disadvantages, or will they vote with their feet, and register with neighbouring, non-teaching practices? This would render teaching practices financially vulnerable, as capitation is the main source of GP income ${ }^{40}$. "Patient fatigue" may in fact reflect doctors' anxiety that repeatedly asking patients with chronic illnesses to see the students will disturb the doctor-patient relationship. This relationship may also be jeopardized if the doctor is unavailable for a couple of days each week because of teaching commitments. The work in Chapter 8, together with other work from the $\mathrm{UK}^{44-47}$, goes some way to providing reassurance on this front.

\section{Quality control}

Quality assurance is a vital part of any educational programme, and future funding to medical schools may be partly determined by the Quality Assurance Agency for Higher Education's review of teaching ${ }^{48}$. It is made difficult in general practice by its geographical dispersal and its individualistic nature ${ }^{49}$. There are several elements to quality assurance in teaching, including course design, initial teacher accreditation, an on-going programme of staff development, and detailed student feedback. Tutors should be involved in the setting and monitoring (e.g. by peer observation) of educational standards, thus ensuring that they are able to assess the needs of individual students, effectively use a range of teaching methods, and critically assess their own performance. Quality assurance also depends on a culture of provide in providing and receiving a high standard of teaching within the institution ${ }^{50}$.

\section{Burnout}

At the moment the pioneers of community-based teaching are full of enthusiasm but, innovators move on to new areas, teaching may become yet another chore in an over-filled day for those that are left. Practices that have become dependent on teaching income could be reluctant to stop, but no longer have the enthusiasm to deliver. Training several potential teachers within each practice and varying the tutor's role may avoid burnout. The ideal may be a cycle of practice-based teaching of both clinical skills and primary care, followed by departmental teaching and involvement in designing new course materials, followed by a fallow period before returning to practice-based teaching. Payment for the rest period may be cost-effective if it results in sustained enthusiasm among experienced staff.

\section{University departments of primary care}

A varied and expanding programme of community-based teaching presents university departments with a considerable workload in terms of course design and evaluation, teacher training, student assessment, quality control and administration. This can have a detrimental effect on the other academic activities of the department and on the career paths of those involved, as promotion is still largely based on research activity. However, senior academic 
managerial support, together with the appropriate resources to accompany the teaching programmes, enables the department to attract new staff who wish to enhance their teaching expertise. The department must ensure that such staff are also involved in research, and, if appointed at a junior level, are expected to register for higher degrees. Adequate administrative support is essential to prevent academic staff using time on administrative tasks.

\section{University linked practices}

The solution to many of the problems described above may be facilitated by the development of university linked practices (ULPs). These are practices that contract with a university department of primary care to undertake a substantial amount of undergraduate teaching and / or research in return for ongoing, guaranteed income (Box 3). Close co-operation with health authorities and the local medical committee is needed in view of the service and list size implications.

A national system for accreditation of ULPs, similar to that for appointment of post-graduate training practices (Box 4), would assist with issues of quality control. Continuous monitoring of teaching, with early intervention where a practice appears to have difficulty in delivering high quality teaching, is essential. Although most community-based teaching will take place in a limited number of ULPs fairly near a medical school, there will always be a need to retain some smaller practices where enthusiastic tutors teach students about the discipline of general practice in a range of different settings.

\section{Box 3 Contracts for university linked practices}

\section{The academic department undertakes to provide:}

- rolling 3-5 year contracts to enable practices to commit to leases for teaching space and additional staff where needed,

- provision of 'teaching the teachers' programmes,

- appropriate academic and administrative support.

\section{The practice undertakes to provide:}

- protected teaching time (e.g. two days/week),

- support from the whole primary care team,

- appropriate list size and practice infrastructure to support the teaching activities,

- high quality record keeping and computerization,

- full involvement in 'teaching the teachers' programme,

- strict adherence to quality control guidelines. 
Box 4 Criteria for approving trainers and training practices

\section{Practice criteria:}

- premises of adequate quality and size,

- well-maintained patient records,

- adequate number and range of employed staff, with evidence of a functioning team,

- support in training from all the partners,

- adequate organization and practice management,

- commitment to preventive care and agreed standards of medical practice,

- presence of appropriate equipment and library facilities.

\section{Trainer criteria:}

- attendance at preparatory 'teaching the teachers' courses,

- attendance at on-going staff development courses,

- ability to provide protected teaching time,

- familiarity with a variety of teaching and assessment techniques.

Based on North Thames (East) Region, The GP Registrar Year in General Practice, $8^{\text {th }}$ edition, revised 1997.

\section{Research and evaluation}

In addition to routine quality assurance, there is a need for educational research. The current culture within the NHS is to evaluate new technology thoroughly before introducing it into routine use; the same should apply to medical education which may have a considerable impact on health care delivery. We cannot advocate a change from the traditional hospital based teaching toward teaching in general practice unless we can demonstrate that this benefits students. Although the work in this thesis is reassuring on this score, we need to ask what is the added value of general practice based teaching? Could any of the advantages of general practice based teaching be gained more effectively in hospital? Many different models of general practice based teaching are being introduced ${ }^{44: 51: 52}$; each of these should be fully evaluated with readiness to jettison unsuccessful pilots.

We could consider a levy, similar to the current NHS research and development levy, on national medical educational funds to enable rigorous evaluation of new educational initiatives, including their impact on clinical practice, so that we can move toward evidencebased education.

\section{Conclusions}

The work presented here demonstrated unequivocally that it is possible to teach internal medicine in general practice. Students acquire their clinical skills at least as well as on a traditional teaching hospital clerkship, and perceive that they learn more about the psychosocial impact of ill health and more about communication skills in general practice, whereas they learn more about management of acute illness, investigations and specialisms in hospital. GP tutors are positive about teaching, stating that it improves morale and perceived clinical 
competence. Patients enjoy being involved in medical education, seeing it as an opportunity to give something back to the health service and learn more about their own condition.

These preliminary findings however, are not enough to justify continued expansion of general practice based teaching. We urgently need to determine what the added benefits of general practice based learning are for students. Unanswered questions are numerous, and include: to what extent does general practice based teaching improve students' communication skills? Does the enhanced awareness of the psycho-social components of health persist? Are there specific skills and attitudes which are better acquired in general practice than in hospital, (and vice versa) and if so, what are they, how can they be measured, and what is the impact of these on patient care? Does teaching in general practice improve patient care? If so, how and why? Does general practice based learning change students' career intentions, and if so does this persist into career choice?

Until the answers to some of these questions are available, the driving force for expanding general practice based teaching is likely to continue to be pragmatic - general practice, being relatively new to undergraduate teaching, can introduce well designed courses, adequately resourced, and delivered by well trained teachers. These features are not necessarily unique to general practice; hospital teachers are responding to student and government pressure to improve student learning in hospital.

So what do I want for medical education as we enter this new millennium? First and foremost, a recognition that education is a vital component of professional practice, and must be treated as such. This implies respect, with appropriate status, promotion prospects and pay, for those involved in teaching. I would like to see educational practice based on a firm and ever developing research base, with a thriving community of educational researchers. And, as far as general practice based teaching is concerned, I would like to see a constantly self-critical and innovative approach to evaluation and development. 


\section{References}

1. Lilley P. Best evidence medical education (BEME): report of meeting - 3 - 5 December 1999, London, UK. Medical Teacher 2000;22:242-5.

2. Donaldson, L. Service Increment for Teaching Accountability Report 1998/99. 1-55. Leeds: Department of Health; 1999.

3. Murray E, Gruppen LD, Catton P, Hays RB, Woolliscroft JO. The accountability of clinical education: its definition and assessment. Med Educ 2000;34:871-9.

4. Campbell M, Fitzpatrick R, Haines A, Kinmonth AL, Sandercock P, Spiegelhalter D et al. Framework for design and evaluation of complex interventions to improve health. BMJ 2000;321:694-6.

5. Roland M, Torgerson DJ. What are pragmatic trials? BMJ 1998;316:285.

6. Pope C, Mays N. Reaching the parts other methods cannot reach: an introduction to qualitative methods in health and health services research. BMJ 1995;311:42-5.

7. Bradley F, Wiles R, Kinmonth AL, Mant D, Gantley M. Development and evaluation of complex interventions in health services research: case study of the Southampton heart integrated care project (SHIP). The SHIP Collaborative Group. BMJ 1999;318:711-5.

8. Young LE, Jillings CR. Qualitative methods add quality to cardiovascular science. Can J Cardiol 2000;16:793-7.

9. Kraiczi H, Hedner J, Peker Y, Grote L. Comparison of atenolol, amlodipine, enalapril, hydrochlorothiazide, and losartan for antihypertensive treatment in patients with obstructive sleep apneoa. Am J Respir Crit Care Med 2000; 161:1423-8.

10. Chard JA, Lilford RJ. The use of equipoise in clinical trials. Soc Sci Med 1998;47:8918.

11. Torgerson DJ, Sibbald B. Understanding controlled trials. What is a patient preference trial?. BMJ 1998;316:360.

12. Moore GT, Block SD, Style CB, Mitchell R. The influence of the New Pathway curriculum on Harvard medical students. Acad Med 1994;69:983-9.

13. Stephenson J, Imrie J. Why do we need randomised controlled trials to assess behavioural interventions? BMJ 1998;316:611-3.

14. Nelson MS, Clayton BL, Moreno R. How medical school faculty regard educational research and make pedagogical decisions. Acad Med 1990;65:122-6.

15. Rook R. Strategic Framework for the Use of the NHS R \& D Levy. 1-7. Wetherby: Department of Health; 1997.

16. Kendrick T, Campbell J, Armstrong D. Prospects for general practice research are bright despite research assessment exercise. BMJ 1999;318:194. 
17. Ali I, Cohen R, Reznick R. Demonstration of acquisition of trauma management skills by senior medical students completing the ATLS Program. J Trauma 1995;38:687-91.

18. Nyquist JG, Naylor AJ, Woodward LG, Dixon S. Use of performance-based assessment to evaluate the impact of a skill-oriented continuing education program. Acad Med 1994;69:S51-S53.

19. Berg D, Sebastian J, Heudebert G. Development, implementation, and evaluation of an advanced physical diagnosis course for senior medical students. Acad Med 1994;69:758-64.

20. Kokotailo PK, Langhough R, Neary EJ, Matson SC, Fleming MF. Improving pediatric residents' alcohol and other drug use clinical skills: use of an experiential curriculum. Pediatrics 1995;96:99-104.

21. van der Vleuten CP, Swanson AG. Assessment of clinical skills with standardised patients: state of the art. Teaching and Learning in Medicine 1990;2:58-76.

22. Sloan DA, Donnelly MB, Schwartz RW, Felts JL, Blue AV, Strodel WE. The use of objective structured clinical examination (OSCE) for evaluation and instruction in graduate medical education. J Surg Res 1996;63:225-30.

23. Niehaus AH, DaRosa DA, Markwell SJ, Folse R. Is test security a concern when OSCE stations are repeated across clerkship rotations? Acad Med 1996;71:287-9.

24. Colliver JA, Barrows HS, Vu NV, Verhulst SJ, Mast TA, Travis TA. Test security in examinations that use standardized-patient cases at one medical school. Acad Med 1991;66:279-82.

25. Mays N, Pope C. Rigour and qualitative research. BMJ 1995;311:109-12.

26. Lowry S. Trends in health care and their effects on medical education. $B M J$ 1993;306:255-88.

27. Lowry S. What's wrong with medical Education in Britain? BMJ 1992;305:1277-80.

28. Oswald $\mathrm{N}$. Where should we train doctors in the future? Less in hospitals, more in general practices. BMJ 1991;303:71.

29. Whitehouse CR, Roland M, Campion P. Teaching Medicine in the Community: A guide for undergraduate education. Oxford: Oxford University Press; 1997.

30. London Economics. Allocating Medical SIFTR within Camberwell DHA. London: London Economics; 1991. p. 1-38.

31. Winyard, G. SIFT into the Future. Future arrangements for allocating funds and contracting for NHS service support and facilities for teaching undergraduate medical students. London: Department of Health; 1995. p. 1-53.

32. Clack GB, Bevan G, Peters TJ, Eddleston AL. King's model for allocating service increment for teaching and research (SIFTR). BMJ 1992;305:95-6. 
33. Whitehouse CR. Planning for Community-oriented Medical Education in Manchester. Education for Health 1996;9:45-59.

34. Wilson A, Fraser R, McKinley RK, Preston Whyte E, Wynn A. Undergraduate teaching in the community: can general practice deliver? Br J Gen Pract 1996;46:457-60.

35. Gray J, Fine B. General practitioner teaching in the community: a study of their teaching experience and interest in undergraduate teaching in the future. $\mathrm{Br} \mathrm{J} \mathrm{Gen} \mathrm{Pract}$ 1997; 47:623-6.

36. A Working Party of the Royal College of General Practitioners. The future general practitioner: Learning and teaching. London: BMJ Publications; 1972.

37. Asuzu MC. Undergraduate Training in Epidemiology and Research Methods at the University of Ibadan. Annals of Community-Oriented Education 1994;7:145-51.

38. Rothman A, Hays RB, Mann K, Petrusa E, Sefton A, Towle A et al. Curriculum Development. In Davis WK, Jolly B, Page GG, Rothman A, White BAC, eds. Moving Medical Education from the Hospital to the Community. A current review of teaching medical students in community-based settings. Ann Arbor: University of Michigan Medical School; 1997. p 33-58.

39. Jolly B, Albano MG, Altman DF, Bouhuijs PA, Dohner C, Gordon J et al. Faculty Development. In Davis WK, Jolly B, Page GG, Rothman A, White BAC, eds. Moving Medical Education from the Hospital to the Community. A current review of teaching medical students in community-based settings. Ann Arbor: University of Michigan Medical School; 1997. p 59-86.

40. Department of Health. Statement of Fees and Allowances payable to General Medical Practitioners in England and Wales from 1 April 1990. London: HMSO; 1990.

41. Cooke F, Galasko G, Ramrakha V, Richards D, Rose A, Watkins J. Medical students in general practice: how do patients feel? Br J Gen Pract 1996;46:361-2.

42. Jones S, Oswald N, Date J, Hinds D. Attitudes of patients to medical student participation: general practice consultations on the Cambridge community-based clinical course. Med Educ 1996;30:14-7.

43. O'Flynn N, Spencer J, Jones R. Consent and confidentiality in general practice: survey of patients' views on presence of students. BMJ 1997;315:1142.

44. Stacy R, Spencer J. Patients as teachers: a qualitative study of patients' views on their role in a community-based undergraduate project. Med Educ 1999;33:688-94.

45. Gantley M, Rickets M, Sheldon M, Carter Y. Patients in east London seem happy to give GPs consent for training [letter]. BMJ 1998;316:1391.

46. Thistlethwaite JE,,Jordan JJ. Patient-centred consultations: a comparison of student experience and understanding in two clinical environments. Med Educ 1999;33:678-85. 
47. Wykurz G. Patients in medical education: from passive participants to active partners. Med Educ 1999;33:634-6.

48. Randall J. Progress on the Dearing Quality Agenda. Higher Quality - The Bulletin of the Quality Assurance Agency for Higher Education 1997;1:1-2.

49. Price DA, Miflin BM, Mudge PR, Jackson CL. The quality of medical teaching and learning in rural settings: the learner's perspective. Med Educ 1994;28:239-51.

50. Vroeijenstijn AI. Quality assurance in medical education. Acad Med 1995;70:S59-S67.

51. Parle J, Greenfield S, Thomas C, Ross N, Lester H, Skelton J et al. Community-based clinical education at the University of Birmingham Medical School. Acad Med 1999;74:248-53.

52. Macfarlane F, McLennan E, Murray E, Wallace P. CeMENT (Community Based Medical Education in North Thames) Project Report. London: CeMENT; 1998. 


\section{Summary}

\section{Chapter 1}

This thesis examines the teaching of internal medicine and clinical skills to undergraduate medical students in general practice. The opening chapter outlines the historical and sociopolitical background which led to the development of undergraduate teaching in general practice, both internationally and in the UK. The research questions addressed in the body of the thesis are introduced.

\section{Chapter 2}

Chapter 2 is an overview of the pilot phase, providing a description of the various course models developed, and a pilot evaluation. The aim of developing an internal medicine clerkship in general practice was to replace a traditional hospital junior medical clerkship. The learning objectives for the general practice based clerkship, known as the "Medicine in the Community" firm, were identical to those for the hospital clerkships, and concentrated on students acquiring the basic clinical skills of history taking, physical examination and communication with patients. In addition students were expected to develop an appropriate knowledge base to be able to use the skills, and there was an on-going process of assisting students to develop appropriate professional attitudes. The teaching methods involved students being attached to selected, trained general practitioner (GP) tutors in pairs or groups of 4 - 6, initially for two days a week, but subsequently for the whole week. The clerkship lasted 5 weeks. While in practice students saw selected patients (with "good" histories or physical signs) who had common medical problems. Each week was dedicated to a particular symptom: chest pain; breathlessness; abdominal pain and change in bowel habit; problems with mobility; and in the last week students concentrated on multi-system disorders such as diabetes mellitus and alcohol or drug misuse. Tutors were responsible for observing students during the history taking or physical examination, and providing teaching on investigation, management and differential diagnosis. In addition to the practice based teaching, students attended a weekly seminar with a departmental GP tutor and a simulated patient for more formal teaching of diagnostic skills. Assessment of student performance at the end of the clerkship was by an Objective Structured Clinical Examination (OSCE).

As the pilot evaluation suggested that this method of teaching was extremely popular with students, acceptable to tutors, and appeared to be adequately effective in terms of student learning, the teaching programme was able to continue and expand.

\section{Chapter 3}

As the general practice based clerkship was designed to replace a hospital based clerkship, it was essential to determine whether students acquired their clinical skills as well in general practice as in hospital. Chapter 3 reports on a study examining this question. The objective of the trial was to determine whether students acquired clinical skills as well in general practice as in hospital and whether there was any difference in the acquisition of specific skills in the two environments. The trial used a randomised crossover design and involved the entire annual intake of first year clinical students at University College London Medical 
School (UCLMS). The intervention was a 10 week block of general internal medicine, of which one half was taught in general practice, and the other half in hospital. Students were randomly allocated to start in one location, and crossed over to the other location after five weeks. The outcome measures were students' performance in two equivalent nine station OSCEs administered at the mid and end points of the block, allowing a direct comparison of the two groups' performance at five weeks and an analysis of covariance, using their first examination scores as a covariate, to determine students' relative improvement over the second five weeks of their attachment. The results were that 225 students rotated through the block; all took at least one examination and $208(92 \%)$ took both. For the first half of the year there was no significant difference in the students' acquisition of clinical skills in the two environments; later, however, students taught in general practice improved slightly more than those taught in hospital $(\mathrm{P}=0.007)$. The conclusions were that students could learn clinical skills as well in general practice as in hospital; more work was needed to clarify where specific skills, knowledge, and attitudes were best learnt to allow rational planning of the undergraduate curriculum.

\section{Chapter 4}

Following on from the study in chapter 3, two studies were undertaken to determine the relative strengths and weaknesses of learning medicine in general practice and in hospital. Chapter 4 presents a questionnaire study undertaken to provide some answers to this question, while chapter 5 presents a qualitative study examining this issue.

The aims of the study in chapter 4 were to obtain students' perceptions of the degree to which teaching of general internal medicine enabled them to achieve the medical school's objectives for the first clinical year; to obtain process data on the learning opportunities available to students; and to determine their views of the educational qualities of their attachments. In addition we sought to determine whether specific learning objectives were better addressed in general practice or in hospital, and whether students' stated clinical experience correlated with their views on their achievement of clinical objectives. Both the study population and the intervention were identical to those in chapter 3. The outcome measure was a questionnaire survey of students perceptions' of their learning on the two halves of the block. Each student completed the same questionnaire twice, once after their hospital experience and once after their general practice experience. Subsequent subgroup analysis was done to ascertain the impact of different models of learning medicine in general practice. Statistical analysis was done using the SPSS package for Windows 3.1. Group means were calculated for each response, and the mean difference for each student's responses for the two learning environments were analysed using t-tests for paired samples. In the subgroup analysis, analysis of variance was calculated using both parametric ANOVA and non-parametric (1way Kruskal-Wallis) tests. Both tests found the same questions to yield significant differences; probability values using the non-parametric tests were presented. The results were that students perceived they learnt more about history taking and physical examination in the community, whereas they learnt more about writing up their clerkings, keeping progress notes and disease management in hospital. Although they found the general practice attachment to be slightly more enjoyable than the hospital attachments, both environments were perceived as equally challenging, interesting and stimulating them to learn more. Students felt that they had taken and presented more histories per week in general practice, performed approximately equal numbers of clinical examinations in both environments, but were observed more by their tutors during clinical examinations in general practice. More written clerkings were commented on each week in general practice. The conclusions were 
that general practice and hospital environments had different strengths which needed to be considered for rational curriculum development.

\section{Chapter 5}

The aim of this study was to obtain the perceptions of first-year clinical medical students of the relative advantages and disadvantages of community-based and hospital-based clinical teaching. This was a qualitative study, which used a purposive sample of first-year clinical medical students who had experienced both general practice-based and hospital-based teaching. Participants were invited to participate in individual semi-structured interviews or focus groups. Interviews and focus groups were audio-taped and transcribed to facilitate content analysis of the data.

Twenty-four students participated in individual interviews and a further eighteen took part in focus groups. Respondents identified advantages and disadvantages specific to teaching in each setting. Chief advantages of hospital-based learning were perceived to include learning about specialties and the management of acute conditions, and gaining experience of procedures and investigations. General practice-based learning was perceived as particularly appropriate for learning about psychosocial issues in medicine, for increasing students' awareness of patient autonomy and for improving communication skills. In addition, aspects of organisation and of teaching methods employed by community tutors were viewed as conducive to a positive educational experience. Students perceived some areas, such as clinical skills teaching, to be equally-well learned in either setting.

\section{Chapter 6}

Chapters 3,4 and 5 had provided some insight into the relative strengths and weaknesses of general practice based and hospital based teaching of internal medicine; however the reasons underlying these findings were unclear. The aims of the study in chapter 6 were to determine the proportion of time students spent on different activities on an internal medicine clerkship, and to determine whether this differs in general practice and in hospital and to determine students views on the educational value and enjoyment of various activities. Students prospectively completed a log diary, recording their activities for two weeks; one week of their general practice based clerkship and one week of the hospital based clerkship. The response rate was $68 \%$. Students spent approximately 5.5 hours per day on teaching and learning activities in both environments, with more time ( 50 minutes vs 30 minutes, $\mathrm{p}=.007$ ) on unsupervised interaction with patients in hospital than in general practice, and more time (53 minutes vs 21 minutes, $\mathrm{p}<.001$ ) undergoing assessment in general practice than in hospital. Standard deviations for mean differences were wide, due to the heterogeneous nature of the data. Students perceived supervised interaction with patients and teaching by doctor as the most educational activities. The conclusions were that students greatly valued interactions with patients, perceiving these as both educational and enjoyable. Curriculum planners must continue to place patient based learning at the centre of undergraduate medical education. The heterogeneity of the data suggested that individual students had very different experiences, despite apparently similar timetables. 


\section{Samenvatting}

\section{Hoofdstuk 1}

In dit proefschrift wordt een onderzoek beschreven naar onderwijs in de interne geneeskunde en klinische vaardigheden aan geneeskundestudenten in de huisartspraktijk. In het eerste hoofdstuk wordt de historische en sociaal-politieke achtergrond geschetst die geleid heeft tot de ontwikkeling van onderwijs aan geneeskundestudenten in de huisartspraktijk, zowel in het Verenigd Koninkrijk als daarbuiten. Ook worden de onderzoeksvragen die centraal staan in dit proefschrift besproken.

\section{Hoofdstuk 2}

Hoofdstuk 2 is gewijd aan de pilotstudie. De verschillende onderwijsprogramma's die ontwikkeld zijn, worden besproken evenals een pilot-evaluatie. Het co-assistentschap interne geneeskunde in de huisartspraktijk werd ontwikkeld als vervanging voor een traditioneel coassistentschap interne geneeskunde in het ziekenhuis. De leerdoelen van het co-assistentschap in de huisartspraktijk, het "Extramuraal Co-assistentschap Interne", waren hetzelfde als van het co-assistentchap in het ziekenhuis. De belangrijkste hiervan waren: het verwerven van vaardigheden met betrekking tot anamnese, lichamelijk onderzoek en communicatie met patiënten. Daarnaast werden studenten geacht voldoende kennis te verwerven om deze vaardigheden te kunnen toepassen en werden studenten tijdens het co-assistentschap steeds begeleid bij het ontwikkelen van adequate professionele attitudes. Het co-assistentschap was als volgt georganiseerd: studenten liepen stage in duo's of groepjes van 4-6 bij speciaal geselecteerde en getrainde huisarts-tutoren, eerst twee dagen per week en later een hele week. Het co-assistentschap duurde 5 weken. In de praktijk zagen de studenten geselecteerde patiënten (met een 'goede' anamnese of symptomen) met veelvoorkomende klachten. Elke week werd aandacht besteed aan een specifiek probleem: pijn op de borst, kortademigheid, buikpijn, veranderingen in de stoelgang; problemen met mobiliteit; en in de laatste week stondenproblemen centraal waarbij meerdere systemen betrokken zijn, bijvoorbeeld diabetes en alcohol- en drugsmisbruik. De huisarts-tutoren hadden tot taak de studenten te observeren tijdens het afnemen van de anamnese en het lichamelijk onderzoek, en ze moesten onderwijs geven over aanvullend onderzoek, beleid en differentiaaldiagnose. Naast het onderwijs in de praktijk hadden de studenten elke week een formele onderwijsbijeenkomst met een huisartstutor van de Afdeling Huisartsgeneeskunde en een simulatiepatiënt waar aandacht besteed werd aan diagnostische vaardigheden. Aan het eind van het co-assistentschap werden de studenten beoordeeld met behulp van een stationsexamen (OSCE).

Uit de pilot-evaluatie bleek dat de studenten zeer enthousiast waren over dit onderwijs, dat het aanvaardbaar was voor de tutoren en dat het voldoende effectief was wat betreft leerzaamheid voor studenten. Het onderwijsprogramma kon dan ook voortgezet en uitgebreid worden. 


\section{Hoofdstuk 3}

Omdat het co-assistentschap in de huisartspraktijk opgezet was als vervanging van het coassistentschap in het ziekenhuis was het belangrijk om te onderzoeken of de klinische vaardigheden door de studenten even goed geleerd werden in de huisartspraktijk als in het ziekenhuis. Het onderzoek waarin deze vraag centraal stond, wordt beschreven in hoofdstuk 3. Het doel van dit onderzoek was te bepalen of de studenten de klinische vaardigheden in de huisartspraktijk net zo goed leerden als in het ziekenhuis en of er verschillen waren tussen beide settings betreffende het aanleren van bepaalde vaardigheden. De onderzoeksopzet bestond uit een gerandomiseerd cross-over-onderzoek waaraan werd deelgenomen door alle studenten in het eerste jaar van de klinische fase van de studie geneeskunde aan de University College London Medical School (UCLMS). Het onderzoek betrof een blok interne geneeskunde van 10 weken: 5 weken in de huisartspraktijk en 5 weken in het ziekenhuis. Bij de start van het co-assistentschap werd willekeurig bepaald waar een student begon en na 5 weken gingen de studenten naar de andere locatie. De uitkomstmaten van het onderzoek waren de prestaties van studenten op twee gelijkwaardige stationsexamens van 9 stations, halverwege en aan het eind van het blok. Op deze manier konden de prestaties van beide groepen na 5 weken vergeleken worden en kon de co-variantie bepaald worden, met de resultaten op het eerste examen als co-variabele, teneinde de relatieve vorderingen van de studenten te bepalen in de tweede 5 weken van het co-assistentschap. Aan het blok werd deelgenomen door 225 studenten; alle studenten deden ten minste één examen en 208 studenten $(92 \%)$ deden beide examens. Tijdens de eerste helft van het jaar was er geen significant verschil tussen beide locaties wat betreft de door de studenten verworven vaardigheden; daarna bleek echter dat de studenten in de huisartspraktijk een iets grotere toename in vaardigheden te zien gaven dan de studenten in het ziekenhuis $(\mathrm{P}=0.007)$. De conclusie was dat klinische vaardigheden net zo goed in de huisartspraktijk geleerd kunnen worden als in het ziekenhuis; verder onderzoek moest uitwijzen waar specifieke vaardigheden, kennis en attitudes het best geleerd kunnen worden om te komen tot een rationele planning van de geneeskundeopleiding.

\section{Hoofdstuk 4}

Als vervolg op het onderzoek beschreven in hoofdstuk 3 zijn twee onderzoeken gedaan om een sterkte-zwakteanalyse te maken van een co-assistentschap interne geneeskunde in de huisartspraktijk en het ziekenhuis. Hoofdstuk vier is gewijd aan een onderzoek waarin een enquête werd afgenomen om deze vraag te kunnen beantwoorden. In hoofdstuk 5 wordt een kwalitatief onderzoek beschreven over hetzelfde onderwerp.

Het onderzoek dat beschreven wordt in hoofdstuk 4 had tot doel: de mening te peilen van studenten over de mate waarin het onderwijs in de interne geneeskunde hun de mogelijkheid bood te voldoen aan de leerdoelen voor het eerste jaar van de klinische fase; data te verzamelen over de mogelijkheden die studenten kregen om te leren; de mening van studenten te peilen over de onderwijskundige kwaliteit van de verschillende co-assistentschappen. Daarnaast wilden we onderzoeken of bepaalde leerdoelen beter pasten bij een coassistentschap in de huisartsenpraktijk of in het ziekenhuis en of de mening van de studenten over hun klinische ervaringen overeenkwam met hun mening over het voldoen aan de klinische leerdoelen. De methode en de onderzoekspopulatie waren dezelfde als in hoofdstuk 3. De uitkomstmaat was een enquête waarin studenten naar hun mening gevraagd werd over hun leerervaringen in de twee delen van het blok. Elke student vulde dezelfde enquête 
tweemaal in, na het co-assistentschap in het ziekenhuis en na het co-assistentschap in de huisartsenpraktijk. Vervolgens werden de resultaten per subgroep geanalyseerd om het effect te meten van de verschillende modellen voor het leren van interne geneeskunde in de huisartspraktijk. De statistische analyse werd uitgevoerd met behulp van SPSS voor Windows 3.1. De groepsgemiddelden werden berekend voor elk antwoord. Met behulp van t-toetsen voor gepaarde steekproeven werd het gemiddelde verschil berekend tussen de antwoorden van elke student betreffende beide leeromgevingen. Variantieanalyse werd uitgevoerd in de analyse van de subgroepen met behulp van parametrische ANOVA en non-parametrische toetsen (eenzijdige Kruskal-Wallis-toets). Bij beide toetsen bleek dat dezelfde vragen significante verschillen opleverden; de p-waarden voor de non-parametrische toetsen werden weergegeven. Het bleek dat de studenten van mening waren dat ze in de huisartspraktijk meer leerden over anamnese en lichamelijk onderzoek, maar dat ze in het ziekenhuis meer leerden over verslaglegging, het maken van aantekeningen over de voortgang en hoe ziekten in het ziekenhuis behandeld worden. Hoewel de studenten het co-assistentschap in de huisartspraktijk iets aantrekkelijker vonden dan het co-assistentschap in het ziekenhuis, vonden ze beide even uitdagend en boeiend en werden ze door beide gemotiveerd om meer te leren. De studenten gaven aan dat ze in de huisartspraktijk per week vaker een anamnese afnamen en presenteerden, dat ze ongeveer evenveel patiënten onderzochten in beide settings, maar dat ze in de huisartspraktijk vaker geobserveerd werden bij het onderzoeken van patiënten. In de huisartspraktijk werden hun verslagen vaker besproken. Geconcludeerd werd dat zowel de huisartspraktijk als het ziekenhuis hun eigen, verschillende, sterke punten hadden en dat het belangrijk is om hiermee rekening te houden bij het ontwerpen van een curriculum.

\section{Hoofdstuk 5}

Het doel van dit onderzoek was om de meningen te inventariseren van eerstejaars coassistenten betreffende de voor- en nadelen van klinisch onderwijs in de eerste lijn en in het ziekenhuis. Het betrof een kwalitatief onderzoek onder een steekproef van eerstejaars coassistenten die ervaring hadden met klinisch onderwijs in de huisartspraktijk en in het ziekenhuis. De deelnemende studenten werden uitgenodigd om deel te nemen aan individuele semi-gestructureerde interviews of een focusgroepdiscussie. Zowel de interviews als de focusgroepbijeenkomsten werden opgenomen op geluidsband en getranscribeerd om de data te kunnen analyseren.

Vierentwintig studenten namen deel aan de individuele interviews en nog eens 18 studenten namen deel aan de focusgroepdiscussies. De deelnemers gaven aan dat beide locaties specifieke voor- en nadelen hadden. De belangrijkste voordelen van het ziekenhuis waren het leren over specialismen en acute situaties, en het opdoen van ervaring met procedures en aanvullend onderzoek. Het leren in de huisartspraktijk vonden de studenten vooral geschikt om te leren over psychosociale aspecten van de geneeskunde, om zich beter bewust te worden van de autonomie van patiënten en om communicatievaardigheden te verbeteren. Bovendien werd een aantal aspecten van de organisatie van het co-assistentschap in de huisartspraktijk en de onderwijsmethoden die door de huisarts-tutor werden gehanteerd gezien als een bijdrage aan een positieve leerervaring. De studenten gaven aan dat voor sommige onderwerpen, zoals het leren van vaardigheden, beide settingen even geschikt waren. 


\section{Hoofdstuk 6}

Hoofdstuk 3, 4 en 5 leverden inzicht op in de sterke en zwakke punten van onderwijs interne geneeskunde in de huisartspraktijk in vergelijking met het co-assistentschap in het ziekenhuis; de onderliggende factoren van deze bevindingen waren echter niet duidelijk. Het onderzoek dat in hoofdstuk 6 beschreven wordt, had tot doel te bepalen hoeveel tijd de studenten besteedden aan verschillende werkzaamheden tijdens het co-assistentschap interne geneeskunde en te bepalen of hierin verschillen bestonden tussen de huisartspraktijk en het ziekenhuis. Ook werd de mening van studenten gevraagd over de leerzaamheid van de verschillende activiteiten en of ze de werkzaamheden aantrekkelijk vonden. De studenten hielden prospectief een logboek bij waarin ze gedurende twee weken hun activiteiten opschreven: dit betrof één week van het co-assistentschap in de huisartspraktijk en één week co-assistentschap in het ziekenhuis. De respons bedroeg 68\%. De studenten besteedden op beide locaties per dag ongeveer 5.5 uur aan onderwijsactiviteiten. In het ziekenhuis besteedden zij meer tijd dan in de huisartspraktijk ( 50 minuten versus 30 minuten, $\mathrm{p}=.007$ ) aan contacten met patiënten waarbij zij niet geobserveerd werden en in de huisartspraktijk werd meer tijd besteed aan beoordelingsgesprekken dan in het ziekenhuis ( 53 minuten tegenover 21 minuten, $\mathrm{p}<.001$ ). De standaarddeviaties van de gemiddelde verschillen waren groot tengevolge van de heterogeniteit van de data. De studenten vonden patiëntencontacten met supervisie en onderwijs door artsen de meest leerzame activiteiten. Geconcludeerd kan worden dat studenten patiëntencontacten zeer waarderen en dat ze deze zowel leerzaam als leuk vinden. Curriculumplanners moeten patiëntgecentreerd leren dan ook een centrale plaats geven in de geneeskundeopleiding. De heterogeniteit van de data wijst erop dat de ervaringen van studenten tijdens het co-assistentschap, ondanks het feit dat de roosters op het eerste gezicht vergelijkbaar zijn, zeer sterk uiteenlopen.

\section{Hoofdstuk 7}

In het onderzoek dat in dit artikel beschreven wordt, zijn de kosten van het co-assistentschap interne geneeskunde in de huisartspraktijk berekend aan de hand van de opgedane ervaringen. Bij de kostenberekening is uitgegaan van de vaste lasten voor WP en NWP ten laste van de faculteit en vervangingskosten voor de huisartspraktijken om aan de verplichtingen tegenover de National Health Service te kunnen blijven voldoen. Kosten voor huisvesting en dergelijke zijn buiten beschouwing gebleven en de overeenkomstige kosten van een co-assistentschap in het ziekenhuis konden niet worden berekend. Er is een voorstel gedaan voor financiering op de lange termijn, dat inmiddels is omgezet in nationaal beleid. Sinds de publicatie van dit artikel is er financiering beschikbaar gekomen voor de huisartspraktijken via de Service Increment for Teaching (SIFT).

\section{Hoofdstuk 8}

Of onderwijsprogramma's op de lange termijn blijven functioneren is afhankelijk van de actieve en enthousiaste inzet van alle betrokkenen, niet alleen de studenten. De huisartstutoren namen een nieuwe tol op zich, die meer en andere vaardigheden en kennis vereiste dan het werken in de praktijk of het traditionele onderwijs in de huisartsgeneeskunde volgens het leermeester-gezelmodel. In dezelfde periode hadden de huisartsen te maken met ingrijpende veranderingen in de huisartspraktijk. Er was veel stress onder huisartsen. Veel 
huisartsen gingen vervroegd met pensioen en het was moeilijk om nieuwe huisartsen te vinden omdat minder artsen de huisartsopleiding kiezen. Van zeer groot belang voor de continuïteit van het programma was de invloed die het onderwijsprogramma had op de motivatie van de huisartsen. Toen dit onderzoek in 1997 werd uitgevoerd liep er een programma in Londen om meer onderwijs te geven in de huisartspraktijk. Dit maakte het mogelijk om een onderzoek te doen waarbij interviews werden afgenomen bij huisartsen van alle deelnemende geneeskundeopleidingen die betrokken waren bij klinisch vaardigheidsonderwijs.

Het doel van het onderzoek was om de mening van de huisartsen te peilen over de invloed van het geven van vaardigheidsonderwijs en de bijbehorende docententrainingen op hun motivatie en dagelijkse praktijk. In een semi-gestructureerd interview zijn vragen over het effect van onderwijs en docententraining op motivatie, zelfvertrouwen betreffende klinische vaardigheden en vaardigheden als docent, en dagelijkse praktijk voorgelegd aan 30 huisartsen die betrokken waren bij onderwijs in klinische vaardigheden. Het belangrijkste resultaat was dat de huisartsen vonden dat hun motivatie positief beïnvloed werd. Binnen docententrainingen werd dit toegeschreven aan de steun die men kreeg van collegae; verbeterde docentvaardigheden; en het opfrissen van klinische kennis en vaardigheden. Binnen het functioneren als docent werd dit toegeschreven aan het feit dat men het eigen blikveld kon verbreden; contact had met enthousiaste studenten; meer tijd kon besteden aan patiëntencontacten; beter functioneerde in de praktijk; en verbetering van docentvaardigheden en het imago van de praktijk. Problemen met onderwijs geven hadden te maken met externe factoren zoals tijd- en ruimtegebrek en bezorgdheid of de vervanging terwijl men bezig was met onderwijs. Geconcludeerd werd dat onderwijs in klinische vaardigheden een positief effect kan hebben op de motivatie van huisartsen door het contact met studenten en collegae, waarbij wel belangrijk is dat er goede oplossingen gevonden worden voor logistieke en financiële problemen.

\section{Hoofdstuk 9}

Patiënten zijn ook van groot belang voor het onderwijs in de huisartspraktijk. Deze aanpak van klinisch vaardigheidsonderwijs vraagt van patiënten een tijdsinvestering van 2 tot 3 uur om geneeskundestudenten te helpen leren. Sommige patiënten doen dit regelmatig, 6-10 keer per jaar, wat een aanzienlijke tijdsinvestering betekent. Patiënten komen speciaal voor het onderwijs naar de praktijk en krijgen dan niet de gebruikelijke medische zorg. Het was dan ook belangrijk om te onderzoeken wat patiënten vinden van dit soort onderwijs en of ze het gevoel hebben dat er druk op hen wordt uitgeoefend om mee te doen, wat hun redenen zijn om mee te doen en of ze vinden dat er aanpassingen nodig zijn in het programma om tegemoet te komen aan de behoeften van patiënten.

Het doel van dit onderzoek was om inzicht te krijgen in wat patiënten vinden van onderwijs in de eerste lijn om zo inzicht te krijgen in zowel de positieve als de negatieve kanten voor de deelnemende patiënten. Semi-gestructureerde interviews werden afgenomen bij 15 patiënten uit de huisartspraktijken die deelnamen aan het programma "Extramuraal Co-assistentschap Interne". De belangrijkste bevindingen waren dat de deelnemers zeer positief oordeelden over deelname aan het onderwijsprogramma. Dit hing samen met twee onderliggende factoren: altruïstische motieven en eigenbelang. De altruïstische motieven waren: het verlenen van een dienst aan de maatschappij en iets terugdoen voor het gezondheidszorgsysteem. Aspecten die samenhingen met eigenbelang waren: het opdoen van kennis, een versterkt gevoel van 
eigenwaarde en sociale contacten. Aspecten waar patiënten zich zorgen over maakten waren: verlegenheid, extra nadruk op de ziekenrol, en bezorgdheid over het feit dat studenten toegang hadden tot hun gegevens. De conclusie was dat de patiënten hun deelname aan het onderwijsprogramma zeer waarderen en het gevoel hebben dat ze een waardevolle bijdrage leveren. De bevindingen van dit onderzoek zijn geruststellend voor de deelnemende artsen en artsen die deelname in de toekomst overwegen. Dokters moeten zich bewust zijn van mogelijke veranderingen in de arts-patiëntverhouding als zij patiënten actief betrekken bij het onderwijs.

\section{Hoofdstuk 10}

In het laatste hoofdstuk wordt het belang van onderzoek van onderwijs besproken. Een aantal uitdagingen voor onderzoekers van onderwijs wordt besproken en oplossingen voorgesteld. Dit hoofdstuk geeft ook een samenvatting van aspecten waar rekening mee gehouden moet worden als men klinisch vaardigheidsonderwijs in de huisartspraktijk op grote schaal wil invoeren en continueren. Hieronder vallen: aantal onderwijspraktijken; toewijzing van middelen; docententraining van huisartsen voor hun rol als tutor en voorkomen van burnout; de invloed op de praktijkvoering; infrastructuur zoals een ruimte waar studenten kunnen studeren, bibliotheek en IT-voorzieningen, administratieve ondersteuning; het effect op patiënten en patiëntenzorg; en de voortdurende noodzaak om onderzoek te doen en te evalueren. 

